\title{
Mental slowness after stroke : assessment and treatment
}

Citation for published version (APA):

Winkens, I. (2009). Mental slowness after stroke : assessment and treatment. [Doctoral Thesis, Maastricht University]. NeuroPsych Publishers. https://doi.org/10.26481/dis.20090409iw

Document status and date:

Published: 01/01/2009

DOI:

10.26481/dis.20090409iw

Document Version:

Publisher's PDF, also known as Version of record

\section{Please check the document version of this publication:}

- A submitted manuscript is the version of the article upon submission and before peer-review. There can be important differences between the submitted version and the official published version of record.

People interested in the research are advised to contact the author for the final version of the publication, or visit the DOI to the publisher's website.

- The final author version and the galley proof are versions of the publication after peer review.

- The final published version features the final layout of the paper including the volume, issue and page numbers.

Link to publication

\footnotetext{
General rights rights.

- You may freely distribute the URL identifying the publication in the public portal. please follow below link for the End User Agreement:

www.umlib.nl/taverne-license

Take down policy

If you believe that this document breaches copyright please contact us at:

repository@maastrichtuniversity.nl

providing details and we will investigate your claim.
}

Copyright and moral rights for the publications made accessible in the public portal are retained by the authors and/or other copyright owners and it is a condition of accessing publications that users recognise and abide by the legal requirements associated with these

- Users may download and print one copy of any publication from the public portal for the purpose of private study or research.

- You may not further distribute the material or use it for any profit-making activity or commercial gain

If the publication is distributed under the terms of Article $25 \mathrm{fa}$ of the Dutch Copyright Act, indicated by the "Taverne" license above, 


\section{Mental slowness after stroke: assessment and treatment}

Neuropsych Publishers Maastricht, The Netherlands 
(C) I.Winkens, Maastricht 2009

$\begin{array}{ll}\text { Cover } & \text { Lisette Winkens-Hendrix } \\ \text { Lay-out } & \text { Richard Hanssen } \\ \text { Production } & \text { Datawyse BV, Maastricht } \\ \text { ISBN } & 978-90-75579-37-6\end{array}$

Neuropsych Publishers is a non-profit organization, which aims at promoting the science of 'Brain and Behavior' and improving the application of the products of this science in health care and education. NeuroPysch Publishers accomplishes these aims by publishing books, dissertations and other products of scientific activity, by disseminating educational material and publication of tests, assessment scales and other psychometric instruments in the field of Neuropsychology, Neuropsychiatry and other areas within the domain of Brain and Behavior.

Postal address: NeuroPsych Publishers

Department of Psychiatry and Neuropsychology

Maastricht University

P.O. Box 616

NL-6200 MD Maastricht, The Netherlands

www-np.unimaas.nl 


\title{
Mental slowness after stroke: assessment and treatment
}

\author{
PROEFSCHRIFT
}

Ter verkrijging van de graad van doctor aan de Universiteit Maastricht, op gezag van de Rector Magnificus, Prof. mr. G.P.M.F. Mols, volgens het besluit van het College van Decanen, in het openbaar te verdedigen op donderdag 9 april 2009 om 14.00 uur

door

Ieke Winkens

Geboren op 7 augustus 1978 te Sittard 


\section{Promotores}

Prof. dr. D.T. Wade

Prof. dr. L. Fasotti

\section{Copromotor}

Dr. C.M. van Heugten

\section{Beoordelingscommissie}

Prof. dr. J. Jolles (voorzitter)

Prof. dr. R.P.C. Kessels (Radboud Universiteit Nijmegen)

Dr. R. Ponds

Prof. dr. J. Schols

Dr. J.M.A. Visser-Meily (UMC Utrecht)

The research described in this thesis was carried out at Vilans, formerly known as the Institute for Rehabilitation Research (iRv), Hoensbroek, in collaboration with the Department of Psychiatry \& Neuropsychology, School of Mental Health and Neuroscience, Maastricht University, The Netherlands.

This study was supported by the Dutch Brain Foundation (grant no. 13F05(2).16) and Vilans.

Financial support for the publication of this thesis was kindly provided by the Remmert Adriaan Laan Foundation, Rehabilitation Foundation Limburg, Boehringer Ingelheim BV, Libra Care Group 




\section{Contents}

1. General introduction 9

2. Manifestations of mental slowness in the daily life of patients 23 with stroke: a qualitative study

3. Disentangling the concept of mental slowness after acquired brain 37 injury: thoughts following a systematic review on measures used to assess functional consequences of mental slowness

4. Reliability and validity of two new instruments for measuring aspects of mental slowness in the daily lives of stroke patients

5. Training patients in Time Pressure Management, a cognitive strategy for mental slowness

6. Efficacy of Time Pressure Management in stroke patients with slowed information processing: a randomized controlled trial

7. Occurrence and measurement of transfer in cognitive rehabilitation: a critical review

8. General discussion

Summary

Samenvatting

Dankwoord

Curriculum Vitae 

Chapter 1

General introduction 

In the Netherlands every year 34.000 to 41.000 people suffer a first-ever stroke [1,2]. Of these patients, $25 \%$ die within one month. The others often have to live with the long lasting consequences, affecting one or more of physical (motor), emotional and cognitive functioning, and usually resulting in disabilities in daily life, sometimes severe.

In an attempt to reduce their level of disability, stroke patients are often referred to a rehabilitation program. In the early stages, patients frequently experience and report cognitive problems as being of minor importance, compared to the somatic problems. This is probably one of the reasons why, for a long time, rehabilitation mainly focused on the amelioration of motor (physical) impairments. However, evidence has grown that cognitive impairments such as hemi-inattention, language disorders, memory problems, attention problems and executive problems - among which slowness of information processing - may also have a negative impact on daily life functioning after stroke [3-5]. When the early rehabilitation period has ended (usually between three to six months after onset) and patients have returned home, they start to be confronted with complex everyday situations, and not infrequently serious problems become manifest.

Cognitive deficits do nowadays receive more attention in rehabilitation programs. Wade et al [6] were among the first to argue that rehabilitation should concentrate also on cognitive abilities, not only on physical function. Increasingly, rehabilitation programs are becoming multidisciplinary programs, consisting of various therapies that address the specific problems that patients experience and that partners and therapists observe. Cognitive rehabilitation is usually part of these multidisciplinary programs.

Hochstenbach et al [3] and Rasquin et al [7] have shown that the most common cognitive impairments after stroke include slowness of information processing (50-70\%), neglect $(50 \%)$, visuospatial deficits $(40 \%)$, language problems $(40 \%)$, difficulties with calculation $(34-40 \%)$, and reduced attention and memory (30\%). Other studies have shown that patients rate slowness of information processing high on a list of cognitive complaints $[8,9]$.

This slowness of information processing is thought to influence many daily life activities adversely, especially when these activities concern novel or time-pressured tasks and situations, where continuous conscious processing of incoming information is needed and/ or where processing is required to be fast, to be simultaneous, or to be completed before situations change or within certain external time limits [10-12]. This applies to many everyday situations. Continuous and/or fast processing is needed for example when driving a car through heavy traffic, when sustaining an important conversation, when listening to a teacher and simultaneously making notes, and even when reading subtitles on television. Patients with slow information processing are expected to miss important information and/or to make errors, and in some situations (when driving a car for instance) this could lead to hazardous and dangerous situations.

In addition, it is probable that patients will experience a distressing feeling of time pressure when they feel that there is not enough time to think and act properly during task performance, or that they will not be able to finish a task within a given time limit. 


\section{General theories of speed of information processing}

Impairments in the speed and capacity of the human information processing system have been important topics in the field of psychology for many years [13,14]. Research on individual differences, studied by measuring reaction time, has been the basis for the development of many measures of information processing speed, and has led to theories explaining the concept of and deficits in information processing. Three major theories are described here.

An interesting idea was provided by Posner and Snyder [15] in which a conceptual distinction was made between two qualitatively different processes: controlled processing and automatic processing. This idea was further elaborated by Shiffrin and Schneider in 1977 [11]. Figure 1 gives a schematic impression of their model of information processing. Controlled processes are slow (they take more time), effortful (they require attention), generally serial (occurring in sequence), and are probably limited by the capacity of short-term memory. They must be used when dealing with novel situations. However, because they are capacity limited, factors that reduce capacity (such as fatigue or motivation) affect these cognitively controlled processes adversely, and may lead to slower or less accurate output. Automatic processes, on the other hand do not require attention; they occur in parallel, are fast, fairly effortless and of effectively unlimited capacity. They are responsible for the performance of well-developed skilled behaviors and they require considerable training to develop. New tasks first require slow, controlled processing. Automatic processing can develop (i.e. be learnt) when subjects process stimuli consistently over many trials, meaning that subjects should make the same response each time a stimulus occurs.

Figure 1. A model of information processing. Based on Shiffrin and Schneider, 1977 [11].

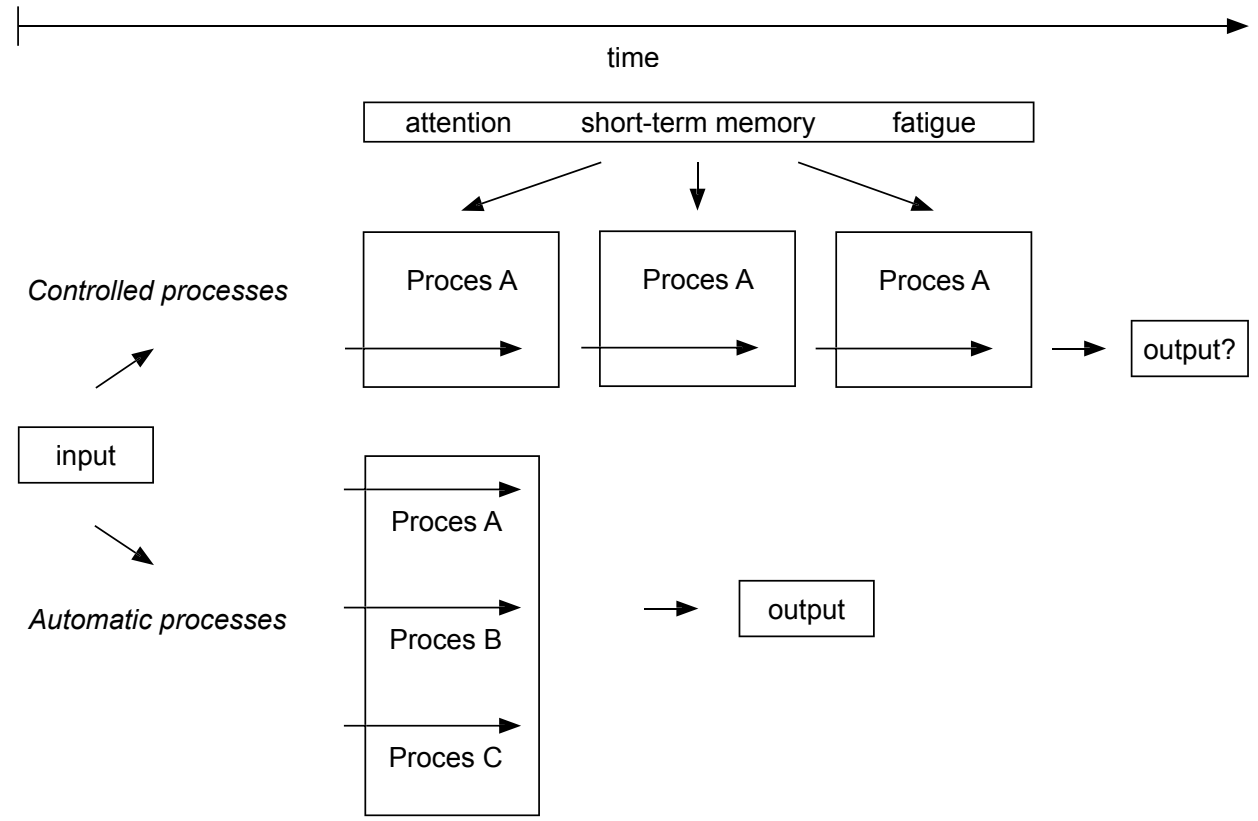


Shiffrin and Schneider suggest that a "Divided Attention Deficit" will occur when (too) much task-relevant information requiring conscious processing is offered in a short amount of time. When having a conversation during driving for example, the limited capacity of the system for controlled processing may be exceeded. Relevant signals may be missed, and required responses may not be given (in the worst case scenario leading to a traffic accident). In practice most drivers stop talking when the demands of driving increase.

Connectionist models give a different explanation for individual or situational differences in processing speed [10]. In these models information or knowledge is represented by an associative network consisting of a large set of interconnected nodes (See Figure 2). Each node has a certain threshold activation level and when the level of this particular node is exceeded, that node (and its associated information or process) is available for use. The nodes are related to each other by links. The retrieval speed of information or knowledge is strongly determined by the degree of nodal activation and the strength of the links between the nodes: retrieval of information is fastest and most accurate when the nodes are highly activated and the links between the nodes are strong. The activation of nodes and the strength of the links get higher each time they are used, whereas both decay over time. This would imply that in well-practiced situations, the links between the nodes are strong, and activation of the node is high. In figure 2 the thick lines and dots represent these strong links and highly activated nodes. In novel situations, the links between nodes are still weak and activation of the node is still low (in the figure this is represented by the thin and striped lines and dots). Processing of novel information thus will require more effort and more time [16].

Figure 2. Connectionist models of information processing. Based on Anderson, 1993 [10].

Well-practiced situations
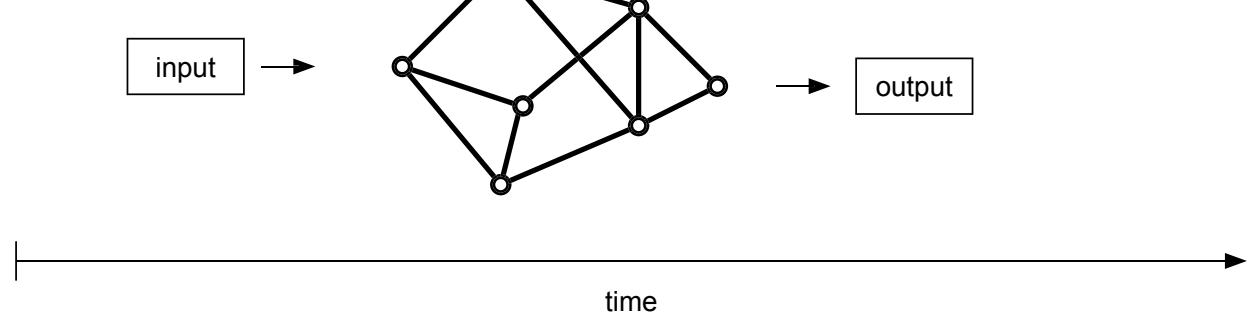

Novel situations
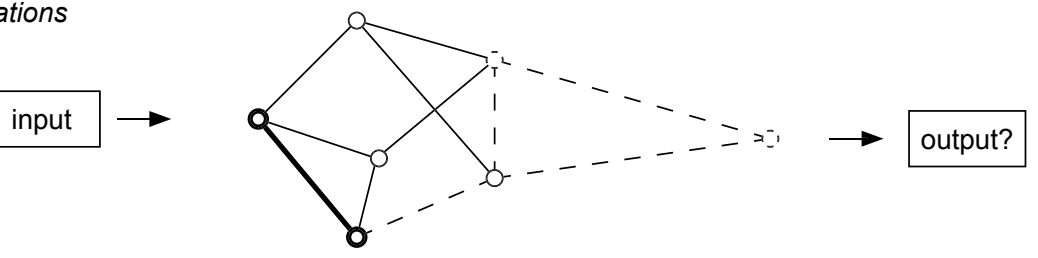

effort 
Lastly Salthouse explains the occurrence of problems by means of the Processing-Speed Theory [12]. The fundamental assumption in this theory is that speed of processing is a relatively general process limiting performance in many cognitive tasks. Two distinct mechanisms are postulated to be responsible for the relation between speed and cognition. The first mechanism is the so-called "limited time mechanism". The basis for this mechanism is simply that the time to perform higher-order cognitive processes is greatly restricted when a large proportion of the available time is occupied by the execution of earlier processes. This mechanism is primarily relevant when there are external time limits: relevant operations are executed too slowly to be successfully completed within the available time. Figure 3 shows that limiting time leads to failure to complete for example a two-stage process. In simple tasks speed of performance is likely to be the primary determinant of individual differences in performance. In more complicated tasks, it is likely that the quality or accuracy of performance is affected by the number of operations that can be carried out in the available time. If complex operations are dependent on the products of simpler operations, and fewer of these products are available because of a slower execution speed, problems can be expected to occur.

Figure 3. Salthouse's processing-speed theory. Based on Salthouse, 1996 [12].

Limited time mechanism

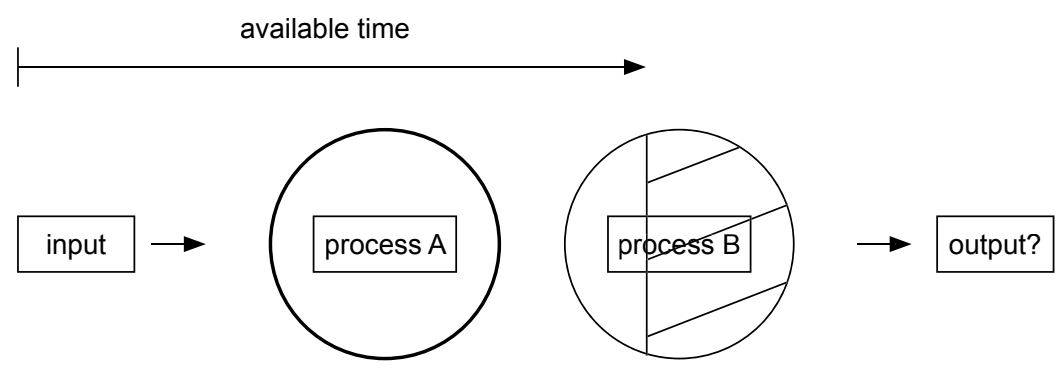

Salthouse suggested a second mechanism, the "simultaneity mechanism". The key assumption is that information decreases in availability over time as a function of decay or displacement (i.e. the products of early processing may be lost or may have become inaccurate before later processing is ready to use it). Processing deficits could emerge because of discrepancies between the time course of loss of information and the speed with which critical operations such as elaboration, rehearsal, or abstraction can be executed. To the extent that this is the case, relevant information may no longer be available by the time it is needed. Moreover, under rapidly changing conditions, the information may no longer be accurate by the time it becomes available. In both cases, when the rate of executing operations is slow, information 'provided' is less likely to be useful. This will occur regardless of the amount of time allowed for processing because the critical limitations are based on internal dynamics. 


\section{General theories of speed of information processing and the injured brain}

Do these general theories of speed of information processing help us understand the occurrence of slowness after acquired brain injury? Several authors have tried to relate empirical data from patients with traumatic brain injury to these general theories. Van Zomeren and Spikman [17] proposed that complaints of patients fit well into the information processing theory of Shiffrin and Schneider. Patients may for example complain that they have difficulty listening to a teacher while at the same time making notes. In such tasks, information processing capacity has to be divided over several different subtasks: listening to the teacher, reading what is written on the black board, and making notes. After acquired brain injury, such subtasks that used to be automatic, now have to be controlled and hence require more time and effort. The automatized aspect is lost. This results in fewer attentional resources to be divided over the subtasks at hand. Consequently, the limited capacity of the slow, serial, controlled processing is likely to be exceeded. The patient will experience time pressure and will complain that he can no longer perform two tasks at the same time.

Timmerman and Brouwer [16] on the other hand suggest that, after acquired brain injury, slowness of information processing observed in tasks is especially dependent on the efficiency with which procedural knowledge and declarative knowledge can be accessed. According to these authors, the basic deficit is a longer access time to stored knowledge. As described above, in connectionist models knowledge can be considered as being 'stored' in a network of interconnected nodes. The higher the strength between the nodes, the easier it is to access the knowledge represented in the network. Timmerman and Brouwer propose that slowness after traumatic brain injury is a result of global decrease of associative strength between nodes, possibly as a result of diffuse functional or structural loss of axonal tissue. This decrease may be an explanation for the fact that patients for example sometimes need more time to come up with names of relatives or to perform daily tasks.

And finally, although Salthouse's theory originally was developed to explain empirical data retrieved from aging studies, his line of thought can easily be extended and be used to help describe the problems that patients with acquired brain injury experience. As said, in Salthouse's theory, two mechanisms can be held responsible for the relation between speed and cognition. First the 'limited time mechanism': slower speed of executing processing operations means that less processing can be completed in a given amount of time. For patients with slowed information processing after acquired brain injury this may mean for example that they will not be able to finish their work within given deadlines, or that they may experience a high sense of time pressure.

He also suggests a second mechanism, a so-called 'simultaneity mechanism' where a slower speed of processing within lower-order networks or modules results in a smaller amount of information being made available for higher-level processing. An example from a group cognitive task that illustrates the point might be a patient who is participating in a work meeting on complex financial issues: he may find himself still trying to work out a problem, while others already have moved on to the next. In his brain he may 
find himself unable to complete a difficult calculation since the information that is needed to perform further calculation already has disappeared from his short term memory due to decay.

\section{Treatment of (problems arising from) slowness of information processing}

Although several longitudinal studies with patients with traumatic brain injury have shown that slowness of information processing usually shows some recovery, for many patients slowness of information processing remains a chronic impairment [18]. Figure 4 shows recovery curves for four-choice reaction time in three groups of patients with traumatic brain injury. The grey area shows the normal range of performance of a healthy control group. After mild head injury, slowness of information processing usually disappears within one to three months. For patients with moderate head injury, recovery may take up to six months. And after severe head injury (i.e. post-traumatic amnesia of at least one week), slowness of information processing may be permanent.

Figure 4. Recovery curves of slowness of information processing in three groups of patients with traumatic brain injury (From Van Zomeren and Deelman [18]).

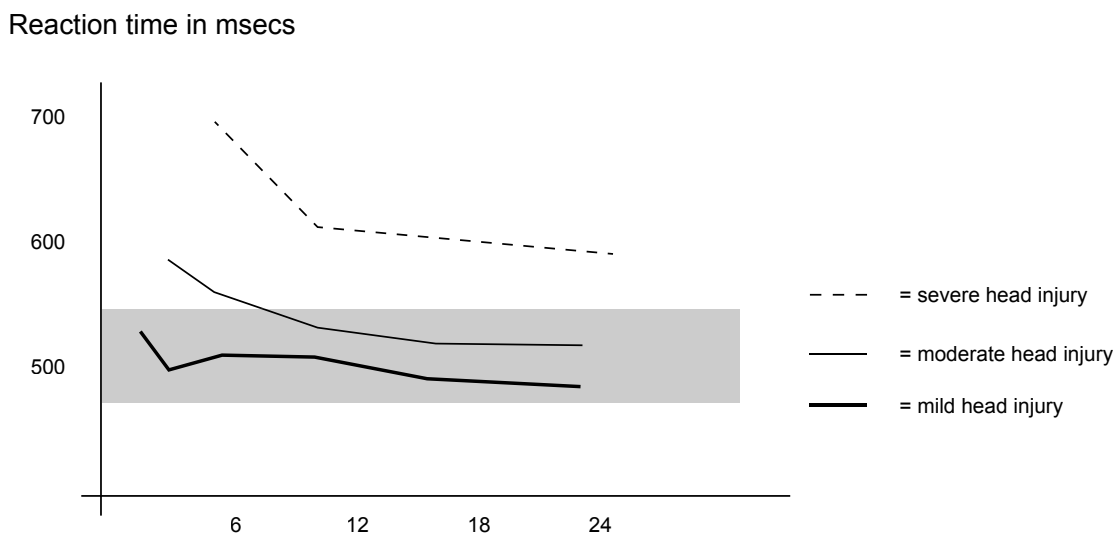

Time in months

Slowness of information processing may also be permanent for some patients with stroke. In a one-year follow-up study with 196 patients with first-ever cerebral stroke, Rasquin et al [7] showed that almost $50 \%$ of the patients in the study still showed impaired speed of information processing one year after stroke.

The findings described above, combined with the fact that many patients with traumatic brain injury or stroke complain of problems in daily life functioning, indicate that rehabilitation for problems arising from slowness of information processing may be necessary. For a long time, theories such as the one from Shiffrin and Schneider and connectionist 
models influenced the content of rehabilitation approaches: rehabilitation focused on impaired functions and attempted to reconstruct the way the function was performed premorbidly (i.e. restoration training). Several studies have shown that such approaches in general are not very effective. Although through repeating a task over and over again it is possible to teach most patients a certain specific task, this may not lead to generalization of the treatment effects to other, non-trained tasks and to daily life functioning as wished $[19,20]$.

Indeed, because of this, over the last decade attention in rehabilitation has shifted from a focus on deficits and impairments to a focus on limitations in daily activities and societal participation [21]. Rehabilitation nowadays concentrates on the problems experienced by the patient, as evidenced by the increasing use of task-specific training in physiotherapy. For slowness of information processing this means that attention has shifted from changing the externally measured speed of information processing to considering both the perception by a person that their mental processes are slower than they expect, termed 'mental slowness', and the actual effects it has on functional activities in daily life.

Few studies have investigated mental slowness (as opposed to slow information processing) - what it means and how it affects patients. It seems likely that patients may describe or react to their cognitive difficulties in several ways. They may complain of fatigue and tiredness, arising from the extra cognitive work needed to achieve the required output. They may complain of slowness, which arises when they compare their perceived speed against their expectations. In addition patients may perceive their performance as less satisfactory, which arises when they compare perceived performance against their premorbid performance. Other phenomena such as increased difficulty in performing tasks, or increased anxiety when they recognise that they may be failing, or low mood because they are performing less well, may also occur. All these aspects are important to patients, and should be included when studying the subject of mental slowness.

Finally, little is known about the effects of cognitive rehabilitation for mental slowness in stroke patients, and systematic treatment programs ready for implementation are lacking in the present practice of most rehabilitation centers.

\section{Objective and research questions of this thesis}

The main objective of the work underlying this thesis was to evaluate the effects of a cognitive strategy training for stroke patients with mental slowness. Strategy training is aimed not at restoring a lost neuropsychological (or other) process or function, but at teaching patients how to adapt by improving the performance of patients using their residual capacities and thus reducing their complaints in daily life. Strategy training has been applied with success in the areas of memory, attention, apraxia and problem-solving in stroke patients as well as patients with traumatic brain injury [22-25]. 
In 2000 Fasotti et al. developed and evaluated the so-called Time Pressure Management training [26]. This training teaches patients to use compensatory strategies either to prevent or to manage time pressure, and hence the patients can compensate for their slowness and deal with the task at hand. The main guideline is to teach patients ways to overcome or prevent time pressure: no (or only a small) change is expected in the speed of information processing itself. The idea is that Time Pressure Management is a general strategy that can be useful for any problem caused by mental slowness: generalization to other, non-trained situations is therefore expected [27]. This is important since patients seen in rehabilitation centers will return to their homes, where they will have to be able to apply the skills they learned in the rehabilitation center.

The effects of the Time Pressure Management training have been evaluated in patients with traumatic brain injury [26]. The results of the study indicated that the training produced greater gains than standard concentration training. However, to date, there are no other studies and no data on the treatment effects of this strategy training for stroke patients.

Thus the most important research question to be answered in this thesis is: "Does Time Pressure Management training lead to better performance on everyday tasks, and to fewer complaints in the everyday lives of stroke patients with mental slowness?". To answer this question, first the main consequences of slow information processing in the daily lives of patients with stroke are investigated; then, the current state of the assessment of mental slowness in neuropsychology and rehabilitation is evaluated; and then, the effects of the training are evaluated in a group of stroke patients.

\section{Outline of this thesis}

The first two chapters describe preliminary work. Chapter 2 presents an exploratory study using semi-structured interviews to investigate the consequences of slowness of information processing in the daily lives of patients with stroke. Chapter $\mathbf{3}$ gives the results of a systematic literature review on the measurement of mental slowness. The aim of the review was to evaluate how mental slowness is measured and whether new instruments are required to evaluate the effects of the Time Pressure Management training. In addition, the conceptual basis for mental slowness and its associated terminology is considered.

The review concluded that new measures were needed, and Chapter $\mathbf{4}$ describes a study into the validity and reliability of two new measures for mental slowness, one measure is aimed at performance on tasks, the other is a questionnaire evaluating perceived consequences of mental slowness. These measures will be used to evaluate the effects of the Time Pressure Management training.

The technique of training patients how to use Time Pressure Management strategies has not been described, and Chapter 5 provides a framework for teaching Time Pressure 
Management. By making use of two cases involved in the randomized trial, this chapter describes the underlying theories and specific elements comprising the treatment, and factors that are considered prerequisites for teaching patients to use it.

The central part of this study, a randomized trial to evaluate the strategy of Time Pressure Management is presented in Chapter 6; it presents the results of a randomized controlled trial into the effects of Time Pressure Management training in stroke patients with mental slowness. Both effects on performance in everyday tasks and effects on the experience of mental slowness are evaluated.

A treatment is only really useful if it improves a patient's performance at home, outside the treatment setting; this is referred to as generalisation of the effects or 'transfer of training'. Chapter 7 summarizes the results of a critical literature review on the measurement and occurrence of transfer in cognitive strategy training. The aim of this review was to evaluate whether and how previous studies measured transfer and whether transfer to everyday situations and behaviors has been found to occur after strategy training.

The main results and conclusions of the studies described in this thesis are discussed in Chapter 8 which also considers both the implications for clinical practice and ideas for future research. 


\section{References}

1. Bots ML, Berger-Van Stijl M, Jager-Geurts MH, Bos M, Reitsma JB, Breteler MMB et al. Incidentie van cerebrovasculaire ziekte in Nederland in 2000. In: Jager-Geurts MH, Peters RJG, Van Dis SJ, Bots ML (eds). Hart- en vaatziekten in Nederland 2006, cijfers over leefstijl- en risicofactoren, ziekte en sterfte. Den Haag: Nederlandse Hartstichting 2006.

2. Struijs JN, Van Genugten MLL, Evers SMAA, Ament AJHA, Baan CA, Van den Bos GAM. Modeling the future burden of stroke in the Netherlands: the impact of aging, hypertension, and smoking. Stroke 2005; 36: $1648-55$.

3. Hochstenbach J, Mulder T, Van Limbeek J, Donders R, Schoonderwaldt, H. Cognitive decline following stroke: a comprehensive study of cognitive decline following stroke. J Clin Exp Neuropsychol 1998; 20 : 503-17.

4. Van Zandvoort MJE, De Haan EHF, Kapelle LJ. Chronic cognitive disturbances after a single supratentorial lacunar infact. Neuropsych Neuropsychol and Beh Neurol 2001; 14(2); 98-102.

5. Pohjasvaara T, Erkinjuntii T, Ylikoski R, Hietanen M, Vataja R, Kaste M. Clinical determinants of poststroke dementia. Stroke 1998; 29: 75-81.

6. Wade DT, Wood VA, Hewer RL. Recovery after stroke - the first three months. J of Neurol Neurosurg and Psych 1985; 48(1): 7-13.

7. Rasquin SM, Lodder, J, Ponds, RW, Winkens, I, Jolles, J, Verhey, FR. Cognitive functioning after stroke: a one-year follow-up study. Dement Geriatr Cogn Disord 2004; 18: 138-144

8. Hochstenbach J. The cognitive, emotional and behavioural consequences of stroke. Doctoral dissertation. Nijmegen: Catholic University Nijmegen (The Netherlands), 1999.

9. Visser-Keizer AC, Meyboom-de Jong B, Deelman BG, Berg IJ, Gerritsen MJ. Subjective changes in emotion, cognition and behaviour after stroke: factors affecting the perception of patients and partners. J Clin Exp Neuropsychol 2002; 24: 1032-45.

10. Anderson JR. Rules of the mind. Hillsdale: Lawrence Erlbaum, 1993.

11. Shiffrin RM, Schneider W. Controlled and automatic human information processing; II: Pereceptual learning, automatic attending and a general theory. Psychol Review 1977; 84: 127-190.

12. Salthouse TA. The processing-speed theory of adult age differences in cognition. Psychol Review 1996; 103(3): 403-428.

13. Eling P, Brouwer W. Aandachtsstoornissen: Een neuropsychologisch handboek. Lisse: Swets en Zeitlinger, 1995.

14. DeLuca J, Kalmar JH. Information processing speed in clinical populations. Psychology Press, 2007. 
15. Posner MI, Snyder CRR. Attention and cognitive control. In: Solso RL (ed). Information processing and cognition: the Loyola Symposium. New Jersey: Erlbaum Hillsdale, 1975.

16. Timmerman ME, Brouwer WH. Slow information processing after very severe closed head injury: impaired access to declarative knowledge and intact application and acquisition of procedural knowledge. Neuropsychologia 1999; 37: 467-478.

17. Van Zomeren AH, Spikman JM. Tempo en aandacht. In: Vandermeulen JAM, Derix MMA, Avezaat CJJ, Mulder Th, Van Strien JW (eds). Niet aangeboren hersenletsel bij volwassenen. Elsevier Gezondheidszorg, 2003.

18. Van Zomeren AH, Deelman BG. Long term recovery of visual reaction time after closed head injury. J of Neurol Neurosurg and Psych 1978; 41: 452-457.

19. Wilson BA. Cognitive rehabilitation: How it is and how it might be. J Int Neuropsychol Soc 1997; 3(5): 487-96.

20. Robertson IH. Does computerized cognitive rehabilitation work? A review. Aphasiology 1990; 4: 381405.

21. Cicerone KD, Dahlberg C, Kalmar K, Langenbahn DM, Malec JF, Bergquist TF et al. Evidence-baed cognitive rehabilitation: Recommendations for clinical practice. Arch Phys Med Rehabil 2000; 81: 15961615 .

22. Milders M, Deelman B, Berg I. Rehabilitation of memory for people's names. Memory 1998;6(1):2136.

23. Kaschel R, Della Sala S, Cantagallo A, Fahlbock A, Laaksonen R, Kazen M. Imagery mnemonics for the rehabilitation of memory: a randomized group controlled trial. Neuropsychol Rehabil 2002;12(2):127153.

24. Geusgens C, Van Heugten C, Donkervoort M, Van den Ende E, Jolles J, Van den Heuvel W. Transfer of training effects in stroke patients with apraxia: an exploratory study. Neuropsychol Rehabil 2006;16(2):213-229.

25. Levine B, Robertson IH, Clare L, Carter G, Hong J, Wilson BA et al. Rehabilitation of executive functioning: an experimental-clinical validation of goal management training. $J$ Int Neuropsychol Soc 2000;6(3):299-312.

26. Fasotti L, Kovacs F, Eling PATM, Brouwer WH. Time Pressure Management as a compensatory strategy training after closed head injury. Neuropsychol Rehabil 2000; 10(1): 47-65.

27. Ben-Yishay Y, Diller L. Cognitive remediation in traumatic brain injury. Update and issues. Arch Phys Med Rehabil 1993: 74: 204-213. 

Chapter 2

\section{Manifestations of mental slowness in the daily life of patients with stroke: a qualitative study}

Published in:

Clinical Rehabilitation 2006; 20: 1-8

I. Winkens, C. van Heugten, L. Fasotti, A. Duits, D. Wade 


\begin{abstract}
Objective. To explore the consequences of mental slowness in the daily life of patients with stroke.

Design. In a cross-sectional survey semi-structured interviews were completed. Interviews were transcribed and coded by two independent reviewers. Qualitative analysis was done by means of the "constant comparison method".

Setting. Three rehabilitation centers in the Netherlands.

Participants. A convenience sample of thirteen patients with stroke, suffering from mental slowness, was derived from December 2003 to May 2004.

Main Outcome Measures. Interview descriptions of the everyday consequences of mental slowness.

Results. Patients experienced many problems in daily life due to mental slowness. These could be divided into two main groups: 1) problems in cognitive functioning; 2) psychological and somatic complaints. In response to these problems, some patients mentioned use of compensation strategies in order to reduce the demands on their information processing capacity.

Conclusions. Mental slowness in cognitive functioning affects a wide range of activities, causing emotional symptoms in many patients and stimulating the use of compensation strategies in some patients.
\end{abstract}




\section{Introduction}

A stroke may have very wide-ranging physical, emotional, behavioural and cognitive consequences [1]. Several studies have found that up to 60 to $80 \%$ of patients with stroke are left with cognitive problems [2,3]. One of the most prominent cognitive complaints after stroke is mental slowness, or slowness of information processing [4-6]. Studies have shown that 50 to $70 \%$ of patients with stroke experience mental slowness [1,4], and that they rate it high on a list of cognitive complaints $[7,8]$.

For patients, mental slowness means that they perform activities with the unpleasant feeling that there is not enough time to think and act properly during task performance, and it can lead to several problems in daily life [9]. For example, patients frequently complain that they have trouble following conversations or subtitles on television, and that they have trouble doing two things at the same time.

Several authors have suggested that mental speed is an intrinsic part of many cognitive functions, and that mental slowness may cause deficits in for example memory, attention and executive functioning. Deficits found in these cognitive domains are often attenuated when the influence of processing speed is taken into account [10-12]. Several models or theories have tried to explain the role of mental slowness in cognitive functioning [1319].

Although there is still no consensus on the concept of mental slowness as a functional disorder, we think that mental slowness manifests itself through its impact upon other mental processes such as memory and problem-solving. Mental slowness cannot be seen as an isolated specific cognitive deficit; it must be considered as one aspect of any cognitive impairment, since all cognitive skills take time. Furthermore, speed is not a specific phenomenon that is either present or absent. It is a relative phenomenon that may affect different skills differently.

Although a thorough and structural insight into the construct of mental slowness as a functional disorder is still lacking, insight into the nature of its consequences at a disability level is urgently needed. First, because mental slowness appears to be one of the most prominent complaints after stroke, often seriously interfering with everyday functioning, and second, because such knowledge is indispensable for the development or improvement of suitable rehabilitation programs.

However, studies focusing on the real-world consequences of mental slowness have been rare. The majority of publications on mental slowness after stroke have derived conclusions from reaction time experiments or other generally accepted neuropsychological tests such as PASAT, Stroop Colour Word Task, Trail Making Task or the Symbol Digit Modalities Test of the WAIS [9]. Recent studies have been critical of the capacity of these measures to assess functional, real-world outcomes [20]. Since most standard neuropsychological tests at best only mimic daily life situations, their predictive value for daily life functioning is limited. 
The few studies that have focused on the changes in daily life functioning after stroke mostly relied on general questionnaires of cognitive functioning that included mental slowness $[7,8]$. A structured inventory has not been made that specifically addresses questions on the real-world consequences of mental slowness in particular. Therefore, the objective of the present study is to explore the main consequences of mental slowness on the daily life of patients with stroke by means of semi-structured interviews. The results of these interviews may help us to understand better the consequences of mental slowness at a disability level, thereby enabling us to develop adequate interventions and ecologically valid instruments.

\section{Methods}

Thirteen patients with stroke participated in this study. The study population was drawn from three rehabilitation centers in the Netherlands. Patients are selected for a rehabilitation centre when there are complex problems requiring a multidisciplinary approach; they are usually younger than 65 years of age, able to follow an intensive rehabilitation program and expected to return to the home situation after a period of rehabilitation. This means the patients have sufficient learning ability, are sufficiently motivated and can fall back on adequate informal care at home [21].

The protocol was approved by the Medical Ethics Board of each participating rehabilitation centre and informed consent was obtained from all participants. Patients were excluded if they did not suffer from mental slowness according to the clinical judgment of their treating psychologist, they were younger than 18 years, they suffered from any other major neurological disease or mental disorder, or a reliable interview was not possible due to very severe cognitive or communicative problems.

\section{Procedure}

Participants were submitted to a semi-structured interview (Table 1), developed with input from researchers and academic clinicians. The interviews were administered using a standardized procedure. In short, participants were asked to describe in their own words what problems they encountered in daily life following the stroke. They were specifically asked to report on all kinds of difficulties they experienced due to cognitive problems, in particular mental slowness. 
Table 1. Main topics of the semi-structured interview.

1. General well-being after stroke, significant changes since stroke.

2. Problems in cognitive functioning, detailed examples of everyday problems related to:

- Memory

- Attention

- Executive functioning

- Mental speed

3. Detailed examples of troublesome situations related to:

- Work

- Family

- Social life

- Hobbies

4. Use of compensation strategies

5. Other topics that did not come up for discussion but were important for the patient to share with the interviewer

The interview started with open questions about how participants' lives had changed since stroke. Subsequently, the interviewer (IW) stimulated participants to talk about specific problems due to cognitive impairments in the domains of, for example, memory, attention and executive functioning. If they did not mention the subject of mental slowness themselves, the interviewer asked more direct questions on whether or not they had experienced difficulties in situations requiring mental speed. Participants were asked to give detailed examples of troublesome situations.

Interviews were conducted between December 2003 and May 2004. Data collection from new patients continued until the authors felt saturation had been reached (i.e. no new concepts were identified). This led to a total of 13 participants.

\section{Data recording and analysis}

The semi-structured, open-ended interviews were tape-recorded and transcribed verbatim for analysis. The interviews lasted between 30 and 40 minutes. The interviews were read and analysed successively by two observers, independent of each other (IW, AD). Data analysis started early in the interview process, after the first five interviews. In this initial stage, the two observers marked all problems related to mental slowness and organized them into preliminary themes. Then, in order to test for validity, both observers confirmed or corrected emerging themes from the early interviews in subsequent interviews, until no more new insights could be obtained, consistent with the 'constant comparison method'[22]. This method requires the observers constantly to consider the relationships between new and analyzed data in an on-going attempt to examine relationships within and between themes. 
Comparison of the final results of the two observers showed that both came to approximately the same themes. There was disagreement on two out of twelve themes, which was resolved through a process of discussion that included a third member of the research team $(\mathrm{CvH})$.

The software programme Atlas.ti version WIN 4.2 was used for qualitative analysis [23].

\section{Results}

Subject characteristics are presented in Table 2.

Table 2

\begin{tabular}{|l|l|}
\hline & $\mathrm{N}=13$ \\
\hline Gender (m / f) & $10 / 3$ \\
\hline Age (mean / range) & $52.6 \quad(41-65)$ \\
\hline Education (mean / range) ${ }^{*}$ & $3.7 \quad(2-6)$ \\
\hline Time since stroke (months) (mean / range) & $23.5 \quad(5.7-46.9)$ \\
\hline Type of stroke (haemorrhage / ischaemic / both) & $3 / 9 / 1$ \\
\hline Affected hemisphere (left / right / unknown) & $4 / 6 / 3$ \\
\hline
\end{tabular}

Three main themes emerged from the interview data: 1) problems in cognitive functioning; 2) psychological and somatic complaints; and 3) compensation strategies. Throughout this paper, in order to remain consistent, the concept of "all participants" indicates that all 13 participants reported similar problems. The concept of "the majority of the participants" indicates that at least 10 out of 13 participants reported similar experiences. Finally, the concept of "many participants" and "few participants" means that 6 to 10 and 1 to 5 participants respectively reported a similar experience.

\section{Problems in cognitive functioning}

Problems in cognitive functioning became evident for all participants as they spoke about how their lives had changed since stroke. They reported several problems that, in their opinion, were related to mental slowness. These included:

- Slower processing of incoming information

The majority of participants complained that they were not able to process incoming information in a fast and adequate way, for instance when having a conversation, when speaking on the telephone, during meetings, when listening to the radio or watching television. For example, one participant stated "My daughter had missed the train, and she called to tell us that she would take the bus, but that she didn't know what time she would arrive. I answered the phone, but I couldn't understand a word she said".

- Reacting slowly or slow decision making 
In addition, many participants felt they reacted slowly or had difficulty making fast decisions, for instance when practicing sports, when driving a car, when having a conversation, or when trying to prevent falls. For example, one participant stated "I often need more time before I can answer. Sometimes I respond immediately, and then I notice that I have made a mistake".

- Difficulty storing information in memory

A third problem mentioned by the majority of the participants was having trouble storing information in memory. They stated that they needed more time, effort and repetition in order to remember, otherwise they forgot what they had just read, forgot to buy certain groceries, misplaced items, forgot appointments, or could not remember where they had just been. For example, one participant stated "If I have to read something, I can read it as much as I like, but I just don 't remember it".

- Difficulty retrieving information from memory

Many participants mentioned that they needed more time and effort to retrieve stored information from memory such as names, words or phone numbers. A few of these participants had trouble solving a puzzle, or trouble coming up with creative ideas. For example, one participant stated "I sometimes need more time to remember certain words or place-names. And then five minutes later I suddenly remember ".

- Difficulty doing two things at the same time

All participants mentioned they had difficulty in dividing attention. They encountered problems when they had to do two things at the same time, which for example is required when participating in traffic, when too many people are speaking at the same time, during cooking or when playing a musical instrument. They also reported they could no longer read a book and watch television at the same time, or could no longer talk while walking, or listen while making notes, or drive a car with the radio on. One participant for example stated "If the telephone rings when I am cooking, I start making mistakes. Either the potatoes are burnt, or the sauce is a failure".

- Being easily distracted

In addition, many participants mentioned that they were easily distracted, for example by noise, or by their own thoughts. One participant stated that "Even the smallest things can be distracting: sounds, movements. I find that very annoying".

- Difficulty learning new skills

A few participants had trouble learning new skills. They reported they needed more time or repetition, for example when learning how to handle a new mobile phone, a videorecorder (VCR) or a personal computer. One participant stated "Handling a new mobile phone costs a lot of effort. I need much more time to learn it".

- No longer performing tasks automatically

Finally, the majority of participants reported that they could no longer perform tasks automatically. They needed a period of thinking first and therefore needed more time to perform the task. As a consequence, these participants were not able to do many activities in one day, or made mistakes when trying to perform tasks quickly. For example, one participant stated "Even when doing the simplest tasks I have to think first. I can no longer perform tasks automatically. They take so much time ". 


\section{Psychological and somatic complaints}

In addition to the cognitive problems, a second main theme emerged from the data. The majority of the participants reported psychological or somatic complaints due to the cognitive problems mentioned above.

- Somatic complaints

The majority of participants complained of fatigue, dizziness, or headaches when they were engaged in the situations mentioned above. For example, one participant stated "I can make only a few telephone calls, because I'm really exhausted afterwards".

- Psychological complaints

In addition, many participants reported agitation or an unpleasant feeling of time pressure. They reported that they felt there was not enough time to deal with the situation at hand, sometimes even leading to panic reactions, emotionality or irritability. For example, one participant stated "I answered the phone but I couldn't understand a word she said, and I even got angry".

\section{Compensation strategies}

The final theme to emerge from the interview data was the use of compensation strategies. The majority of the participants mentioned the use of compensation strategies in response to the problem situations mentioned above. These strategies can be sorted into two categories:

- Passive (avoidance) strategies

Many participants reported that they tried to avoid or to withdraw from situations that made them feel uncomfortable. For instance, they no longer went to parties or friends, or stopped working. One participant stated "When I am in a busy pub, where a lot of people are talking at the same time, I'd rather go home. The fast conversation drives me crazy".

- Active strategies

The majority of participants reported that they tried to handle situations in a more active way. For example, they tried to reduce the demands on information processing capacity by making notes or listening selectively when there was too much information to process; they asked others to speak slowly or to repeat information; they took more time to perform a task and did just one thing at a time. A few participants tried to prepare tasks beforehand, or tried to think the task over before they actually started. Further, they tried to shut out noise or distraction, avoided crowded stores or heavy traffic, but instead engaged in such situations when it was quiet. Finally, they informed other people, in that way decreasing demands or expectations. They asked others to be quiet whenever they had to concentrate, or asked them for help. For example one participant stated "If I know it will be a busy week, I try to prepare as much as I can beforehand. For instance, I prepare dinner in the weekends, and put it in the freezer in case there are people coming over". 


\section{Discussion}

The main goal of the present study was to explore the consequences of mental slowness on daily life functioning of patients with stroke. Unlike most studies that usually derive their conclusions from neuropsychological test results or broad questionnaires on general cognitive functioning, we administered semi-structured interviews, which made it possible to specifically address the real-world consequences of mental slowness in particular.

The main finding of our study is that patients with stroke report that mental slowness causes a wide range of disabilities in daily life. Not only do patients complain of a slowing in processing incoming information or in reaction time, but also they complain of everyday problems of higher-order cognitive functioning, like problems in decision making, in storing information in and retrieving information from memory, problems in dividing attention, being easily distracted, problems in learning new skills and in performing tasks automatically.

These findings are in accordance with the findings of earlier studies and the theories referred to in the introduction, arguing that mental slowness may underlie other cognitive deficits [11-19]. The results particularly seem to point in the direction of the Processing Speed Theory, that argues that mental slowness is a fundamental part of cognitive functioning in general, not only causing problems in dividing attention or in retrieving information from memory, but having an impact on many cognitive functions [19]. However, firm conclusions on the concept of mental slowness at a functional level cannot yet be drawn on the basis of these first, exploratory results.

In addition, the problems of cognitive functioning resulting from mental slowness provoke physical and psychological problems in many patients, such as fatigue, dizziness or headaches, agitation, an unpleasant feeling of time pressure, panic reactions, emotionality or irritability, which in turn lead to even worse performance in situations with time pressure. These findings are in line with earlier studies by, for example, Hochstenbach [7] and Visser-Keizer et al. [8], who found that emotional and behavioural problems are quite common after stroke. Such reactions might be induced or strengthened by awareness of post-injury changes and confrontation with impairments [8].

In response to problem situations, some patients spontaneously use compensation strategies. Not only do patients tend to avoid difficult situations, but they also find more active ways to reduce demands on information processing capacity, for example by making notes, asking others to slow down, doing just one thing at a time, preparing tasks beforehand, and avoiding noise and distraction. In addition, they ask other persons for help and understanding. The fact that patients spontaneously use compensation strategies leads to high expectations about the effects of treatments aimed at improving the coping style of patients by means of cognitive strategies, thereby reducing time pressure and improving daily life functioning. Successful coping with mental slowness might even decrease emotional or behavioural disturbances [8]. 
Some limitations of this study need to be considered. First, the results of this study are based on a small sample of 13 patients. However, the authors included patients until they felt saturation had been reached. By comparing the results of every new interview with the results of earlier interviews, the authors decided whether it was likely that further interviews would lead to new results. After 13 patients, the authors felt no more new results would be obtained.

Second, the study sample was a selective group of mainly recovered, Dutch patients who were completing a rehabilitation program, had a relatively favourable prognosis and for most of whom the stroke occurred a long time ago. This does not allow us to generalize the results on the frequency of the reported problems to all patients with stroke, especially those with less favourable prognosis, or those who do not go to a rehabilitation centre. However, the participants ranged from those with good recovery to those left with more severe problems. Since the few patients in this study with more recent stroke or patients who were still severely disabled either reported few or no problems (which could be due to limited insight) or reported the same kind of problems as patients for whom stroke was longer ago, we feel we can generalize on the nature and content of the problems mentioned by these patients. Apparently, patients who have participated in a rehabilitation program still encounter many problems in daily life due to their mental slowness. This makes mental slowness an obvious goal for rehabilitation.

Third, the interviews were only semi-structured. This could have biased the results since it enabled the interviewer to steer the interviews, and therefore the patients' answers, in the direction of pre-existing hypotheses. However, this unstructured design was needed since this study was a first exploration into the nature of the complaints, which requires a fairly broad approach.

Finally, on the basis of these explorative results, it can not be excluded that the problems mentioned in the interviews were caused by other factors than mental slowness, such as memory or attentive problems, fatigue or depression. It is very difficult to distinguish between various components of cognitive functioning and their separate and often similar effects. As described in the introduction, there is no such thing as a separate function of mental speed. There cannot be a neural module or network responsible for speed, independent of other cognitive and neurological functions. It is very difficult to study mental slowness without studying people who have changes in other cognitive functions. So, unambiguous conclusions on the influence of slowness in particular cannot be drawn on the basis of these interviews.

However, the main purpose of the study was to explore the possible consequences of mental slowness in daily life functioning of stroke patients, not to determine etiology. We feel that in all problems mentioned by the participants, mental slowness plays an important role. A second study has now started in which we relate performance on everyday tasks (disabilities) to performance on neuropsychological tests (functional disorders). The main research question will be whether performance on these everyday tasks can be better predicted by performance on speed of information processing tests, rather than by performance on for example specific cognitive tasks for attention and memory. 
Mental slowness causes many problems in the daily life of patients with stroke. The finding that mental slowness is a multi-dimensional concept causing impairments in many domains has an important implication for the rehabilitation of patients. Therapists should focus on such problems and inform patients and partners on the possible consequences of mental slowness. In addition, they can encourage them to use strategies to control and reduce time pressure, for example by asking others to speak slowly, by limiting the amount of information that is given to the patient, or by making sure the patient can do just one thing at a time. This may be very effective and may contribute to improvements in a variety of domains. Equally important for the patient and his partner is the fact that mental slowness can lead to physical or emotional problems. Patients that are under constant time pressure can easily become agitated or frustrated. Therapists should be aware of the possibility that successful coping may reduce these problems. One possible approach towards coping with mental slowness is Time Pressure Management (TPM) [24]. TPM is a set of cognitive strategies, teaching patients ways to compensate for the consequences of mental slowness. In a future study, we will provide further insight into the effectiveness of this treatment technique for stroke patients.

In addition, the results of this study have given us a first handle for developing two new instruments for measuring mental slowness on a disability level. One is a questionnaire, evaluating the frequency and severity of everyday problems caused by mental slowness. The other is an observation task, consisting of five everyday activities under time pressure (e.g. making a telephone call and listening to the radio news). In a future study, we will investigate some first aspects of the reliability and validity of these newly developed instruments.

\section{Clinical messages}

- After stroke patients experience cognitive difficulties that seem to relate to slowing of information processing

- These difficulties also are associated with fatigue and other symptoms arising during activities.

- Patients may avoid stressful situations, or develop coping strategies

\section{Acknowledgements}

The authors would like to thank all the patients who were interviewed, and the participating psychologists of the rehabilitation centres Hoensbroeck (Hoensbroek), Blixembosch (Eindhoven) and De Hoogstraat (Utrecht) for their active collaboration in this study. 


\section{References}

1. Hochstenbach J, Mulder T, Van Limbeek J, Donders R, Schoonderwaldt, H. Cognitive decline following stroke: a comprehensive study of cognitive decline following stroke. J Clin Exp Neuropsychol 1998; 20: 503-17.

2. Tatemichi TK, Desmond DW, Stern Y, Paik M, Sano M, Bagiella E. Cognitive impairment after stroke: Frequency, patterns and relationship to functional abilities. J Neurol Neurosurg Psychiatry 1994; 57: 202207.

3. Rasquin SM, Verhey FR, Lousberg R, Winkens I, Lodder J. Vascular cognitive disorders: memory, mental speed and cognitive flexibility after stroke. J Neurol Sci 2002; 203-204: 115-9.

4. Rasquin SM, Lodder, J, Ponds, RW, Winkens, I, Jolles, J, Verhey, FR. Cognitive functioning after stroke: a one-year follow-up study. Dement Geriatr Cogn Disord 2004; 18: 138-144

5. Ballard C, Stephens S, Kenny RA, Kalaria R,Tovee M, O’Brien J. Profile of neuropsychological deficits in older stroke survivors without dementia. Dement Geriatr Cogn Disord 2003; 16: 52-56.

6. Gerritsen MJ, Berg IJ, Deelman BG, Visser-Keizer AC, Meyboom-De Jong B. Speed of information processing after unilateral stroke. J Clin Exp Neuropsychol 2003; 25: 1-13.

7. Hochstenbach J. The cognitive, emotional, and behavioural consequences of stroke. [Dissertation]. Catholic University Nijmegen, the Netherlands; 1999.

8. Visser-Keizer AC, Meyboom-de Jong B, Deelman BG, Berg IJ, Gerritsen MJ. Subjective changes in emotion, cognition and behaviour after stroke: factors affecting the perception of patients and partners. $J$ Clin Exp Neuropsychol 2002; 24: 1032-45.

9. Van Zomeren AH, Spikman JM. Tempo en aandacht. In: Vandermeulen JAM, Derix MMA, Avezaat CJJ, Mulder Th, Van Strien JW, editors. Niet aangeboren hersenletsel bij volwassenen. Maarssen: Elsvier Gezondheidszorg; 2003.

10. Veltman JC, Brouwer WH, Van Zomeren AH. Central executive aspects of attention in subacute severe and very severe closed head injury patients: Planning, inhibition, flexibility, and divided attention. Neuropsychology, 1996; 10: 357-367.

12. Kail R, Salthouse TA. Processing speed as a mental capacity. Acta Psychol, 1994; 86: 199-225.

13. Spikman JM, Van Zomeren AH, Deelman BG. Deficits of attention after closed-head injury: slowness only? J Clin Exp Neuropsychol 1996; 37: 467-478.

14. Schneider W, Shiffrin RM. Controlled and automatic human information processing: I. Detection, search and attention. Psychol Rev, 1977; 84: 1-66. 
15. Van Zomeren AH, Brouwer WH. Head injury and concepts of attention. In: Levin HS, Grafman J, Eisenberg HM, editors. Neurobehavioral recovery from head injury. New York: Oxford University Press; 1987.

16. Timmerman ME, Brouwer WH. Slow information processing after very severe closed head injury: impaired access to declarative knowledge and intact application and acquisition of procedural knowledge. Neuropsychologia, 1999; 37: 467-478.

17. Anderson JR. Language, memory and thought. Hillsdale: Lawrence Erlbaum; 1976.

18. Anderson JR. Rules of the mind. Hillsdale: Lawrence Erlbaum; 1993.

19. Salthouse TA. The processing-speed theory of adult age differences in cognition. Psychol Rev, 1996; 103: 403-28.

20. Ylvisaker M, Hanks R, Johnson-Greene D. Perspectives on rehabilitation of individuals with cognitive impairment after brain injury: rationale for reconsideration of theoretical paradigms. J Head Trauma Rehabil, 2002; 17: 191-209.

21. Transmuraal Zorgmodel CVA Regio Heuvelland, een model voor de verbetering van kwaliteit van zorg voor CVA-patiënten in de regio Heuvelland. Maastricht, the Netherlands; 1996.

22. Glaser B, Strauss A. The discovery of grounded theory: strategies for qualitative research. New York: Aldine de Gruyter; 1967.

23. Muhr T. Atlas.ti: The Knowledge Workbench. Visual Qualitative Data Analysis, Management and Theory Building [computer program]. Version WIN 4.2. Scientific Software Development: Berlin; 1998.

24. Fasotti L, Kovacs F, Eling PATM, Brouwer WH. Time Pressure Management as a compensatory strategy training after closed head injury. Neuropsychol Rehabil, 2000; 10: 47-65. 

Chapter 3

Disentangling the concept of mental slowness after acquired brain injury: thoughts following a systematic review on measures used to assess functional consequences of mental slowness

I. Winkens, C. Van Heugten, D. Wade, L. Fasotti 


\begin{abstract}
Objective. To review systematically measures evaluating two aspects of mental slowness - limitations in activities and patients' perceived experiences of slowness - for use with patients with acquired brain injury. And to discuss the conceptual basis of mental slowness.

Data sources. Electronic literature searches in PubMed, PsycINFO, Embase, CINAHL (1982 - March 2008). Reference lists also were reviewed.

Study selection. English language papers in which slowness was measured as an outcome. Papers not included were theoretical and review papers, studies not using measures for mental slowness, studies involving animals or children, studies involving subjects with diagnoses other than stroke or Traumatic Brain Injury.

Data synthesis. 1257 papers were identified, 253 were included. Measures were classified into four categories: 1) 218 studies used standardised neuropsychological tests measuring specific impairments related to mental slowness; 2) 22 described tests or questionnaires measuring general cognitive impairment. Slowness was just one of several items measured; 3) five described measures of everyday consequences of mental slowness; 4) 22 studies used measures of general everyday functioning.

Conclusions. Most studies used neuropsychological tests unrelated to daily life functioning. Five focused on actual or perceived limitations in everyday functioning. This small number may either reflect the lack of a clear conceptual basis underlying the construct of mental slowness making the search for relevant studies difficult or the lack of relevant measures of everyday functioning affected by mental slowness. We conclude that the concept of mental slowness has at least four components that should be specified separately.
\end{abstract}




\section{Introduction}

After acquired brain damage due to stroke or traumatic brain injury many patients complain of "mental slowness" [1,2].

Patients complaining of or labeled as having "mental slowness" may present with a range of problems and complaints. There may be an externally observed slowness with patients showing slowed performance on neuropsychological tasks; patients may have problems with everyday situations where events proceed at a rate they cannot control, such as conversations, driving a car and watching television; and there may be a feeling within the person that things happen too quickly, that one can no longer keep up mentally with cognitive demands being made by external events which in turn may lead to feelings of fatigue, altered mood, irritability etc $[3,4]$.

The frequency of these problems, and their impact on daily life, make "mental slowness" a prime target for accurate diagnosis and for cognitive rehabilitation.

Measuring the speed of cognitive functioning is one of the oldest techniques in neuropsychology [5]. Inspired by a practical problem at the Greenwich Observatory in 1794, where large individual differences were found in the accuracy of recording transit times of stars, Donders in 1868 developed the paradigm for the standard reaction time experiment: he found that by subtracting reaction times of several different experimental conditions, one can measure the duration of elementary processes (e.g. sensory discrimination and motor response). This was the origin of mental chronometry.

Later, the speed of mental processes became an important focus of interest in (modern) psychology. During and after World War II, experimental psychology was greatly influenced by the development of new technology, which placed heavy demands on the cognitive capacities of the user: machines had to be controlled, attention had to be paid to noisy radar screens, and air traffic controllers had to make decisions under time pressure and give directions based on quickly changing information. Great difficulties often occurred when interpreting and processing these large amounts of information. To prevent these problems, the limits of human information processing had to be investigated. This led to the development of many information processing models and theories, for instance the filter model by Broadbent [6], or the model of automatic versus controlled processing by Schneider and Shiffrin [7].

In the meantime psychologists began with examining the effects of brain damage. Researchers introduced many kinds of neuropsychological instruments to demonstrate the presence of slowed information processing in patients. In 1944 Ruesch showed prolonged visual reaction times after traumatic brain injury [8]. This finding was later confirmed by several others $[9,10,11,12,13]$.

Although many patients show some recovery, most will not return to their premorbid levels of speed of information processing, especially in more complex tasks. In addition, many patients still will experience the unpleasant feeling that there is not enough time 
available to think and act properly during task execution $[14,15]$. Rehabilitation may be considered.

Rehabilitation now concentrates on problems experienced by the brain injured patient; attention has shifted from a focus on deficits and impairments to a focus on limitations in daily activities and on other perceived consequences of the brain injury $[16,17]$. This change in focus may also explain why strategy training is being offered more frequently to patients with brain injury. Strategy training is aimed not at restoring a lost neuropsychological process or function, but at improving the performance of patients within their abilities and reducing their complaints. Patients are taught compensatory strategies that should enable them to minimize disabilities and participation problems and to function more independently in daily life.

For patients who have slow mental processes this may mean that patients learn to restructure tasks in which they do not have enough time in such a way that time pressure is prevented or managed [18].

The effects of strategy training can in fact only be measured in terms of observation of the restructured activity and in terms of general questionnaires about perceived consequences. The effects of the training are not expected to cause change at the (irreparable) impairment level. Nonetheless many psychologists still assess treatment effectiveness by means of psychometric measures, presumed to reflect a change in the level of neurocognitive impairments [17,19]. Even when the measured improvements can be attributed to treatment, the relationship between these changes at a mental level and functional improvements may not be clear or limited.

More important, in strategy training the goal is to train subjects to use compensatory strategies. In these cases the actual treatment benefits may not be apparent on measures that do not provide the opportunity to use such compensations (which highly structured tests of the speed of mental processes do not allow). Cicerone et al [16] strongly recommend that when evaluating rehabilitation, outcome measures should be tailored to the specific intended effects of cognitive interventions. Such measures need to focus on activities that are likely to be affected by the cognitive deficit of interest (in this case generalised slowness in many mental processes) because only these activities are likely to benefit from strategy training.

For some cognitive functions this has occurred already. For example, Zoccolotti et al. developed a semi-quantitative and functional evaluation instrument to evaluate the effects of neglect training on everyday activities and functional independence [20].

In the context of a study of treatment to alleviate the effects of "mental slowness", we set out to discover existing outcome measures designed to evaluate limitations in daily activities affected by and/or the perceived consequences of "mental slowness". We undertook a systematic search for measures and the results are presented here. However, the difficulty we had in performing this review led us to the conclusion that the conceptual basis of "mental slowness" is still unclear, and that a discussion of the concept is neces- 
sary. The major part of the discussion section will be used to start this and we will use the few findings from the review to illustrate our thoughts.

\section{Method}

A literature search was conducted in four electronic databases: PubMed, PsycINFO, Embase and CINAHL (1982 - March 2008). Exclusion criteria were: 1) non-English language papers; 2) theoretical or review papers; 3) studies not using outcome measures for mental slowness or speed of information processing; 4) animal studies; 5) studies involving children; 6) studies involving subjects other than persons clinically diagnosed with acquired brain injury, in particular stroke and TBI.

We were primarily interested in measures used to evaluate limitations in daily activities and perceived consequences of "mental slowness". Combinations of the following keywords were used: type of cognitive disorder or function (mental slowness, speed of information processing) and type of brain injury (stroke or TBI). Both controlled vocabulary words (MESH terms, Thesaurus terms) and free text words were combined in our searches. Details of the search are shown in Appendix 1. In addition, reference lists from identified articles were hand searched to complete the initial list of references.

All abstracts were independently reviewed by two persons (IW, CvH). Initially there was disagreement over 146 abstracts. However, this high rate appeared to be due to indistinct criteria: there was uncertainty whether or not to exclude case studies, and papers about patient groups with silent infarcts, CADASIL, or Vascular Dementia, as well as papers about motor slowness or general IQ tests in which processing speed was one of several factors measured. After joint discussion it was decided to exclude these papers resulting in disagreement over only eleven abstracts $(<1 \%)$. For these eleven papers and for sixteen other papers that could not be rejected or included just by reading the abstract, full texts were obtained and a decision was made after reading the full text. Data from selected papers were then extracted for analysis. 


\section{Results}

Figure 1. Search results
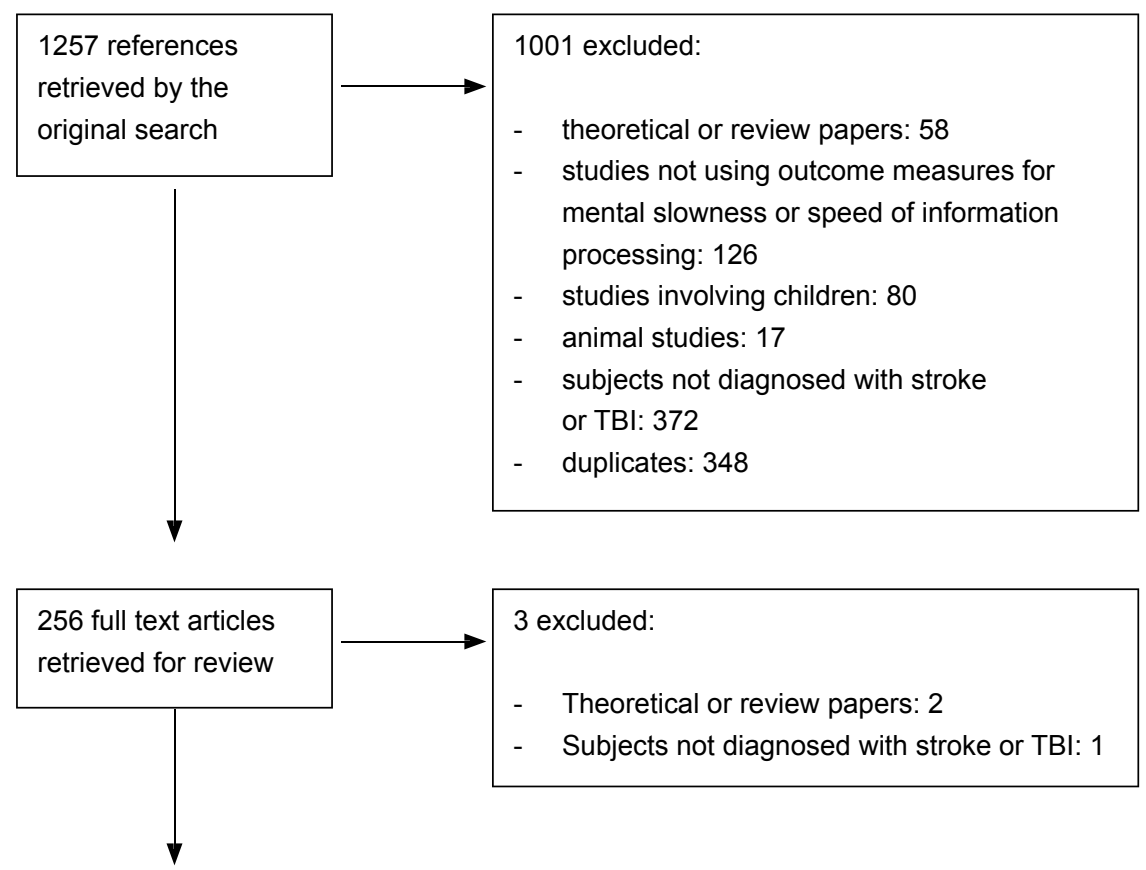

253 papers included in the analysis*:

- 218 studies used standardised neuropsychological tests

- 22 studies used tests or questionnaires measuring general cognitive impairments

- 5 studies used measures designed to detect everyday consequences of mental slowness

- 22 studies used measures designed to detect general everyday functioning

* Some studies used more than one type of instrument

The search identified 1257 published papers. After removing 348 duplicates, another 656 papers were excluded according to the exclusion criteria described in the method section: 1) theoretical or review papers $(\mathrm{n}=60) ; 2)$ studies not using outcome measures for mental slowness or speed of information processing $(n=126) ; 3)$ animal studies $(n=17) ; 4)$ studies involving children $(\mathrm{n}=80)$; subjects other than persons clinically diagnosed with stroke or TBI $(\mathrm{n}=373)$ (see Figure 1).

Eventually, 253 papers were eligible for inclusion. A variety of (outcome) measures for 
assessing mental slowness were used. Of the 253 studies, some focused on speed of information processing in particular. Others focused on themes like depression, or vocational outcome after rehabilitation and studied mental slowness as a covariate or predictor. Still other studies focused on cognitive functioning in general, in which case general questionnaires or measures were used. Slowness was then just one of many items studied.

Several studies used measures falling into different categories.

Having read the abstracts, we considered that measures fell into the following four categories of instruments:

1 Standardised neuropsychological tests measuring specific impairments related to speed of mental processes, usually unrelated to daily life functioning. The tests used most often were simple and choice Reaction Time tasks, but also common were tests traditionally developed for evaluating the presence of deficits in attention, such as coding tasks (e.g. the Symbol Digit Modalities Test and the Letter Digit Substitution Test); serial addition tasks (e.g. the Paced Auditory Serial Addition Test); and the Stroop Colour Word Task and Trail Making Test. For these tests the outcome of interest is the time needed to perform the test, or the number of correct answers within a certain time limit [21]. It is difficult to describe exactly how often a particular test was used. Sometimes it was only mentioned that neuropsychological tests for speed were part of a cognitive screening battery. More often, tests were not mentioned by name in the abstract. A total of 218 studies used measures falling into this category.

2 Tests or questionnaires measuring general cognitive impairments, generally by self-report of perceived deficits. Examples of such instruments are the Rivermead Post Concussion Symptoms Questionnaire, and the Neurobehavioral Rating scale $[22,23]$. Twenty-two studies used measures falling into this category.

3 Measures designed to detect or measure the everyday consequences of mental slowness in particular. Five studies used rating scales, (video) observations, virtual reality tasks, or specific questionnaires and self-reports (see below for further details). Table 1 displays all measures used in these studies.

4 Measures designed to detect general everyday functioning where performance in terms of daily life functioning, independence, social interaction, productive outcome etc was being studied in relation to mental speed or speed of information processing. Examples of these measures are the Functional Independence Measure, driving tasks, etc $[24,25](n=22)$. 


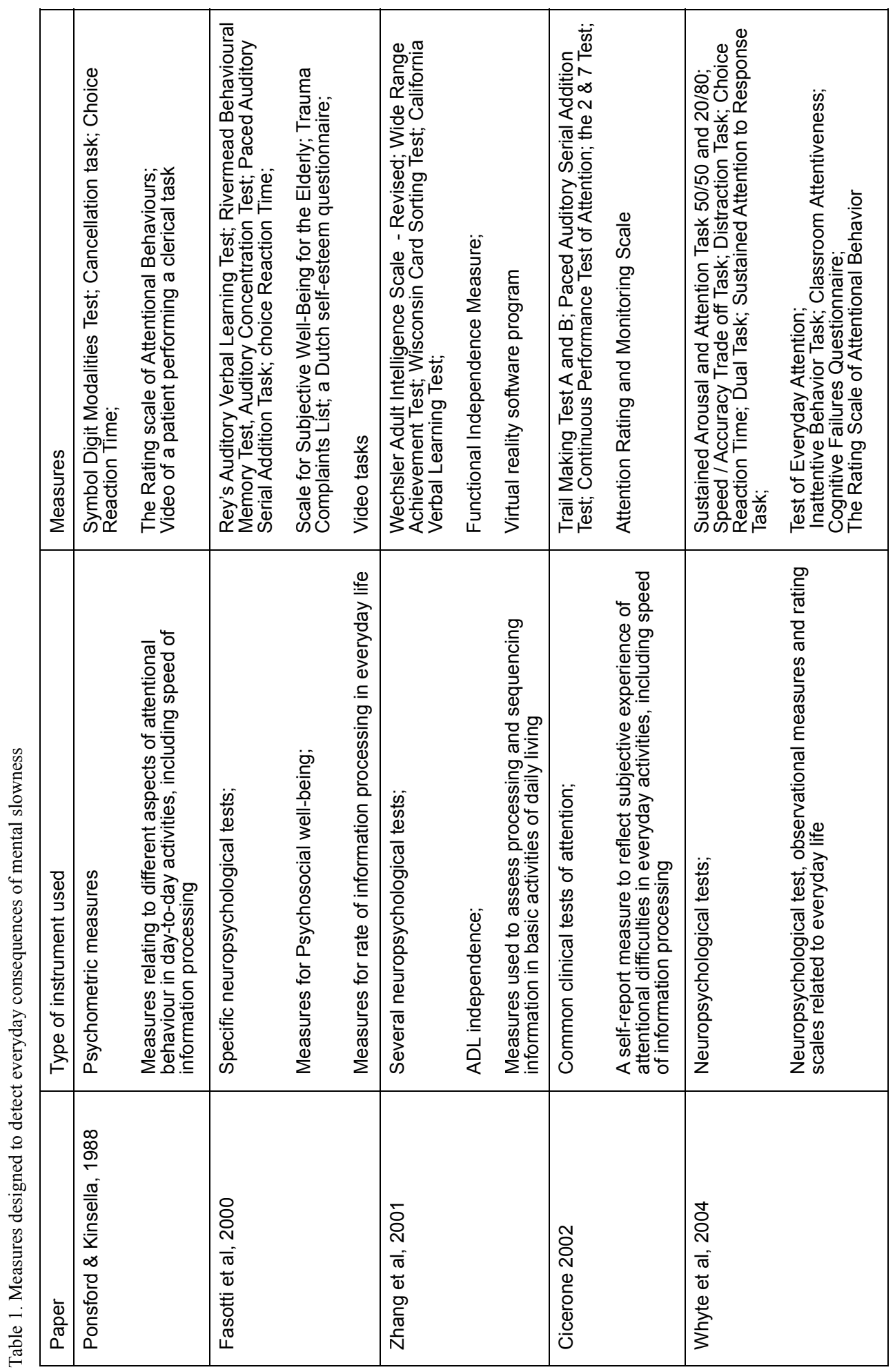




\section{Measures detecting/measuring everyday consequences of mental slowness}

We were primarily interested in measures used to detect and/or measure the everyday consequences of mental slowness, be it limitations in daily activities or the patient's experience of slowness. Further details are given here on the five studies that included measures from category three.

Ponsford and Kinsella [26] used a rating scale completed by the patient's occupational therapist, the Rating Scale of Attentional Behaviours, to evaluate the effects of a computer-mediated programme for the remediation of deficits in speed of information processing. The rating scale contained fifteen items reflecting a broad range of observable clinical behaviours, linked conceptually with aspects of attention such as slowness, distractibility, and attention to detail. Each item was scored from 0 to 4 reflecting the frequency with which it was apparent $(0=$ not at all; $4=$ always $)$. Additionally, a 30 -minutes video of the patient performing a clerical task in the OT department was used as a measure of the effects of training on overt attentional behaviours such as distractibility and ability to sustain attention to a task in a situation that was more closely related to functional activities.

Fasotti et al [18] used two video tasks to evaluate the effects of Time Pressure Management (TPM). In one, patients were told they were about to buy a waterbed and were required to ask for more information about this item. The shop assistant's answers were shown on a video. In the other task, a set of instructions was given to the patient on how to use part of a software package. The instructions emphasized that the patients should remember as much information as possible and they were allowed to do anything to make this easier, except for writing down the information. The video was started and time was recorded on a stopwatch. Simultaneously, an audiotape with recorded radio broadcasts was started. The sound level was preset at a level at which the video could still be understood. If the patient asked for the radio to be turned off, the sound level was set to another preset level which was lower but still audible. Halfway through the video the telephone rang and the way the patient dealt with this disturbance was recorded on a behaviour observation list. At the end, the patient's reproduction score was calculated by dividing the reproduced items by the total number of information units presented in the task.

For the "software" task, the instructions were slightly different, in that the purpose was to remember as much as possible in order to perform an assignment later. At the end the patient was asked to execute the task. The reproduction score was based on the number of steps reached in the execution. In addition, for both tests a behavioural observation list had been developed to assess the use of strategies (for example asking if the radio could be turned off, interrupting the video, reiterating the information etc.)

Zhang et al [27] used a computer-simulated virtual reality environment to assess the ability of patients to process and sequence information involved in basic activities of daily living. This environment simulated a typical kitchen with standard objects and appliances. Subjects navigated through the environment by using a computer cursor or touch screen. The simulated task involved preparing a bowl of soup. This task was divided into 30 
steps, categorized as follows: information processing, problem solving, logical sequencing and speed of responding. The overall assessment score was based on the number of correct responses and the time needed to complete daily living tasks representing the speed of processing information and finishing tasks.

Cicerone [28] used a self-report measure - the Attention Rating and Monitoring Scale to evaluate the effectiveness of an intervention for attentional deficits. The intervention emphasized the conscious and deliberate use of strategies to allocate attentional resources effectively and to manage the rate of information during task performance. The Attention Rating and Monitoring Scale consists of 15 items relating to problems with concentration, mental effort, and cognitive symptoms associated with attention difficulties. Participants rated how often they had experienced each difficulty in their day-to-day functioning over the past two weeks. Although the formal psychometric properties of this scale have not been examined, it has been shown to discriminate between a group of patients diagnosed with mild traumatic brain injury and a group of non-injured controls.

Finally, Whyte et al [29] used a wide range of attentional measures to evaluate the effects of methylphenidate on a variety of aspects of attention, including mental processing speed, ranging from impairments to activity levels. The measures included computerized and paper-and-pencil tests of attention, but also videotaped records of individuals working in a distracting environment, real-time observational scoring of attentiveness in a classroom environment, and rating scales of attentiveness. The effect of mental processing speed on actual activities was measured by means of two subtests of the Test of Everyday Attention: locating items on a map, and looking for phone numbers in a directory - the number of targets circled and time per target are recorded. In addition work productivity was measured by the Inattentive Behavior Task: here the participant is asked to perform three tasks at a work table (e.g. one is sorting items into their correct bowls) while being videotaped. Meanwhile a research assistant carries out a series of naturalistic distractions like making a phone call. The number of items correctly sorted is recorded.

\section{Discussion}

The review only identified five papers (from an original 253 selected) that appeared to use a measure of "mental slowness" or of its consequences. We conclude that the concept of "mental slowness" is too imprecise to be clinically useful, and that it should be replaced by more precise description of clinical phenomena.

\section{The review: results and limitations}

Several types of measures were identified in this systematic review. Most of the measures associated with "mental slowness" were actually measures of the speed of performance of particular cognitive tasks that are unrelated to daily activities. These findings are in line with the conclusion that Cicerone et al [16] and Geusgens et al [19] drew in their review papers on evidence-based cognitive rehabilitation: many studies still assess treatment ef- 
fectiveness by means of psychometric measures. In addition we found measures of general cognitive functioning and measures of general everyday functioning, where slowness was just one of several items measured. Only five studies used instruments that were more 'ecologically valid' and that approximated activities in natural contexts. They all tried to detect the presence of mental slowness in terms of the (perceived) speed or accuracy with which patients performed all kinds of everyday tasks. For example, Ponsford and Kinsella [26] rated the speed with which participants performed day-to-day activities. Fasotti et al [18] on the other hand used videotasks to study the accuracy with which persons with mental slowness processed and remembered incoming information. And Whyte et al [29] used as a measure of mental slowness the time needed and the accuracy with which persons located items on a map or phone numbers in a directory.

However, most instruments were used in only one study and little or nothing is known about their clinimetric properties. In addition, the instruments did not focus on perceived consequences, and, for some, much equipment was needed.

This review may have only identified five studies for one or more reasons. First of all, we were interested in instruments useful in stroke and TBI patients, and hence limited our search to these population groups. We do know of a few related studies with groups of healthy older adults using Timed Instrumental Activities of Daily Living (TIADL) tasks [30]. This measure consists of tasks sampling five common activities of daily living. The tasks address the following five IADL domains: 1) communication: finding a telephone number; 2) finance: making change; 3) cooking: reading ingredients on a can of food; 4) shopping: finding items on a shelf, and 5) medicine: reading directions on a medicine bottle. For all tasks the examiner records the time taken to perform the task and whether the subject commits any errors in performing the task. The test has good test-retest reliability (Pearson correlation coefficient 0.85).

In addition, The Road Sign Test has been used to evaluate effects of interventions on everyday speed in healthy older adults $[31,32]$. In the Road Sign Test, participants view road signs (pedestrians, bicycle, right and left turn arrows) with and without a red slash. They are instructed to disregard signs with a red slash and to respond as quickly as possible, using a computer mouse, to signs without a slash. Of primary interest is the time taken to complete each task. Accuracy of response is also recorded.

Second, the search was also limited by the great difficulty in identifying studies that were investigating "mental slowness", by which we mean a reduction in performance in daily activities and/or the perception by the patient that cognitive functioning is reduced in performance (speed and/or accuracy and/or effort needed). "Mental slowness" and information processing slowness are only two of a variety of terms that have all been used to define how fast information is processed cognitively. Both terms are frequently used in the field of neuropsychology, but when used in the literature, there is little debate about (or explanation of) their meaning. They usually refer to either the time required to execute a cognitive task or the amount of work that can be completed within a finite period of time [33]. Little or nothing is said, however, about possible resulting symptoms and complaints. Operationalisation of the construct is difficult - it can not be understood in isola- 
tion from other cognitive abilities and other factors, and it varies across studies [33].

The difficulty in identifying relevant studies arose from the lack of specific terms (words) and this may arise from the lack of any agreement on a clear conceptual (theoretical) basis of the concept of "mental slowness" itself. Searching for studies on an imprecise or variably defined concept will certainly miss studies of relevance and may do so in a biased way.

A third and related possibility is that there just are no relevant measures of everyday functioning related to "mental slowness". Again the lack of a clear conceptual basis might have discouraged the development of instruments investigating possible consequences of "mental slowness". When there is no agreement on the central feature of "mental slowness" and the possible symptoms and complaints resulting from it, it is difficult to construct useful instruments that focus on these symptoms and complaints.

The problem of agreeing and defining the constructs used to describe and explain observations affects many concepts within neurology and neuropsychology, such as spasticity, neglect and apraxia. However, for some of these concepts, clear definitions have been made and measurements focusing on everyday consequences do exist [20,34].

We therefore believe that the main conclusion of this systematic review is that there should be a critical reconsideration of the concept of "mental slowness", and the remainder of this discussion undertakes this.

\section{Mental slowness; what is it?}

It is generally accepted that disease may lead to a person having 'symptoms and signs'. These symptoms and signs are the manifestation of a disease at the level of a person. Within the WHO ICF model disturbances in the functioning of the person are referred to as impairments. Impairments may arise from pathology, but may also arise in other ways, for example through expectation and as a manifestation of dysfunction under stress. However impairments arise, they may limit activities [35].

The key feature to consider is that most impairments are simply constructs. They are useful ideas that are derived from observations, usually of activities or by listening to a person's report. Constructs may summarise or explain a series of behavioural observations, including those made in constrained 'test' conditions. They may predict other observations and may predict that certain interventions will help. However they have no independent reality. The constructs used are often powerful and helpful, but they remain simply constructs.

"Mental slowness" is also a term that could be used to summarise a set of observations, but there is no agreement on the underlying construct of the relevant observations. "Mental slowness" however differs from many other neurological and cognitive impairments in one very important way. Many neurological impairments such as, for example, aphasia can, in principle at least, be attributed to the disturbance of some specific function that is 
linked to some specific location or network within the brain. Speed, in contrast, is a property of all cognitive and neurological functions. No single brain region or network has been, or is likely to be, identified as the neural substrate for the speed of performance of a specific process [33]. Rather, each neural network of complex interconnectivity across multiple regions of the brain underlying each identified function will operate at its own 'normal' speed and each may be slowed when some part is disrupted by disease or damage. Speed is one aspect of the function of each and every process; it is not an independent entity. "Mental slowness" therefore must manifest itself or be perceived through its impact upon mental processes and the behaviours arising from those processes.

This is not to say that a concept of information processing speed or of "mental speed" is not useful. There is a large body of evidence that demonstrates the interaction of information processing speed with other cognitive domains. For example it can negatively impact verbal abilities, long-term memory and working memory [33]. It is also possible and indeed likely that someone with slowness in one cognitive process will also be impaired in other cognitive domains, which will be reflected in many everyday tasks.

Thus "mental slowness" could be used to refer to a generalised slowing across two or more mental processes, and one hypothesis might be that a central information processing deficits underlies this. For example Van Zomeren and Spikman [1] state that "mental slowness" influences a patient's information processing capacity. In everyday life, attention often has to be divided over many different (sub)tasks. When this process is slowed, the patient will experience time pressure and will not be able to perform two tasks at the same time. Theoretically, this is in line with Shiffrin and Schneider's model of information processing [7]: when the capacity of the slow, serial, controlled information processes is exceeded, divided attention deficits occur.

Other authors further argue that information processing speed is a basic resource of the cognitive system, a primary contributor in other cognitive abilities [36]. Based on many findings from reaction time studies they argue that changes in processing speed mediate declines in performance on many more complex cognitive tasks.

Rabbit, however, has criticized global accounts of cognitive aging, arguing that measures of reaction time index the efficiency of the cognitive system rather than representing its fundamental building blocks. He states that we should always be careful to consider the involvement of other, task-specific factors [37]. Eventually one does not measure just the time that is needed to process information: many other factors determine response speed. For example motor deficits, motivation and use of compensatory strategies may determine whether mental slowness will lead to handicap or not. People continue to function but with less efficiency: the output may be less precise and/or they may need compensatory strategies and/or they may take longer to reach their conclusion. This may manifest to the patient as requiring more 'effort' and/or being 'slower' and/or being less accurate.

The consequences of slowness in one or more mental processes may therefore vary considerably. First, an observer may find that the patient shows slowed performance on specific cognitive tasks in laboratory settings. Second, the patient may experience increased 
difficulty and/or be observed (measured) to have reduced effectiveness in performing some or many everyday tasks such as having a conversation or driving a car. Third, the patient may perceive him or herself as being slow, which probably arises when he or she compares their perceived speed against his own expectation. Finally patients also may experience secondary effects such as fatigue and tiredness, which probably arises from the extra cognitive work or effort required to achieve the desired output, and/or they may complain of increased agitation when they recognise that they may be failing, or low mood because they are performing less well [3].

Most tests for "mental slowness" usually focus on only one of the several aspects described above. However, as shown, "mental slowness" can have many meanings, and therefore can be measured in many different ways and with different outcomes.

It is specifically important to note that measuring speed of information processing is not appropriate as the only or even as the most important measure. Patients performing poorly on laboratory tasks may not necessarily show deficits in everyday life. A mixture of factors such as context or the ability to use compensatory strategies may influence performance. In addition patients may perceive themselves as being slow, may feel fatigue or agitation, even when performance on structured tasks is at an average level.

Thus we believe that any discussion or investigation of "mental slowness" should consider all these aspects:

- Performance on activities where slowness may have a major impact on effectiveness (e.g. measuring time taken and/or accuracy and/or safety and/or errors etc)

- Perception by the patient of slowness and/or being under pressure and/or of increased difficulty in performing activities, particularly those where speed is important.

- Secondary consequences of slowness on the patient such as:

- Fatigue and tiredness

- Irritability, agitation, anxiety

- Low mood

- Measured speed of information processing on structured specific cognitive tasks, usually a variety of tasks covering different cognitive domains or processes.

When the aim of a study is to evaluate the effects of treatments, instruments that focus on several aspects should be used. Instruments that measure the perception of slowness and its associated feelings, and those that measure performance in everyday activities are probably more likely to detect change or differences and are certainly more relevant to patients.

In our review we found a few measures that bore some relationship to actual function and the experience of mental slowness in everyday life. However, most of these measures were used in only one study, and little or nothing is known about their clinimetric properties. Therefore we developed two new instruments, one of which is based on the instruments by Owsley et al [30] and Fasotti et al [18]. In the Mental Slowness Observation Test [4] 
performance on tasks is observed. The test consists of four subtasks like following a route description and looking up phone numbers. The outcome of interest is the time needed to perform the task and the number of correct answers; the use of compensatory strategies is allowed. The Mental Slowness Questionnaire [4] evaluates the consequences of mental slowness in terms of perceived slowness in daily life activities. Both instruments have been shown to offer reliable and valid methods for measuring limitations in daily activities related to mental slowness and perceived consequences.

In conclusion, we think that a clear conceptual basis for mental slowness is a prerequisite for research in this area and for the development of new instruments and suitable rehabilitation methods. We are aware that much work still needs to be done, but the discussion we have started here may be a first step on the way. We specifically suggest that both clinicians and researchers should be more specific about their observations or treatment objectives when investigating or discussing "mental slowness". 


\section{References}

1. Van Zomeren AH, Spikman JM. Tempo en aandacht. In: Vandermeulen JAM, Derix MMA, Avezaat CJJ, Mulder Th, Van Strien JW (eds). Niet aangeboren hersenletsel bij volwassenen. Maarssen: Elsvier Gezondheidszorg; 2003.

2. Visser-Keizer AC, Meyboom-de Jong B, Deelman BG, Berg IJ, Gerritsen MJ. Subjective changes in emotion, cognition and behaviour after stroke: factors affecting the perception of patients and partners. $\mathrm{J}$ Clin Exp Neuropsychol 2002; 24: 1032-45.

3. Winkens I, Van Heugten CM, Fasotti L, Duits AA, Wade DT. Manifestations of mental slowness in the daily life of stroke patients. Clin Rehab 2006; 20: 827-34.

4. Winkens I, Van Heugten CM, Fasotti L, Wade DT. Reliability and validity of two new instruments for measuring aspects of mental slowness in the daily lives of stroke patients. Neuropsychol Rehab. Published online, April 3rd, 2008.

5. Eling P, Brouwer W. Aandachtsstoornissen. Een neuropsychologisch handboek [Attention deficits. A neuropsychological handbook]. Lisse: Swets \& Zeitlinger, 1995.

6. Broadbent DE. Task combination and the selective intake of information. Acta Psychologica 1982; 50: 253-290.

7. Schneider W, Shiffrin MW. Controlled and automatic human information processing: 1 Detection, search and attention. Psychology Review 1977; 84: 1-66.

8. Ruesch J. Visual tests in head injuries. Dark adaptation, negative after-image, tachistoscopic examinations and reaction time in head injuries. J of Neurosurg 1944; 1: 243-251.

9. Norman B, Svahn EK. A follow-up study of severe brain injuries. Act Psych Scand 1961; 37: 236-264.

10. Miller E. Simple and choice reaction time following severe head injury. Cortex 1970; 6: 121-127.

11. Gronwall D, Sampson H. The psychological effects of concussion. Auckland: Oxford University Press, 1874.

12. Van Zomeren AH, Deelman BG. Differential effects of simple and choice reaction after closed head injury. Clin Neurol and Neurosurg 1976; 79(2): 81-90.

13. Ponsford, J.L., \& Kinsella, G. (1992). Attentional deficits following closed head injury. Journal of Clinical and Experimental Neuropsychology, 14, 822-838.

14. Van Zomeren AH, Brouwer WH. Clinical neuropsychology of attention. New York: Oxford University Press, 1994.

15. Van Zomeren AH, Fasotti L. Impairments of attention in brain-damaged patients. In: Von Steinbuechel N, Von Cramon DY, Poepoep E (eds). Neuropschological Rehabilitation. Berlin: Springer Verlag, 1992

16. Cicerone KD, Dahlberg C, Kalmar K, Langenbahn DM, Malec JF, Bergquist TF et al. Evidence-based cognitive rehabilitation: Recommendations for clinical practice. Arch Phys Med Rehabil 2000; 81(12): 1596-1615. 
17. Cicerone KD, Dahlberg C, Malec JF, Langenbahn DM, Felicetti T, Kneipp S et al. Evidence-based cognitive rehabilitation: Updated review of the literature from 1998 through 2002. Arch Phys Med Rehabil 2005; 86: 1681-1692.

18. Fasotti L, Kovacs F, Eling PATM, Brouwer WH. Time Pressure Management as a compensatory strategy training after closed head injury. Neuropsychol Rehab 2000; 10: 47-65.

19. Geusgens CAV, Winkens I, Van Heugten CM, Jolles J, Van den Heuvel WJA. The occurrence and measurement of transfer in cognitive rehabilitation: A critical review. J of Rehab Med 2007; 39(6): 425-439.

20. Zoccolotti P, Antonucci G, Judica A. Psychometric characteristics of two semi-structured scales for the functional evaluation of hemi-inattenion in extrapersonal and personal space. Neuropsy Rehab 1992; 2(3): 179-191.

21. Lezak MD. Neuropsychological assessment. New York: Oxford University Press, 2004.

22. Eyres S, Carey A, Gilworth G, Neumann V, Tennant A. Construct validity and reliability of the Rivermead Post-Concussion Symptoms Questionnaire. Clin Rehab 2005; 19(8): 878-887.

23. Sultzer DL, Levin HS, Mahler ME, et al. Assessment of cognitive, psychiatric, and behavioural disturbances in patients with dementia: The Neurobehavioural Rating Scale. J of Am Ger Soc 1992; 40: 549-555.

24. Linacre JM, Heinemann AW, Wright BD, Granger CV, Hamilton B. The structure and stability of the Functional Independence Measure. Arch of Phys Med and Rehab 1994; 75: 127-32.

25. Brouwer WH, Withaar FK, Tant MC, Van Zomeren AH. Attention and driving in traumatic brain injury: A question of coping with time pressure. J of Head Traum Rehab 2002; 17(1): 1-15.

26. Ponsford JL, Kinsella G. Evaluation of a remedial program for attention deficits following closed head injury. J of Clin and Exp Neuropsychol 1988; 10(6): 693-708.

27. Zhang L, Abreu BC, Masel B, Scheibel RS, Christiansen CH, Huddleston N, et al. Virtual reality in the assessment of selected cognitive function after brain injury. Am J of Phys Med and Rehab 2001; 80(8): 597-604.

28. Cicerone KD. Remediation of "working attention" in mild traumatic brain injury. Brain Injury 2002; 16(3): 185-95.

29. Whyte J, Hart T, Vaccaro M, Grieb-Neff P, Risser A, Polansky M, et al. Effects of methylphenidate on attention deficits after traumatic brain injury: A multidimensional, randomized, controlled trial. Am J of Phys Med and Rehab 2004; 83(6): 401-420.

30. Owsley C, Sloane M, McGwin GJr, Ball K. Timed instrumental activities of daily living tasks; Relationship to cognitive function and everyday performance assessments in older adults. Gerontology 2002; 48(4): 254-65.

31. Roenker DL, Cissell GM, Ball KK, Wadley VG, Edwards JD. Speed of processing and driving simulator training result in improved driving performance. Human Factors 2003; 45: 218-233. 
32. Jobe JB, Smith DM, Ball K, Tennstedt SL, Marsiske M, Willis SL, et al. ACTIVE: A cognitive intervention trial to promote independence in older adults. Controll Clin Trials 2001; 22(4): 453-79.

33. DeLuca J, Kalmar JH. Information processing speed in clinical populations. Psychology Press, 2007.

34. Van Heugten CM, Dekker J, Deelman BG, Stehmann-Saris JC Kinebanian A. A diagnostic test for apraxia in stroke patients: Internal consistency and diagnostic value. Clin Neuropychol 1999; 13(2): 182-92.

35. Wade DT, Halligan P. New wine in old bottles: The WHO ICF as an explanatory model of human behaviour. Clin Rehab 2003; 18: 349-54.

36. Salthouse TA. The processing-speed theory of adult age differences in cognition. Psychol Rev, 1996; 103: 403-28.

37. Duncan J, Phillips L, McLeod P. Measuring the mind. Speed, control, and age. Oxford: Oxford University Press, 2005.

Appendix 1. Details of literature search in MEDLINE. Similar terms (Thesaurus terms and free text words) were used in the other databases

\begin{tabular}{|c|c|c|}
\hline \multicolumn{3}{|c|}{ Text words / MESH TERMS } \\
\hline Cognitive functioning & Type of brain injury & Limits \\
\hline $\begin{array}{l}\text { (slow* AND (mental* OR } \\
\text { perceive* OR cognit* OR } \\
\text { (information) process* OR } \\
\text { tempo)) OR } \\
\text { (speed* AND (mental* OR } \\
\text { perceive* OR cognit* OR } \\
\text { (information) process*)) OR } \\
\text { time pressure }\end{array}$ & $\begin{array}{l}\text { CEREBROVASCULAR } \\
\text { ACCIDENT OR } \\
\text { CEREBROVASCULAR } \\
\text { DISORDERS OR BRAIN } \\
\text { INJURIES OR stroke OR } \\
\text { ischem* OR hemorrhag* } \\
\text { OR brain injury* OR brain } \\
\text { lesion* OR head injury* OR } \\
\text { brain concussion* OR brain } \\
\text { damage* OR brain infarct* } \\
\text { OR brain embolism OR brain } \\
\text { contusion* }\end{array}$ & $\begin{array}{l}\text { Human studies, > } 18 \text { yrs, } \\
\text { English / Dutch }\end{array}$ \\
\hline
\end{tabular}

$*=$ wild card, such that it would include all possible transformations of the term. For example "brain damage*" includes "brain damages", "brain damaging", "damaged brain", etc. 
Chapter 4

Reliability and validity of two new instruments for measuring aspects of mental slowness in the daily

lives of stroke patients

Published in:

Neuropsychological Rehabilitation: An International Journal 2009; 19(1): 64-85.

I. Winkens, C. Van Heugten, L. Fasotti, D. Wade. 


\begin{abstract}
Objective. To examine psychometric characteristics of two measures related to mental slowness experienced after stroke: one measure is aimed at performance on tasks, the other is a questionnaire evaluating perceived consequences of mental slowness.

Method. 37 stroke patients and 33 matched controls were studied. A subgroup of 10 patients and 22 controls was observed by two independent raters to determine inter-rater reliability, a subgroup of 18 patients completed the questionnaire twice over a two-week interval to determine test-retest stability.

Results. Internal consistency was acceptable for the Mental Slowness Observation Test (Cronbach's $\alpha=.61$ and .73) and good for the Mental Slowness Questionnaire $(\alpha=.91)$. For the Observation Test, correlations between the results of the two raters ranged between .77 and .99 and Intra Class Correlation coefficients were between .86 and .99 . For the Questionnaire, correlations between two test occasions ranged between .85 and .90 and Intra Class Correlation coefficients were between .91 and .95. Correlations of between 0.52 and 0.67 were found between the Observation Test and neuropsychological tasks for speed of information processing. The Questionnaire correlated most strongly with scores on tests for ADL functioning, fatigue and depression (correlations ranged between .37 and .63).

Conclusion. The two new instruments offer reliable and valid methods for measuring limitations in daily activities related to mental slowness and some of the consequences of mental slowness in terms of sense of time pressure, fatigue, depressive complaints and independent ADL functioning.
\end{abstract}




\section{Introduction}

Slowness of information processing, or mental slowness, is a prominent consequence of stroke [1-3]. Several studies have shown that $50 \%$ to $70 \%$ of patients with stroke show slowed performance on neuropsychological tests $[4,5]$. Also, patients rate mental slowness high on a list of cognitive complaints $[6,7]$.

Patients experience this slowness in several ways. It may mean that they perform activities with the unpleasant feeling of time pressure, the feeling that there is not enough time to think and act properly during task performance. In a previous study we found that slowed information processing affects a wide range of activities, especially in situations in which time pressure is present. Not only do stroke patients complain of difficulties when processing incoming information (e.g. when having a conversation or watching television), but they also report problems with memory, attention and learning. In addition patients experience physical and psychological complaints as a consequence of mental slowness, such as fatigue, higher irritability and emotionality, headaches and dizziness [8].

For neuropsychologists, slowness of information processing, has traditionally been evaluated through standardized tests like the Paced Auditory Serial Addition Task (PASAT), the Symbol Digit Modalities Test (SDMT) and Reaction Time tasks [9]. However, we think that, in addition to a reduced speed of performance on simple neuropsychological tests such as Reaction Time tasks (which usually have a mental as well as a motor component), the concept of "mental slowness" can encompass at least two more aspects, possibly, but not necessarily, related to one another: 1) a perception that mental processing is slow, leading to a sense of time pressure, fatigue, etc; and 2) observed difficulties in performing time pressured daily activities where mental speed is important. Extrapolating the results of neuropsychological tests to the latter two aspects may be misleading [10]. The experience of mental slowness in a patient's everyday functioning may not necessarily be concurrent with measured slowed information processing. Especially for the purpose of rehabilitation it is essential to gain insight into the functional problems experienced and factors related to them, which requires standardized instruments that specifically assess limitations in daily activities related to the experience of mental slowness.

In the present study we have developed a set of standardized observations which measure performance on time pressure tasks and a questionnaire which measures perceived consequences related to mental slowness in stroke patients. We present internal consistency, inter-rater and test-retest reliability, and construct validity of these newly developed instruments.

\section{Method}

\section{Participants}

Subjects were recruited from the stroke population of five rehabilitation centers in the Netherlands where patients are admitted to a rehabilitation centre when there are complex sensory-motor, cognitive and/or behaviour problems requiring a multidisciplinary reha- 
bilitation approach. Most patients are younger than 65 years, able to follow an intensive rehabilitation program and are expected to return to their home situation after rehabilitation. This means that the patients are expected to have sufficient learning ability, are sufficiently motivated and have adequate informal care at home [11].

For this study, there were no further inclusion criteria. Psychologists were asked to recruit patients with stroke, but not necessarily suffering from mental or cognitive slowness. Patients were excluded if they were younger than 18 years, were less than 6 weeks poststroke, had suffered from disabling psychiatric disease, had been hospitalized for substance abuse, had other medical or neurological diseases, or had such severe cognitive, communicative, physical or psychological problems that they were unable to perform a neuropsychological assessment (based on the clinical judgment of the treatment team).

Healthy controls were recruited from the personal environment of the researchers. They were matched to the patient group on age, sex and level of education, and were free from present or previous brain injury. Exclusion criteria were the same as for the patient group.

The research protocol was approved by the Medical Ethics Board of each participating rehabilitation centre and informed consent was obtained from all participants.

\section{Measures}

Two new instruments were developed for use with patients who experienced mental slowness: one observed performance on specific activities, the other asked patients to quantify the experience of mental slowness.

\section{Mental Slowness Observation Test (MSOT)}

Based on the previous study [8] and other literature [12] we developed an Observation Test. The test initially consisted of five tasks that are commonplace for most people, are brief, amenable to accurate timing and easily standardized. The tasks were specifically designed to measure performance in time pressure situations: Patients are required to adequately handle incoming information and to work within certain time limits. Examples of the tasks are following a route description, making a telephone call, or looking up telephone numbers. Appendix 1 lists the instructions for each individual task. Instructions were paced or repeated when requested.

Two tasks had a preset maximum time, i.e. subtask 3 (sorting money, 5 minutes) and subtask 5 (looking up telephone numbers, 10 minutes): if the subject did not complete the task within this time period, the item was terminated. Otherwise the tester recorded the time needed to perform each task (Time score), and the number of elements correctly achieved (Elements score). The maximum score per task is 10, the maximum total score is 50 .

\section{Mental Slowness Questionnaire (MSQ)}

The Questionnaire consists of 21 items examining different kinds of daily activities that are likely to be related to mental slowness. Examples of the items are: "I have trouble 
following a conversation", or "I have trouble doing two things at the same time". (Appendix 2.)

Each item is scored on a five-point frequency scale ranging from zero: 'this never happens' to four: 'this happens often'. The maximum total score is 84 . Each problem is also scored on a three-point severity scale ranging from zero: 'not troublesome', to two: 'very troublesome'. For this scale, the maximum total score is 42 . Finally we multiplied the score on the frequency scale by the score on the severity scale. For this weighted scale the maximum total score is 168 .

In addition, several neuropsychological tests for speed of information processing were used to objectify the presence of measured cognitive slowness and its relationship to perceived mental slowness: Paced Auditory Serial Addition Task (PASAT) [13], presented at a pacing with a 3,2 sec. interstimulus interval; Symbol Digit Modalities Test (SDMT) [134]; Simple Reaction Time task, developed for this study: subjects performed the task on a pocket PC. Subjects touched the screen until a stimulus appeared, then withdrew from the screen as fast as possible. Reaction times were measured. The patient group also completed tests for memory (Auditory Verbal Learning Test (AVLT) [15]), attention (Trail Making Test $A$ and B (TMT) [16]; Stroop Color Word Task [17]), ADL functioning (Barthel Activities of Daily Living (ADL) Index [18]), fatigue (Fatigue Severity Scale [19]), and depression (Center for Epidemiologic Studies Depression Scale (CES-D) [20]), to investigate whether performance on these tests would interfere with performance on the two new tests.

\section{Procedure}

All subjects who participated in the study were informed about the purpose of the study and their right to withdraw from the study at any stage. They were then asked to provide demographic information, including their age, level of education and medical history. All 37 stroke patients completed the entire test battery described above. The 33 controls were tested in a single session which consisted only of the Mental Slowness Observation Test, Mental Slowness Questionnaire and measures of cognitive speed.

For several reasons only a subgroup of 10 patients and 22 controls completed the Observation Test while they were observed by two raters simultaneously: patients did not always give permission, and in daily clinical practice it was just not always possible to have two raters present at the same time. In addition only 18 patients completed the Questionnaire a second time two weeks later: either patients did not give permission or did not return the Questionnaire.

The measurements were performed at the rehabilitation centre, the research institute or at home. Each patient was tested by one of two neuropsychologists in sessions of one and a half to two hours (in case of fatigue patients were tested twice, in two one-hour sessions). The Questionnaire was administered twice by the same neuropsychologist. 


\section{Statistical analyses}

The characteristics of the subjects and the results of the assessment procedure are presented using descriptive statistics. Independent samples t tests, Mann-Whitney U tests and $\chi 2$ tests were applied to determine differences between the two groups on each of the relevant demographic and test variables. Score distributions plots were used to describe differences between the two groups on the Observation Test and the Questionnaire.

Internal consistency of the tests was assessed by computing Cronbach's alpha [21]. Interrater reliability and test-retest reliability was measured using simple correlation coefficients (Pearson or Spearman) [22], and Intra-Class Correlation coefficients [23]. Simple correlation coefficients were also used to investigate construct validity. Alpha was set at 05 .

The SPSS version 12.0 package was used for statistical analysis.

\section{Results}

Seventy subjects were included in the study between July 2004 and July 2005: 37 stroke patients and 33 controls. The patient group included 26 men and 11 women and had a mean age of 54.8 years $(\mathrm{SD}=12.1)$. Eleven patients had received higher education, 11 secondary, and 15 primary. (Education grades ranged from 1: elementary school to 8: university degree [24]). Fourteen patients had a left hemisphere stroke, 18 had a right hemisphere stroke and for five patients localisation of stroke was not specifically mentioned in their medical files. Thirty-one patients had suffered an ischemic stroke, four had suffered a haemorrhage, and two had a post-operative infarct after haemorrhage. Twelve patients had recurrent stroke, 25 were first-ever stroke patients. Mean time since stroke was 234 days $(\mathrm{SD}=160$; range $=$ six weeks to 22.9 months). Mean Barthel score was $18.9(\mathrm{SD}=1.9)$. Twenty-eight patients had a score of 19 or 20 ; the patient group was not very disabled.

The control group included 17 males and 16 females and had a mean age of 49.8 years $(\mathrm{SD}=10.1)$. Fifteen subjects had received higher education, nine secondary, and nine had received primary education. Statistical testing revealed that the control and patient group were well matched with respect to $\operatorname{sex}(\chi 2=2.6, p>.05)$, age $(t=-1.9, p>.05)$ and education grade $(Z=-1.4, p>.05)$.

Neuropsychological performance

Table 1 shows the results of both the patient and control group on each of the relevant test variables. The patient group performed significantly more slowly on all measures of information processing speed: SDMT written $(\mathrm{t}=7.4, \mathrm{p}<.01)$, SDMT verbal $(\mathrm{t}=7.2, \mathrm{p}$ $<.01)$, Simple Reaction Time Task $(\mathrm{z}=-4.2, \mathrm{p}<.01)$ and PASAT $(\mathrm{t}=5.1, \mathrm{p}<.01)$. 
Table 1. Neuropsychological test performance (mean, SD)

\begin{tabular}{|l|c|c|}
\hline Test variable & patient group $(\mathrm{N}=37)$ & control group $(\mathrm{N}=33)$ \\
\hline SDMT written & $28.4(10.4)$ & $46.6(10.0)^{* *}$ \\
SDMT verbal & $35.9(11.6)$ & $55.2(10.8)^{\star *}$ \\
Simple Reaction Time Task & $0.51(0.58)$ & $0.29(0.04)^{\star *}$ \\
PASAT & $35.3(9.6)$ & $48.3(10.9)^{\star *}$ \\
\hline AVLT (total) & $40.1(11.6)$ & \\
TMT A (time in seconds) & $62.8(38.1)$ & \\
TMT B (time in seconds) & $153.9(112.8)$ & \\
STROOP 1 (time in seconds) & $66.2(25.5)$ & \\
STROOP 2 (time in seconds) & $89.4(42.8)$ & \\
STROOP 3 (time in seconds) & $156.3(74.0)$ & \\
FSS total (min = 9, max =63) & $31.5(13.1)$ & \\
FSS mean score (max = 7) & $3.5(1.5)$ & \\
CES_D (min = 0, max =60) & $13.4(8.0)$ & \\
\hline
\end{tabular}

${ }^{* *} \mathrm{p}<.01$

SDMT = Symbol Digit Modalities Test PASAT $=$ Paced Auditory Serial Addition Task; AVLT = Auditory Verbal Learning Test; TMT = Trail Making Test; FSS = Fatigue

Severity Scale; CES_D = Centre for Epidemiologic Studies Depression Scale

\section{Mental Slowness Observation Test and Mental Slowness Questionnaire}

Table 2 shows that the patient group scored significantly lower (Elements score) on two of the subtasks (subtask 2, making a telephone call: $\mathrm{z}=-3.4, \mathrm{p}<.01$; subtask 5, looking up phone numbers: $z=-2.8, p<.05)$. One of these tasks was time limited, the other, however, was not. The patient group performed the other subtasks just as well as the control group. However, the time taken to perform these tasks clearly discriminated the patient group from the control group: the patient group was slower than the control group (Time score) on the total Observation Test and on each single subtask, with the exception of task four (listening to the radio news) (total: $\mathrm{z}=-5.3, \mathrm{p}<.01$; subtask $1: \mathrm{t}=-5.1, \mathrm{p}<.01$; subtask $2: \mathrm{t}=-2.5, \mathrm{p}<.05$; subtask $3: \mathrm{z}=-5.3, \mathrm{p}$ $<.01$; subtask $5: \mathrm{z}=-5.3, \mathrm{p}<.01$ ). Performance of listening to the radio news (task 4 ) was the only task that did not discriminate the patient group from the control group on any of the scores. We reanalysed the data after leaving out subtask 4 . The results were not very different (Table 2: total: $\mathrm{z}=-5.6, \mathrm{p}<.01)$. We therefore decided to perform further analyses without subtask 4 .

Table 2 also shows the mean scores of both groups on the Questionnaire. The patient group scored significantly higher than the control group on all three scales of the Questionnaire: they have more complaints, and are more severely disturbed by them. (frequency: $\mathrm{z}=-5.12, \mathrm{p}<.01$; severity: $\mathrm{z}=-5.04, \mathrm{p}<.01$; freq $\mathrm{x}$ sev: $\mathrm{z}=-5.17, \mathrm{p}<.01$ ). 
Table 2. Test results (mean, sd)

\begin{tabular}{|c|c|c|c|}
\hline Test variable & & $\begin{array}{l}\text { patient group } \\
\qquad(\mathrm{N}=37)\end{array}$ & $\begin{array}{l}\text { control group } \\
\qquad(\mathrm{N}=33)\end{array}$ \\
\hline \multicolumn{4}{|l|}{ Mental Slowness Observation Test } \\
\hline \multirow[t]{2}{*}{ Total score over five tasks } & Elements correct & $39.1(8.1)$ & $43.2(4.9)$ \\
\hline & Time in seconds & $1232.3(304.6)$ & $815.8(197.0)^{\star *}$ \\
\hline \multirow[t]{2}{*}{ Total score over four tasks } & Elements correct & $33.0(7.0)$ & $36.4(4.3)$ \\
\hline & Time in seconds & $1045.3(302.9)$ & $616.4(189.8)^{* *}$ \\
\hline \multirow[t]{2}{*}{ Subtask 1: Route description } & Elements correct & $9.1(2.1)$ & $8.5(2.3)$ \\
\hline & Time in seconds & $223.4(93.1)$ & $130.9(50.6)^{\star *}$ \\
\hline \multirow[t]{2}{*}{ Subtask 2: Telephone call } & Elements correct & $8.0(2.5)$ & $9.4(1.8)^{\star \star}$ \\
\hline & Time in seconds & $174.1(84.5)$ & $134.6(31.4)^{\star}$ \\
\hline \multirow[t]{2}{*}{ Subtask 3: Sorting money } & Elements correct & $8.9(2.3)$ & $9.6(0.8)$ \\
\hline & Time in seconds & $199.7(65.8)$ & $118.5(37.0)^{* *}$ \\
\hline \multirow[t]{2}{*}{ Subtask 4: Radio news } & Elements correct & $6.2(2.4)$ & $6.7(2.2)$ \\
\hline & Time in seconds & $187.1(33.2)$ & $193.7(23.5)$ \\
\hline \multirow[t]{2}{*}{ Subtask 5: Telephone numbers } & Elements correct & $7.0(3.4)$ & $8.9(2.2)^{*}$ \\
\hline & Time in seconds & $448.2(145.9)$ & $232.3(128.9)^{\star *}$ \\
\hline \multicolumn{4}{|l|}{ Mental Slowness Questionnaire } \\
\hline \multirow[t]{3}{*}{ Total score } & Frequency & $34.5(20.5)$ & $7.5(10.2)^{\star *}$ \\
\hline & Severity & $16.6(11.5)$ & $3.2(5.1)^{\star *}$ \\
\hline & Freq $\times$ sev & $52.4(39.5)$ & $7.6(15.4)^{\star *}$ \\
\hline
\end{tabular}

${ }^{*} \mathrm{p}<.05$

${ }^{* *} p<.01$

Figures 1 and 2 show the score distributions for both groups on the Mental Slowness Observation Test. The figures show that there were outliers for both the control and the patient group. However, removing the outliers did not lead to significantly different results.

Figure 1 shows that $89 \%(\mathrm{n}=32)$ of the patients were slower than the mean Time score of the control group; $53 \%(\mathrm{n}=19)$ were 2 SD or more slower than the mean Time score of the control group, and $33 \%(n=12)$ of the patients were slower than the slowest person from the control group.

Figure 2 shows that $49 \%(n=18)$ of the stroke patients scored below the mean Elements score of the control group; $24 \%(n=9)$ scored 2 SD or more below the mean score of the control group, but only two patients actually scored below the lowest score of the controls. 
Figure 1. Score distributions for both groups on the Time score of the Mental Slowness Observation Test, showing the number of patients scoring above the mean score of the control group, the number of patients scoring 2 SD above the mean score of the control group and the number of patients scoring above the highest score of the control group

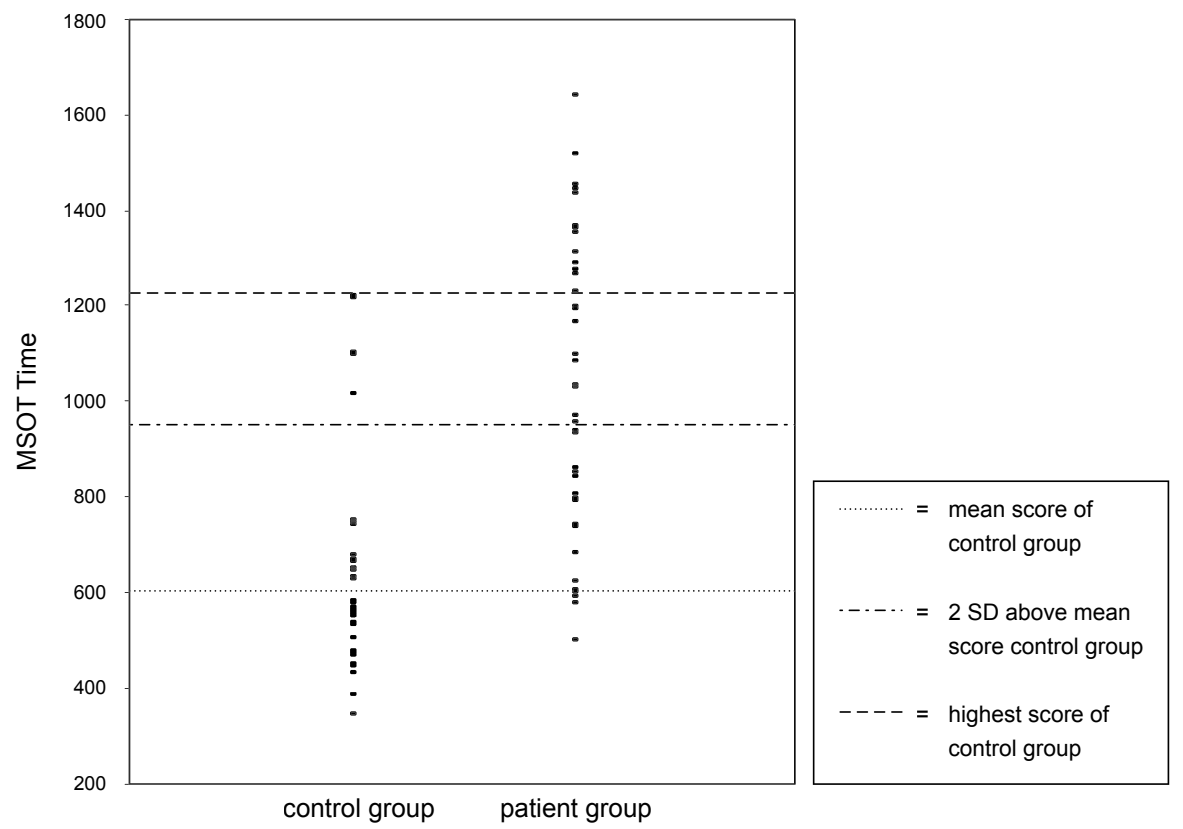

Figure 2. Score distributions for both groups on the Elements score of the Mental Slowness Observation Test, showing the number of patients scoring below the mean score of the control group, the number of patients scoring 2 SD below the mean score of the control group and the number of patients scoring below the lowest score of the control group.

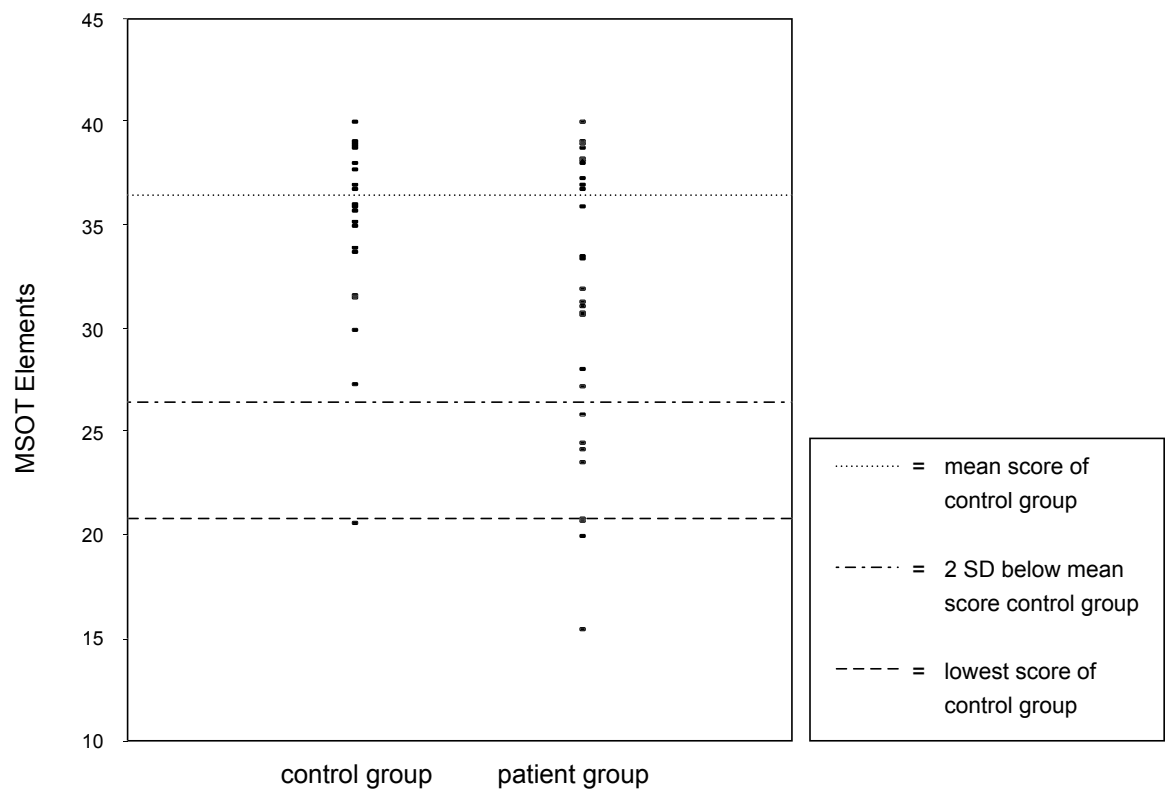


Figure 3 shows the score distributions for both the patient and control group on the freq $\mathrm{x}$ sev scale of the Mental Slowness Questionnaire. The scores of the stroke patients show considerably more variation than those of the control group: patients scored across the total range of possible scores. In addition Figure 3 shows that $84 \%(n=31)$ of the patients scored above the mean score of the control group, that $59 \%(\mathrm{n}=22)$ of the patients scored $2 \mathrm{SD}$ or more above the mean score of the control group, and that $22 \%(n=8)$ had scores above the highest score of the controls.

Figure 3. Score distributions for both groups on the frequency*severity scale of the Mental Slowness Questionnaire, showing the number of patients scoring the mean score of the control group, the number of patients scoring 2 SD above the mean score of the control group and the number of patients scoring above the highest score of the control group

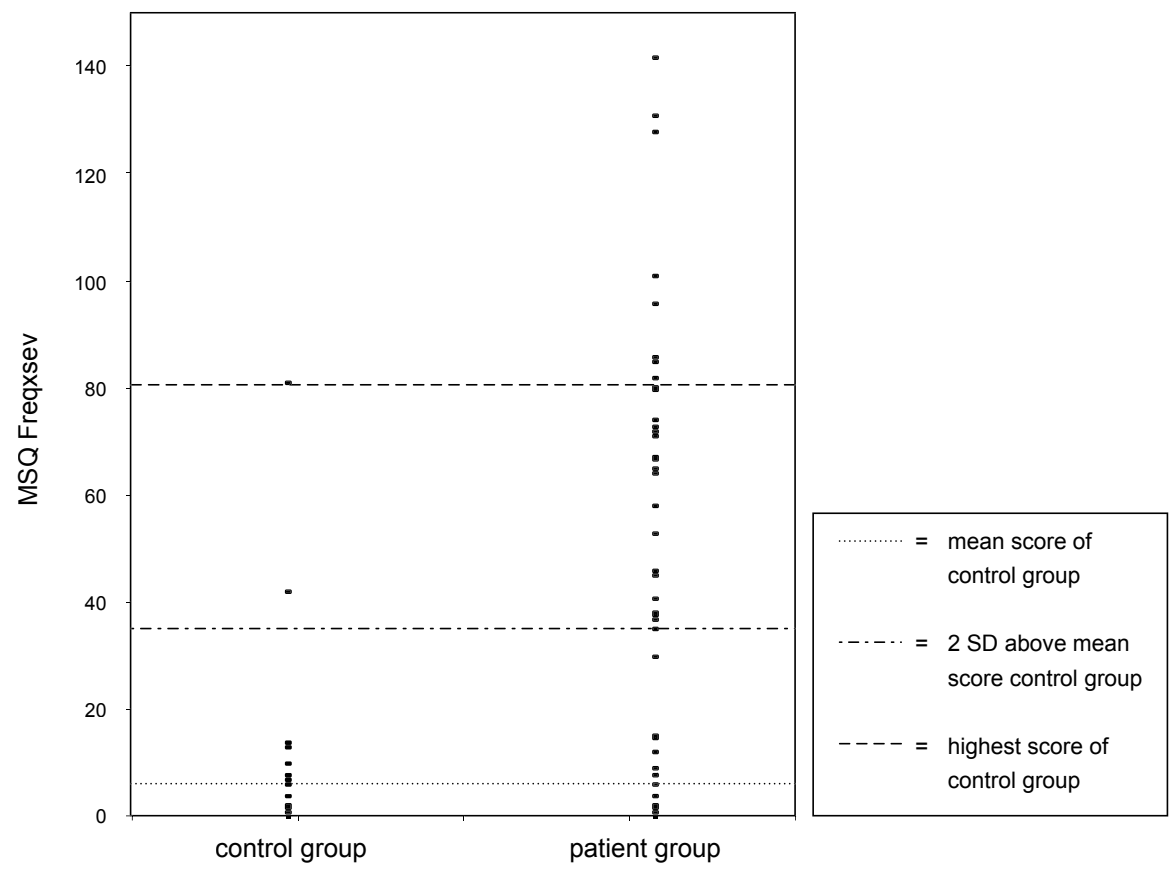




\section{Internal consistency of the MSOT and MSQ}

After omitting subtask 4, Cronbach alpha values for the Observation Task ranged from .61 for the Elements score to .73 for the Time score. The Questionnaire had an alpha value of .91. None of the items in the Questionnaire lowered the alpha value.

Table 3 shows that rater two scored systematically higher than rater one on subtask 1 (following a route description) and on the Total score over 4 tasks (subtask 1: $\mathrm{t}=-2.2$. $\mathrm{p}<.05$; total: $\mathrm{t}=-2.2, \mathrm{p}<.05)$. However, the differences were only small. The table also shows the correlations between the results of the two raters and the Intra Class Correlation coefficients suggesting good inter-rater reliability (Heaton et al., 2001; Van Heugten, 1998).

Table 3. Inter-rater reliability estimates of the Mental Slowness Observation Test

\begin{tabular}{|l|c|c|c|c|}
\hline $\mathrm{N}=32$ & $\begin{array}{c}\text { Rater 1 } \\
\text { Mean (SD) }\end{array}$ & $\begin{array}{c}\text { Rater 2 } \\
\text { Mean (SD) }\end{array}$ & $\begin{array}{c}\text { Correlation } \\
\text { coefficients }\end{array}$ & $\begin{array}{l}\text { Intra Class } \\
\text { Correlation } \\
\text { coefficients }\end{array}$ \\
\hline Test variable & $33.8(7.0)$ & $34.31(6.7)^{*}$ & $.98^{* *}$ & $.99^{* *}$ \\
\hline $\begin{array}{l}\text { Total score over four tasks } \\
\text { (Elements correct) }\end{array}$ & $7.9(2.7)$ & $8.3(2.7)^{*}$ & $.94^{* *}$ & $.97^{* *}$ \\
\hline $\begin{array}{l}\text { Subtask 1: } \\
\text { Route description }\end{array}$ & $8.7(2.4)$ & $8.9(2.1)$ & $.97^{* *}$ & $.98^{* *}$ \\
\hline $\begin{array}{l}\text { Subtask 2: } \\
\text { Telephone Call }\end{array}$ & $9.0(2.2)$ & $9.0(2.1)$ & $.90^{* *}$ & $.99^{* *}$ \\
\hline $\begin{array}{l}\text { Subtask 3: } \\
\text { Sorting Money }\end{array}$ & $6.4(2.1)$ & $6.0(2.4)$ & $.77^{* *}$ & \\
\hline $\begin{array}{l}\text { Subtask 4: } \\
\text { Radio news }\end{array}$ & $8.3(2.7)$ & $8.2(2.8)$ & $.99^{* *}$ & $.86^{* *}$ \\
\hline $\begin{array}{l}\text { Subtask 5: } \\
\text { Telephone numbers }\end{array}$ & & & & \\
\hline \\
$*$ p<.05
\end{tabular}




\section{Test-retest reliability of the MSQ}

Table 4 shows that there were no systematic differences between the scores on test occasion one and test occasion two regarding all three scales of the Questionnaire. Correlations ranged between .85 and .90 and Intra Class Correlation coefficients ranged between .91 and .95 .

Table 4. Test-retest reliability estimates of the Mental Slowness Questionnaire

\begin{tabular}{|l|c|c|c|c|}
\hline $\mathrm{N}=18$ & $\begin{array}{c}\text { Test occasion 1 } \\
\text { Mean (SD) }\end{array}$ & $\begin{array}{c}\text { Test occasion 2 } \\
\text { Mean (SD) }\end{array}$ & $\begin{array}{c}\text { Correlation } \\
\text { coefficients }\end{array}$ & $\begin{array}{c}\text { Intra Class } \\
\text { Correlation } \\
\text { coefficients }\end{array}$ \\
\hline Frequency & $45.0(13.9)$ & $44.3(18.6)$ & $.85^{* *}$ & $.91^{* *}$ \\
\hline Severity & $22.6(9.0)$ & $23.4(9.9)$ & $.90^{* *}$ & $.95^{* *}$ \\
\hline Freq x sev & $65.4(36.2)$ & $64.1(40.2)$ & $.89^{* *}$ & $.94^{* *}$ \\
\hline
\end{tabular}

${ }^{* *} \mathrm{p}<.01$

\section{Construct validity}

All tests for speed of information processing - except the Simple Reaction Time Task correlated significantly with the total Time score of the Mental Slowness Observation Test (SDMT written: $\mathrm{r}=-.67, \mathrm{p}<.01$; SDMT verbal: $\mathrm{r}=-.52, \mathrm{p}<.01$; PASAT: $\mathrm{r}=-.58, \mathrm{p}<.01$ ). The SDMT also had significant correlations with the total Elements score of the MSOT (SDMT written: $\mathrm{r}=.66, \mathrm{p}<.01$; SDMT verbal: $\mathrm{r}=.59, \mathrm{p}<.05$ ). Patients who were slow on tests for speed of information processing made more mistakes on the Mental Slowness Observation Test and needed more time to complete the test. In addition, several other neuropsychological tests had significant correlations with both the total Time score of the Observation Test (AVLT: $\mathrm{r}=-.43, \mathrm{p}<.01$; TMT A: $\mathrm{r}=.57, \mathrm{p}<.05$; TMT B: $\mathrm{r}=.69, \mathrm{p}<.01$ ). and the total Elements score (TMT A: $r=-.59, \mathrm{p}<.01$; TMT B: $r=-.59, \mathrm{p}<.01$; Stroop card 1: $\mathrm{r}=-.33, \mathrm{p}<.05)$. And finally, the Elements score of the Observation Test correlated significantly with the Barthel ADL Index $(r=.40, p<.05)$ and Center for Epidemiologic Studies Depression scale $(\mathrm{r}=.35, \mathrm{p}<.05)$, indicating that patients with depressive complaints and less independence in ADL functioning performed worse on the Observation Test.

The Mental Slowness Questionnaire did not correlate with the Mental Slowness Observation Test, showing that patients with few or no complaints on the Questionnaire are not necessarily the ones that do well on the Observation Test. In addition the Questionnaire did not correlate with any of the neuropsychological tests for speed of information processing, memory or attention. However, the Questionnaire had significant correlations with the Barthel ADL Index $(r=.37, p<.05)$, Fatigue Severity Scale $(r=.41, p<.05)$ and Centre for Epidemiologic Studies Depression scale $(r=.63, \mathrm{p}<.01)$. 


\section{Discussion}

In the present study it was found that stroke patients need considerably more time to complete four out of five subtasks of a newly-developed Mental Slowness Observation Test than do matched controls without stroke. Moreover, patients make more mistakes on two out of five subtasks. One of these tasks was time-limited, the other was not. This might lead one to argue that tasks for measuring mental slowness should evaluate only time. However, the results showed no clear-cut speed-accuracy trade off: such a trade off would imply that subjects will perform better if they take enough time for the task at hand. But this is not what we have found: some subjects were very fast and made no or few mistakes; others worked very fast but performed badly. Therefore we suggest using both the Time and Elements scores.

The finding that performances on one subtask - listening to a radio broadcast - were only slightly different between patients and controls may be explained as follows: this subtask, contrary to the other subtasks, was not a self-paced task: participants listened to radio news that was recorded on a tape, without opportunity to interrupt or ask for repetition. However, contrary to our expectations, patients did not make more mistakes than controls. We therefore have removed this task from the final version of our Observation Test.

The study also found that stroke patients given a newly-developed questionnaire, the Mental Slowness Questionnaire, rated that they had more problems than controls and that they were more troubled by their difficulties. The results confirm our hypotheses and validate the Observation Test and questionnaire.

\section{Clinimetric properties}

Both the Observation Test and the questionnaire had reasonable clinimetric properties. Internal consistency was acceptable for the Observation Test and good for the Mental Slowness Questionnaire. The simple correlation coefficients and Intra Class Correlation coefficients indicated good reliability for both the Observation Test and the Questionnaire, suggesting that observation by two independent observers or responding to the questionnaire on two different occasions should lead to similar conclusions.

We had no relevant external criterion for measuring mental slowness in daily life. However, to be able still to say anything about the validity of the Observation Test, we used the second best criterion and correlated observed performance with the Observation Test to the results of neuropsychological tasks for speed of information processing. Strong correlations were found implying that the Observation Test indeed measures at least one component of the construct of mental slowness. However, we were interested in measuring the other two aspects of slowness, namely the perception that mental processing is slow, and observed difficulties in daily activities where time pressure is important. Although we are aware that we could not compare the new instrument to a gold standard measuring mental slowness in everyday situations, we do believe that this instrument 
comes closer to our goal than standardised neuropsychological tests. In addition we are aware that the correlations between the Observation Test and tests of cognitive slowness do not exclude the relevance of other functional abilities in the execution of complex daily life tasks under time pressure. Speed is a property of all cognitive and neurological functions, a resource of cognitive functioning in general $[25,26]$. It manifests itself, or can be perceived, through its impact upon several mental processes like memory, attention or executive functioning. It is not possible to study mental slowness without studying subjective or objective change in other (cognitive) functions and it can be expected that one also finds significant relationships with several other neuropsychological tests such as Trail Making Task A and B, the Auditory Verbal Learning Task and a test for independence in ADL functioning. In addition, one must be aware that for example motor abilities, aphasia and neglect (which we did not specifically measure) also play a decisive role in the performance of daily life tasks. Although we excluded patients with severe problems, it is evident that even mild deficits may hamper patients in their performance.

However, the aim of the study was the construction of a practical rehabilitation based instrument, a structured observation test reflecting the everyday consequences of mental slowness and time pressure. The significant correlations with structured speed tasks and the good interrater reliability show that this test is a useful measure reflecting the everyday consequences of mental slowness.

The results of the Questionnaire did not correlate with the results of the Observation Test or any of the other neuropsychological tests for speed of information processing. This could have several reasons. First it may be due to an awareness problem of the patient, which would be in accordance with previous studies that showed that subjective self-reported complaints do not always match with task performance [27,28]. Second, we think that it is possible for patients to perform daily life tasks normally, even when they are indeed slower. This could be due to, for example, appropriate use of strategies. And last, patients may feel they have become slower than before, while still being able to perform on a average or above average level.

Thus the questionnaire does not primarily measure the actual limitation of activities caused by mental slowness. It does measure a patient's perception of the impact of mental slowness upon his performance, manifest as a change in his well-being. This may encompass a wide variety of complaints: patients may complain of slowness when they compare performance to their expectation, of fatigue and tiredness arising from the extra cognitive input required, or of low mood because of poor performance. Our finding that the Questionnaire correlated most strongly with scores on scales for independent ADL functioning, fatigue and depression is therefore not surprising. Patients who are less independent in ADL performance attribute this to slowness, and feel more fatigued and depressed, but it is not possible to disentangle the complex interrelationships between cognitive functioning, mood, fatigue and limitation on activities.

We think the results suggest that the two sets of data measure different aspects of the construct of mental slowness: one measures the subjective perception that mental processing is slow (leading to a sense of time pressure, feeling that more effort is needed, to complaints of fatigue etc), the other measures observed difficulties in performing daily activities with a significant time pressure component. 


\section{Limitations}

Some limitations of this study need to be considered. First, the study sample was a selected group of patients admitted to a rehabilitation centre. In the Netherlands, only $10 \%$ of the stroke population is eligible for rehabilitation [29]. This does not allow to generalize the results of this study to all stroke patients, especially those who are older or those with a less favourable prognosis.

Second, the new instruments should not be considered 'gold standards' for diagnosing mental slowness after stroke. These instruments aim to quantify the extent of mental slowness, not to determine its presence. Before using the instruments as diagnostic tools, future studies should focus on several other clinimetric properties like sensitivity, specificity and divergent validity and on the usefulness of these instruments for groups of patients different from the one described in this study.

\section{Conclusion}

In conclusion, both instruments offer reasonably reliable and valid methods for assessing two aspects of the construct of mental slowness as experienced by patients after stroke: the observation task measures actual performance of time pressure activities experienced in normal life; and the questionnaire measures the patient's subjective experience of slowness and its consequences in terms of experienced time pressure, fatigue, changes in emotion and ADL functioning. Although for both measures sensitivity to changes due to treatment still has to be proven, they might be useful tools in studies evaluating the effectiveness of treatments and especially the generalizability of these effects to everyday life.

\section{Acknowledgements}

The authors would like to thank Esther Habets and all the patients and employees of the rehabilitation centres Hoensbroeck (Hoensbroek), Blixembosch (Eindhoven), Leypark (Tilburg), De Hoogstraat (Utrecht) and Sint Maartenskliniek (Nijmegen) for their active collaboration in this study. 


\section{References}

1. Ballard C, Stephens S, Kenny RA, Kalaria R, Tovee M, O’Brien J. Profile of neuropsychological deficits in older stroke survivors without dementia. Dement and Ger Cogn Dis 2003; 16: 52-56.

2. Gerritsen MJ, Berg IJ, Deelman BG, Visser-Keizer AC, Meyboom-De Jong B. Speed of information processing after unilateral stroke. $\mathrm{J}$ of Clin and Exp Neuropsychol 2003; 25: 1-13.

3. Rasquin SM, Lodder J, Ponds RW, Winkens I, Jolles J. Cognitive functioning after stroke: a one-year follow-up study. Dement and Ger Cogn Dis 2004; 18: 138-144.

4. Hochstenbach J, Mulder T, Van Limbeek J, Donders R, Schoonderwaldt H. Cognitive decline following stroke: a comprehensive study of cognitive decline following stroke. J of Clin and Exp Neuropsychol 1998; 20: 503-17.

5. Rasquin SM, Verhey FR, Lousberg R, Winkens I, Lodder J. Vascular cognitive disorders: memory, mental speed and cognitive flexibility after stroke. J of the Neurol Sci 2002; 203-204: 115-9.

6. Hochstenbach J. The cognitive, emotional, and behavioural consequences of stroke [Dissertation]. Nijmegen, The Netherlands: Catholic University Nijmegen, 1999.

7. Visser-Keizer AC, Meyboom-de Jong B, Deelman BG, Berg IJ, Gerritsen MJ. Subjective changes in emotion, cognition and behaviour after stroke: factors affecting the perception of patients and partners. $\mathrm{J}$ of Clin and Exp Neuropsychol 2002; 24: 1032-45.

8. Winkens I, Van Heugten CM, Fasotti L, Duits AA, Wade DT. Manifestations of mental slowness in the daily life of stroke patients. Clinical Rehabilitation 2006; 20: 827-34.

9. Van Zomeren AH, Spikman JM. Tempo en aandacht (Speed and attention). In: Vandermeulen JAM, Derix MMA, Avezaat CJJ, Mulder Th, Van Strien JW.(Eds.). Niet aangeboren hersenletsel bij volwassenen (Acquired brain injury in adults). Maarssen, the Netherlands: Elsvier Gezondheidszorg, 2003.

10. Ylvisaker M, Hanks R, Johnson-Greene D. Perspectives on rehabilitation of individuals with cognitive impairment after brain injury: rationale for reconsideration of theoretical paradigms. J of Head Traum Rehab 2002; 17: 191-209.

11. Synchron. Transmuraal Zorgmodel CVA Regio Heuvelland, een model voor de verbetering van kwaliteit van zorg voor CVA-patiënten in de regio Heuvelland (Transmural model for the improvement of care for stroke patients in the region "Heuvelland", the Netherlands). Maastricht, The Netherlands, 1996.

12. Owsley C, Sloane M, McGwin GJr, Ball. Timed Instrumental Activities of Daily Living Tasks: Relationships to cognitive function and everyday performance assessments in older adults. Gerontology 2002; 48: 254-265.

13. Gronwall DMA, Sampson H. The psychological effects of concussion. Auckland: Auckland University Press, 1974.

14. Smith A. Symbol Digit Substitution Test (SDMT). Manual (Revised). Los Angeles, USA: Western Psychological Services, 1982. 
15. Brand PA, Jolles J. Learning and retrieval rate of words presented auditory and visually. J of Gen Psychol 1985; 112: 201-210.

16. Reitan RM. Validity of the Trail Making Test as an indicator of organic brain damage. Perc and Mot Skills 1958; 8: 271-276.

17. Houx PJ, Jolles J, Vreeling FW. Stroop interference : aging effects assessed with the Stroop Color-Word Test. Exp Aging Res 1993; 19: 204-224.

18. Collin C, Wade DT, Davies S, Home V. The Barthel ADL Index: A reliability study. Int Dis Stud 1988; 10(2): 61-63.

19. Krupp LB, LaRocca NG, Muir-Nash J, Steinberg AD. The Fatigue Severity Scale: Application to patients with multiple sclerosis and systemic lupus erythematosus. Arch of Neurol 1989; 46: 1121-1123.

20. Shinar D, Gross CR, Price TR, Banko M, Bolduc PL, Robinson RG. Screening for depression in stroke patients: the reliability and validity of the Center for Epidemiologic Studies Depression Scale. Stroke 1986; 17: 241-245.

21. Haan R. Clinimetrics in stroke [Dissertation]. Amsterdam, the Netherlands: University of Amsterdam, 1994.

22. Heaton RK, Temkin N, Dikmen S, Avitable N, Taylor MJ, Marcotte TD, Grant I. Detecting change: A comparison of three neuropsychological methods, using normal and clinical samples. Arch of Clin Neuropsychol 2001; 16: 75-91.

23. Van Heugten CM. Apraxia in stroke patients: assessment and treatment [Dissertation]. Groningen, the Netherlands: Groningen University, 1998.

24. Jolles J, Houx PJ, Van Boxtel MPJ, Ponds RWHM. The Maastricht Aging Study: determinants of cognitive aging. Maastricht, the Netherlands: Neuropsych Publishers, 1995.

25. Salthouse TA. The processing-speed theory of adult age differences in cognition. Psychological Review $1996,103,403-428$.

26. Spikman JM, Van Zomeren AH, Deelman BG. Deficits of attention after closed-head injury: slowness only? J of Clin and Exp Neuropsychol 1996; 37: 467-478.

27. Schofield PW, Marder K, Dooneief G, Jacobs DM, Sano M, Stern Y. Association of subjective memory complaints with subsequent cognitive decline in community-dwelling elderly individuals with baseline cognitive impairment. Am J of Psych 1997; 154(5): 609-615.

28. Ponds RWHM. Forgetfulness and cognitive aging. Prevalence, characteristics, and determinants [Dissertation]. Maastricht, the Netherlands: Maastricht University, 1998.

29. Van Exel J, Koopmanschap MA, Van Wijngaarden JDH, Scholte Op Reimer WJ. Costs of stroke and stroke services: determinants of patient costs and a comparison of costs of regular care and care organised in stroke services. Cost Effectiveness and Resource Allocation 2003, 1(1), 2. 


\section{Appendix 1. Mental Slowness Observation Test}

(Pencil and paper is lying in front of the patient)

General instructions to the subject are as follows:

"I will ask you to perform five tasks that are very similar to tasks that you may encounter in daily life. For example following a route description, making a telephone call, or looking up telephone numbers. I will observe how well you perform the task and I will be timing you. For all the tasks there is one general rule: you are allowed to do anything you would do in normal life to make these tasks easier for yourself".

\section{Subtask 1: following a route description}

Instruction:

"Imagine you are in an unfamiliar city, and you would like to know where the nearest bakery is. Let's pretend I am a pedestrian, and you decide to ask me. In a minute I will give you a route description. Afterwards, I would like you to draw the route on a map, and tell me where the bakery is (the map will be handed to the patient after the route description is given). So please make sure that you'll know how to get to the bakery".

Read the following route description to the patient:

"You walk straight on and then take the second turn on your right. When you reach the Bank you go left. Then you take the second turn on your right. You will pass an ancient gate. Keep on walking until you reach a pub, there you turn left. Keep on walking and the bakery will be on your right".

Hand the map to the patient:

"Now try to draw the route on this map. When you are ready, please tell me where the bakery must be".

Time starts when you start reading the route description until the patient shows you on the map where the bakery is. If the patient gets lost and asks for a new route description, take away the map while you read the route description again.

Task materials: paper and pencil, stopwatch, a map, score form.

\section{Subtask 2: making a telephone call}

Instruction:

"Imagine you would like to visit someone in the University hospital in Maastricht. The visiting hour starts at three o'clock. You leave from the train station in Den Bosch, and travel by public transport. You are now going to call the public transport information service to find out what time you have to leave and which train you have to take. This is the telephone number, and this is the question you can ask (hand out paper with informa- 
tion). Please wait until you can speak to an operator. When you have made the phone call, I will ask you to tell me how you will travel. So make sure you can tell me afterwards. Are you ready? Then you can make the phone call (the patient can read the question from a piece of paper).

Time starts when the operator starts speaking until the patient has reported the information.

Task materials: Piece of paper with the question and phone number, stopwatch, paper and pencil, phone, score form.

\section{Subtask 3: sorting money}

Instruction:

"In a minute I will ask you to sort from this pile of money ten precise amounts. The amounts I'm asking for are on this piece of paper (show the paper to the patient). Every time you have sorted out one amount, please put the money back on the pile. Try to do it as fast as possible. I'll give you five minutes to do this, so try to be ready in time. This watch will keep track of time. The alarm goes off whenever 60 seconds have passed, and every time I will tell you how much time is left. Let's start, shall we?

Time limit: 5 minutes

Time starts when the patient picks up the first coin until he has sorted out the last amount.

Task materials: change, stopwatch, timer, score form, piece of paper with the requested amounts

[[Subtask 4: listening to the radio news: has been excluded from the final version of the MSOT.]]

Instruction:

"Imagine you have plans for going to Zandvoort, to the coast, this Saturday and Sunday. You decide to listen to the radio news to find out whether you can expect heavy traffic, what the weather will be like and so forth, so you can decide what you will do and what you have to take with you. In a minute you will listen to a part of the radio news. Afterwards I will ask you some questions. The questions I will ask you are on this piece of paper (show it to the patient). Listen carefully so you will be able to answer the questions. Do you understand this task? Are you ready to begin?"

Time starts when the radio news starts to play until the patient answers the last question.

Task materials: tape recorder and tape, pen and paper, paper with questions, stopwatch, score form. 


\section{Subtask 5: looking up telephone numbers}

Instruction:

"I will ask you to look up several phone numbers in this phone book. These are the people of whom I'd like to know their phone numbers (show names on a piece of paper).You can write the numbers down. You have ten minutes. While you are looking up the phone numbers, I will also ask you several questions you have to answer. At the end of the task I would like you to give me all phone numbers. Do you understand what you have to do? Then you may begin with the first phone number".

Time limit: 10 minutes

Time starts when the patient opens the phone book until he/she gives the last phone number.

Task materials: Phone book, list of names, list of questions, paper and pencil, stopwatch, score form. 


\section{Appendix 2. Mental Slowness Questionnaire}

Below you see a list of situations that may happen in daily life. For every situation, could you fill in whether this has become a problem due to the stroke? If a certain situation has always been a bit of a problem for you, circle the number 0 . If it has worsened, please circle the number that applies to you. The numbers have the following meaning:

$0=$ this never happens to me

$1=$ this rarely happens to me, less than once a week

$2=$ this happens to me now and then, approximately once a week

$3=$ this happens to me frequently, two or three times a week

$4=$ this happens to me often, more often than three times a week

For every question you also fill in how troublesome it is to you when this happens. You can choose between:

not: I do not find this troublesome

fairly: I find this fairly troublesome

very: I find this very troublesome

(Of course, if you fill in that a certain situation never happens to you, you do not have to fill in how troublesome it is to you).

\section{Example}

When someone is talking to me, it takes longer before I understand $\quad \begin{array}{llllll}0 & 1 & 2 & 3 & 4\end{array}$ what he/she is saying

Say that now and then it takes longer before you understand what someone is saying. Then you circle the number 2, with which you say that this situation happens now and then.

How troublesome is this to you?

not fairly very

Perhaps you find it very troublesome that now and then it takes longer before you understand what someone is saying. If this is the case, you circle the word "very" with which you say that you find it very troublesome when this happens. 
$0=$ never $/ 1=$ rarely $/ 2=$ now and then $/ 3=$ frequently $/ 4=$ often

Since stroke...

1. When someone is talking to me, it takes longer before I understand what he/she is saying

How troublesome is this to you?

not fairly very

2. I have trouble keeping up with people (for example when0 $\begin{array}{llll}1 & 2 & 3 & 4\end{array}$

I am on the phone, or in a meeting

How troublesome is this to you?

not fairly very

3. When I am reading (the newspaper, a book), it takes longer

$\begin{array}{lllll}0 & 1 & 2 & 3 & 4\end{array}$ before I understand what it says

How troublesome is this to you?

not fairly very

4. When I am listening to the radio, or watching television,

I can't keep up with the story

How troublesome is this to you?

not fairly very

5. It takes longer before I come up with the right phone number $\quad \begin{array}{lllll}0 & 1 & 2 & 3 & 4\end{array}$ or word

How troublesome is this to you?

not fairly very

6. When I meet someone in the street, it takes a while before I remember who it is

How troublesome is this to you?

not fairly very

7. I can no longer perform tasks automatically, I have to

Think more (when doing household tasks or work)

How troublesome is this to you?

not fairly very 
$0=$ never $/ 1=$ rarely $/ 2=$ now and then $/ 3=$ frequently $/ 4=$ often

Since stroke...

8. I need more time for doing my work or household tasks, because I have to think more (NOT because of physical disabilities)

How troublesome is this to you?

not fairly very

9. When I am engaged in a task, I feel I have too

$\begin{array}{lllll}0 & 1 & 2 & 3 & 4\end{array}$ little time to do it right

How troublesome is this to you?

not fairly very

10. If I have to deal with unexpected events,

$\begin{array}{lllll}0 & 1 & 2 & 3 & 4\end{array}$

I get restless or agitated

How troublesome is this to you?

not fairly very

11. If I do something too fast, I make mistakes or forget things

$\begin{array}{lllll}0 & 1 & 2 & 3 & 4\end{array}$

How troublesome is this to you?

not fairly very

12. I find it difficult to do two things at the same time

$\begin{array}{lllll}0 & 1 & 2 & 3 & 4\end{array}$

(like doing household tasks when someone

is talking to me, or cooking and making a telephone

call at the same time)

How troublesome is this to you?

not fairly very

13. Being in traffic (on foot, by bike or by car) is

$\begin{array}{lllll}0 & 1 & 2 & 3 & 4\end{array}$

difficult for me, because I quickly get overwhelmed

How troublesome is this to you?

not fairly very

14. When I have to do two things at the same time, I

$\begin{array}{lllll}0 & 1 & 2 & 3 & 4\end{array}$ get restless or agitated, or make mistakes

How troublesome is this to you?

not fairly very 
$0=$ never $/ 1=$ rarely $/ 2=$ now and then $/ 3=$ frequently $/ 4=$ often

Since stroke...

15. When I am busy and I am disturbed,

(for example when the phone rings, or someone speaks to me) I start making mistakes

How troublesome is this to you?

not fairly very

16. When I am in a noisy room (e.g. a store

$\begin{array}{lllll}0 & 1 & 2 & 3 & 4\end{array}$ or pub), I have difficulty paying attention

How troublesome is this to you?

not fairly very

17. I get distracted by my own thoughts, and then I $\begin{array}{lllll}0 & 1 & 2 & 3 & 4\end{array}$ make mistakes

How troublesome is this to you?

not fairly very

18. When several people speak at the same time, (e.g.

$\begin{array}{lllll}0 & 1 & 2 & 3 & 4\end{array}$ on a party or in a meeting), I lose track of what they are saying

How troublesome is this to you?

not fairly very

19. I get tired easily because everything seems to go so fast

$\begin{array}{lllll}0 & 1 & 2 & 3 & 4\end{array}$

How troublesome is this to you?

not fairly very

20. When I have to do two things at the same time, I get

$\begin{array}{lllll}0 & 1 & 2 & 3 & 4\end{array}$ tired easily

How troublesome is this to you?

not fairly very

21. If I have to concentrate in a noisy room, I get tired easily

$\begin{array}{lllll}0 & 1 & 2 & 3 & 4\end{array}$

How troublesome is this to you?

not fairly very 
Chapter 5

\section{Training patients in Time Pressure Management, a cognitive strategy for mental slowness}

Published in

Clinical Rehabilitation 2009; 23(1): 79-90. I. Winkens, C. Van Heugten, D. Wade, L. Fasotti. 


\begin{abstract}
Purpose. This paper provides clinical practitioners with a framework for teaching patients Time Pressure Management (TPM), a cognitive strategy that aims to reduce disabilities arising from mental slowness due to acquired brain injury. TPM provides patients with compensatory strategies to deal with time pressure in daily life. Application of the training in clinical practice is illustrated using two case examples from a randomized controlled trial on the effectiveness of TPM for patients with stroke.

Rationale. The TPM approach is based on Michon's task analysis describing levels of decision making in traffic tasks, and by extension all complex cognitive tasks. The basic idea is that decisions with little or no time pressure are not impaired by mental slowness. Therefore, patients should transfer as many actions from situations with high time pressure to situations where the preserved decision levels with little or no time pressure can work, hence reducing time pressure and improving task performance.

Theory into practice. Several factors are considered prerequisites for teaching patients to use TPM. First, sufficient awareness is needed to recognize that there is a deficit and behavioural change is necessary. Sufficient awareness is also required to recognize and anticipate time pressure situations and to realize that the strategy is helpful and might also be useful in new and more difficult circumstances. Second, adequate motivation is needed to learn the strategy. And finally, the training should be adjusted to the patient's individual learning abilities and cognitive skills. The article explains how to achieve these goals with patients.
\end{abstract}




\section{Introduction}

Mental slowness is a common complaint after acquired brain damage due to stroke or traumatic brain injury [1-4]. Patients may present with a wide range of problems and complaints. There may be an externally observed slowness: patients may show slowed performance on neuropsychological tasks, and they may have problems with everyday situations where events proceed at a rate they cannot control, such as in conversations, driving a car and watching television [5]. There may be an internal feeling of slowness that things happen too quickly, so that one can no longer keep up mentally with cognitive demands being made by external events, which may lead to feelings of fatigue, altered mood, irritability etc (Box 1 and 2).

\section{Box 1}

$H B$, a 43 year old man suffered a stroke. Four months later he still noticed a decreased tempo in performing computer work or household tasks, experienced time pressure during conversations and felt that there was always too little time to perform his daily chores. HB felt extremely fatigued and even agitated when performing these tasks.

In this paper we present a strategy training for reducing problems associated with (a feeling of) mental slowness. Strategy training is not aimed at restoring a lost neuropsychological process or function, but at improving the performance of patients within their possibilities and thus reducing their complaints. Patients are taught compensatory strategies that should enable them to maximize activities and participation and to function more independently in daily life, despite the lasting presence of a cognitive deficit. Strategy training has been applied with success in the areas of memory, attention, apraxia and problem-solving in stroke patients as well as traumatic brain injury patients [6-9].

Fasotti et al (2002) developed and evaluated the so called Time Pressure Management (TPM) training [10]. TPM consists of two sorts of cognitive strategies by which subjects either learn to 'prevent' or to 'manage' time pressure, and hence compensate for their slowness and deal with the task at hand. The idea is that TPM training is applicable to every problem caused by mental slowness.

TPM training was initially developed for adults who had sustained a traumatic brain injury. However, it is likely that the training is beneficial also for adults with mental slowness resulting from other causes, such as stroke or multiple sclerosis. The training can be applied to both outpatients and inpatients. However, to recognize deficits and the need for treatment, patients should have had some experiences with time pressure in their own daily lives. Consequently, most patients receiving TPM are in the subacute or chronic phase after brain injury.

TPM training usually is given in sessions of one hour per week, with a maximum of eight to twelve hours. We think that the training should be given either by a psychologist, or by a cognitive or occupational therapist under the supervision of a psychologist. Brain 
injured patients are often confronted with a complex profile of impairments and comorbidities, and simply applying a standard treatment protocol is hardly ever possible. Individualized adjustments are usually necessary.

\section{Box 2}

MA, a 58 year old woman teacher was first seen eight months after a subarachnoid haemorrhage complicated by a cerebral infarction. She was fully independent in personal activities and wished to return to teaching. She did not foresee any difficulties with this. Her treating psychologist, however, noticed that MA was not able to participate in conversations and was not able to perform several tasks in a short amount of time. MA's family reported that she retreated from social activities she had enjoyed before (like making visits and going to birthday parties). Her treating psychologist therefore suggested TPM training.

This paper draws on evidence and on our experience gathered in a randomised controlled trial, and provides suggestions on how TPM training should be given. First, we will describe the rationale behind TPM, and briefly explain the content of the training. Then we will describe in detail how the training should be given, illustrated by two cases extracted from the trial.

\section{Rationale behind TPM}

For any task, decision making can be hierarchically ordered into three levels, differing in the amount of time pressure present [11]. The first level, the "strategic level", concerns decisions (and subsequent actions) that can be undertaken well beforehand. When driving a car for instance, decisions are made with regard to the route and time of departure. For these decisions there is usually enough time and no time pressure is experienced. The second level is the "tactical level", which relates to anticipating events and adapting behaviour before time pressure builds up. To stay with the example of car driving, both the driving speed and distance between the car and the vehicle in front might be adapted at a tactical level. At this level time pressure is present but usually still manageable. The third level is the "operational level", where immediate decisions and actions are required to prevent failure and risks. For example hitting the brakes and turning the wheel to avoid a collision, or reacting to sudden deviations and manoeuvre the car through traffic are operational actions. Here much time pressure is felt.

The basic idea is that the strategic and tactical decision levels are not impaired by mental slowness and that one can strongly reduce time pressure at the operational level by using the preserved ability to take strategic and tactical decisions. In other words, TPM training focuses on the reorganization of the execution of tasks. By breaking up a time pressure task into subtasks and subsequently identifying the amount of time pressure in these subtasks, one can pinpoint decisions and actions that can prevent (strategic) or manage (tactical) time pressure. Patients are taught to shift as many actions as possible 
from the impaired levels with high time pressure to the preserved levels with little or no time pressure. This should minimize the negative consequences of mental slowness and should lead to improvements in task performance. Returning to the driving example for instance, patients may be taught to take strategic decisions, such as leaving on time, or tactical decisions, such as keeping ample distance and not driving too fast. This should give the patient enough time to react in tricky traffic circumstances and even prevent the occurrence of dangerous situations in the first place.

The training is given in three main stages (Figure 1). The remaining of this article will describe in detail how the training should be administered.

\section{TPM training}

\section{Stage 1: Identifying the problem}

Although we will not present fixed selection criteria on how people should be selected for TPM training, there are some factors that need to be taken into account. The first vital step for both the therapist and the patient is to become aware that mental slowness is such a critical problem that many activities are adversely affected by the inability to react to external events at a speed that is necessary or that is felt to be appropriate by the patient. Mental slowness may bring about secondary problems such as emotional changes, fatigue or forgetfulness and it is important that the patient and therapist are aware of this so that TPM training might be considered if so.

Therapists need to be aware that mental slowness may be present, even if the patient does not complain about it directly. Mental slowness may for example explain why patients fail at tasks that otherwise seem within their capability, or why they experience undue fatigue, or emotional disturbances such as irritability or anxiety.

Once the problem is suspected one possible diagnostic response is to administer standardized neuropsychological tests such as the Symbol Digit Modalities Test, Paced Auditory Serial Addition Task or Trail Making Test [12]. However, the relationship between slowness as measured by such tests and the performance of the patient in daily life activities may be very weak [13]. In addition, objectively measured slowness is not necessarily concurrent with experienced slowness.

Therefore it is essential for the therapist to assess both the patient's perception of slowness and to assess his / her performance in daily situations as well. A simple questionnaire, specifically developed to assess the patient's perception of slowness, is the Mental Slowness Questionnaire (MSQ) in which the patient rates 21 items such as "It takes longer before I understand what someone is saying" or "I lose control when I am in traffic"[14] (Box 3). 
Box 3

HB performed at an average level on a simple reaction time task. However, assessment with the Mental Slowness Questionnaire revealed a score of 56 out of 168, meaning that he experienced slowness in quite a few daily life situations. His main complaints were: "I need more time to understand what people are saying, for example in a meeting or on the phone", "I need more time to understand what I am reading", "It takes longer to come up with the right phone numbers, words, or people's names", "I have to think tasks through, I can no longer perform them automatically", "I need more time for doing my work or running the household", "I am easily distracted in a busy pub or store", "I get tired quickly because everything seems to go so fast".

A simple means to quantify both speed and errors on some familiar everyday tasks affected by mental slowness is the Mental Slowness Observation Test (MSOT) [14] (Box 4). This is a semi-structured observation of four tasks:

- Following instructions on a route

- Obtaining train times by telephone

- Sorting money

- Looking up telephone numbers

The patient also needs to be aware of his problems, because sufficient awareness is an important first step for patients to benefit from compensation therapies like TPM [15]. Trying to teach a patient compensatory strategies can be very frustrating for the patient when they have insufficient or no awareness that there is a problem.

Box 4

HB performed poorly on the Mental Slowness Observation Test. When following instructions on a route, he could not keep up with the high rate with which information was presented. He seemed overwhelmed and forgot to write down the information or ask for clarification or repetition. The same thing happened when he tried to obtain train times by telephone: again he was taken by surprise by the large amount of information given and the operator's speech rate. As a consequence, HB could not report any of the information given to him.

Unfortunately, patients may be unaware of or unconcerned about deficits after an acquired brain injury $[15,16]$. First, unawareness may occur because information and feedback on performance have never been provided. Psychological denial also may interfere: patients may deny their problems or defend themselves against awareness because the deficits are too threatening or the deficits and strategies do not fit into the patient's self-concept or lifestyle [15-17]. And third, there may be an organic or neurological reason: damage to regions in the brain responsible for integrating information about ourselves may lead to inaccurate self-reflections [16]. Damage to these same regions can also impair cognitive skills such as memory and abstract reasoning, leading to an inability to integrate past 
experiences, to apply this information into real-world consequences and to learn about deficiencies $[16,18]$.

Neuropsychological test results sometimes may give the first clue that unawareness is present. But more frequently, discrepancies between a patient's actual and predicted performance, the lack of spontaneous error correction and astonished reactions to feedback may draw attention to a lack of unawareness in the patient $[16,18]$ (Box 5).

Box 5

MA reported no complaints on the Mental Slowness Questionnaire, and predicted she would not experience any time pressure or slowness in daily life tasks. On observing her performance on the Mental Slowness Observation Test however, it appeared she could not keep up with the high rate with which information was given and consequently could not report back all that was told. Unfortunately she did not seem to be aware of that. When feedback was given, MA appeared to be very astonished and very disappointed about her poor task performance.

If a patient seems to be aware of a problem but denies it, psychotherapy of some sort might be needed [15]. However, awareness of impaired performance ultimately follows on from feedback on performance at various tasks. Intensive explanation, coaching and demonstration is sometimes needed, because, before progress can occur, patients must understand that some daily activity is impaired. A discussion of the neuropsychological test results with the patient, showing him that deficits are present, may help. Alternatively, to help a patient increase awareness of deficit, the therapist can ask a patient to predict his own task performance and afterwards compare the predicted performance to the actual performance $[16,18]$.

Sometimes it may help to explain the concepts of slowed information processing and mental slowness and how they may arise after brain damage. Finally, the patient should understand that slowness is a common thread in activities that are impaired, and that this has negative implications for everyday functioning. For example, the therapist may draw a patient's attention to the fact that he always has difficulties following conversations in various settings [15].

Throughout the counselling process, the information and examples provided to the patient should be meaningful and personalized in order to engage them in treatment. Examples of situations from the patients' own lives should be used to explain when and where time pressure may occur and how slowness affects performance in these situations [16] (Box 6). Only then will patients be motivated and acknowledge need for treatment, necessary to learn self-corrective procedures. 
Box 6

During the first week of the training, $H B$ registered the kind of time pressure situations he encountered at home. In particular he reported having difficulties watching television and making telephone calls. He usually could not remember much afterwards. It was explained to him that, due to his slowed information processing, he now needed more time to adequately process and store incoming information. However, more time is usually not given, so that to HB it seems as if a movie was being played fast forward. This caused him to miss parts of for example a television show or a conversation.

The goals set during training should be consistent with the patient's wishes, because otherwise motivation might be low [16]. Therefore it is important to consider specific goals for the patient and the process of goal setting with the patient may further increase awareness.

The goals need to be clear, specific, and realistic [18]. "Not experiencing any time pressure" is not a realistic goal; everyone experiences time pressure sometimes, for example when driving through heavy traffic, or when having to finish work within a given deadline. Examples of personal goals can be: "I want to be able to make telephone calls, give appropriate responses and know what I need to know afterwards"; or "I want to stay calm in unexpected situations and deal with them", or "I want to be able to finish my work within given deadlines and not be distracted".

However, adequate goal setting cannot be expected from all patients [19]. Sometimes therapists need to guide clients' attention to activities or situations that are troublesome. Keeping track of errors and performance may help identify goals [20].

Time spent in stage one (and the next stages) might differ from patient to patient and it is important to adjust this stage to the patients' individual levels. For some patients more time needs to be spent in stage one before awareness is increased sufficiently to proceed to stage two. 
Figure 1. Time Pressure Management. Stages, components, and prerequisites.

\begin{tabular}{|c|c|c|c|}
\hline Stages & Components & $\begin{array}{l}\text { Stage specific } \\
\text { Prerequisites }\end{array}$ & Can be achieved by \\
\hline $\begin{array}{l}\text { Stage 1: } \\
\text { Identifying the } \\
\text { problem }\end{array}$ & $\begin{array}{l}\text { - diagnosis of } \\
\text { mental slowness } \\
\text { - patient accepting } \\
\text { the problem }\end{array}$ & $\begin{array}{l}\text { - awareness of } \\
\text { therapist } \\
\text { - awareness of } \\
\text { patient }\end{array}$ & $\begin{array}{l}\text { - neuropsychological } \\
\text { tests } \\
\text { - Mental Slowness } \\
\text { Questionnaire } \\
\text { - Mental Slowness } \\
\text { Observation Test } \\
\\
\text { - feedback and } \\
\text { demonstration }\end{array}$ \\
\hline $\begin{array}{l}\text { Stage 2: } \\
\text { Teaching the strategy }\end{array}$ & $\begin{array}{l}\text { - patient learning the } \\
\text { strategy: } \\
\text { - } \text { analyse the } \\
\text { task for time } \\
\text { pressure } \\
\text { - } \text { make a plan of } \\
\text { decisions and } \\
\text { actions to } \\
\text { undertake before } \\
\text { the task starts } \\
\text { - } \text { make an } \\
\text { emergency plan } \\
\text { - execute the task } \\
\text { - and monitor } \\
\text { - apply the strategy }\end{array}$ & $\begin{array}{l}\text { - anticipatory } \\
\text { awareness and } \\
\text { emergent awareness } \\
\text { - sufficient learning } \\
\text { ability } \\
\text { - adequate cognitive } \\
\text { skills } \\
\text { - enough rest } \\
\text { - sufficient motivation } \\
\\
\text { - patient should } \\
\text { agree that it works }\end{array}$ & $\begin{array}{l}\text { - practice, explanation } \\
\text { and feedback } \\
\text { - distributed practice } \\
\text { - meaningful and } \\
\text { personalized } \\
\text { information and } \\
\text { examples } \\
\\
\\
\text { - practice, feedback } \\
\text { and demonstration }\end{array}$ \\
\hline $\begin{array}{l}\text { Stage 3: } \\
\text { Generalisation }\end{array}$ & $\begin{array}{l}\text { - apply the strategy in } \\
\text { new and more } \\
\text { difficult situations }\end{array}$ & $\begin{array}{l}\text { - awareness that the } \\
\text { strategy is a general } \\
\text { strategy that can be } \\
\text { applied to other } \\
\text { situations as well } \\
\text { - sufficient cognitive } \\
\text { skills }\end{array}$ & $\begin{array}{l}\text { - practice, feedback } \\
\text { and demonstration }\end{array}$ \\
\hline
\end{tabular}

\section{Stage 2: Teaching the strategy}

The second stage of TPM focuses on teaching the patient strategies. Patients are told from the outset that the speed of information processing is not expected to return to premorbid levels, but that they will learn to use a strategy to deal with their slowness. They should be repeatedly informed that the strategies aim to give them enough time to deal with the task at hand so that time pressure is prevented or handled, which can lead to satisfying performance. The patients should be reminded that their priority is always "Let me give myself enough time to do the task."

A short variant of the self-instruction method can be used to trigger the recollection and the use of the strategy [21]. First the therapist should introduce the four steps of the strategy. It is wise for the trainer to demonstrate and explain aloud how a fairly easy task should be performed while using the strategy, for example preparing a meal. 
The patient should learn that his first concern is to analyze the task for time pressure and identify where the preventing or handling strategies might help: "Are there two or more things to be done at the same time for which there is not enough time?"; "Could I be overwhelmed or distracted?“. For example when preparing a meal, several things have to be done at the same time: washing and cutting up ingredients, watching several pans, reading the recipe, etc. If there are no time-pressure actions, then the activity is unlikely to need further use of the strategy.

Next the patient should learn to identify which decisions can be taken and which actions can be performed before actually starting the activity, and to make a plan to undertake these preparatory tasks. This plan may contain any decision or action that reduces time pressure (e.g. optimizing the task environment, making sure there is no need to do several things at once, etc). When preparing a meal the plan may for example consist of reading the recipe thoroughly before actually starting to cook, making sure all ingredients are washed and cut beforehand, and turning off the phone to prevent distraction. These tasks should then be executed, so that the person is ready to undertake the activity.

However, the patient should also be taught to make emergency plans for anything unexpected that may arise during the activity. These emergency plans should list all the actions that could be taken in case of overwhelming time pressure. For example, the patient could consider how he will react when the telephone rings while cooking - will he simply answer it, or ignore it, or is it better to turn off the cooker and then answer it? Does he have an answerphone? (For detailed examples of plans and emergency plans, containing preventing or handling decisions and actions in relation to specific everyday tasks, see Figure 2). 
Figure 2. Examples of plans and emergency plans, containing preventing and handling decisions or actions.

\begin{tabular}{|c|c|c|}
\hline & Plan & Emergency plan \\
\hline $\begin{array}{l}\text { Example 1: } \\
\text { Driving a car }\end{array}$ & \begin{tabular}{|l} 
Before leaving: \\
- study the route so that no sudden \\
decisions have to be made or \\
discussions have to be held while \\
driving; \\
- leave on time, so that you will not have \\
to hurry, or worry that you will be late; \\
During driving: \\
- turn off the radio so that you will not be \\
distracted; \\
- ask passengers not to distract you with \\
difficult conversations and ask them to \\
help you watch road signs etc; \\
- keep ample distance to the cars in front \\
of you so that you can see what is \\
happening further along the road and \\
that you have enough time to react; \\
- do not drive too fast
\end{tabular} & $\begin{array}{l}\text { In case of panic or } \\
\text { overwhelming time pressure: } \\
\text { - move the car to the } \\
\text { side of the road and } \\
\text { stop. Take a break; } \\
\text { - then take another look } \\
\text { at your plan and your } \\
\text { preventing decisions } \\
\text { and actions, and use } \\
\text { them! }\end{array}$ \\
\hline $\begin{array}{l}\text { Example 2: } \\
\text { Cooking a meal }\end{array}$ & \begin{tabular}{|l|} 
Before starting to cook: \\
- read the recipe thoroughly, so that you \\
know what has to be done and in which \\
order, and how much time it will take \\
you to cook the meal; \\
- decide which things can be \\
done first, before putting on \\
the stove; \\
- open cans and wrappings and put \\
everything within arms reach; \\
- wash the vegetables and cut them; \\
- turn off the phone to prevent \\
distraction; \\
During cooking: \\
- do not be distracted by other things. \\
Do not leave the stove to watch \\
television or read a magazine when \\
you have to wait a few minutes (for \\
example when waiting for pans to \\
reach boiling point);
\end{tabular} & $\begin{array}{l}\text { In case of panic or } \\
\text { overwhelming time pressure: } \\
\text { - when the door bell } \\
\text { rings, turn of the } \\
\text { cooker, and then } \\
\text { answer the door; } \\
\text { - when you have to take } \\
\text { care of two things at } \\
\text { the same time (for } \\
\text { example you have to } \\
\text { pour the water of the } \\
\text { pasta, and turn the } \\
\text { meat over to prevent } \\
\text { it from burning), turn } \\
\text { off the cooker, take the } \\
\text { pasta off the stove, } \\
\text { pour the water off, and } \\
\text { then start again with } \\
\text { the meat. }\end{array}$ \\
\hline $\begin{array}{l}\text { Example 3: } \\
\text { Retrieving } \\
\text { information at a } \\
\text { travelling agency }\end{array}$ & $\begin{array}{l}\text { Before going to the agency: } \\
\text { - make a list of all the things you } \\
\text { would like to know; } \\
\text { At the agency: } \\
\text { - read through your questions } \\
\text { while waiting for your turn; } \\
\text { - ask the employee to take you } \\
\text { to a quiet room so that you will } \\
\text { not be distracted, and will not } \\
\text { feel the urge to hurry because } \\
\text { of the queue of people behind } \\
\text { you; } \\
\text { During the conversation: } \\
\text { - make notes; } \\
\text { - ask the employee to speak } \\
\text { slowly so that you can keep up } \\
\text { with him. }\end{array}$ & $\begin{array}{l}\text { In case of overwhelming time } \\
\text { pressure: } \\
\text { - ask for repetition or } \\
\text { more information when } \\
\text { things are not clear; } \\
\text { - ask the employee to } \\
\text { write the important } \\
\text { things down for you; } \\
\text { - ask for a pause to } \\
\text { review your questions: } \\
\text { did you get a satisfying } \\
\text { answer to every } \\
\text { question? }\end{array}$ \\
\hline
\end{tabular}


Finally, the patient needs to learn how to monitor performance; did he succeed in executing the task successfully, did any emergency plans work, what went wrong?

Once the overall strategy has been taught, the patient must learn and memorize the four steps (analyzing time pressure, preventing time pressure, handling time pressure, monitoring task performance), initially using a memory card with the four rules of TPM in written form. In practice the therapist will regularly remind the patient about all four steps, while focusing on training one particular aspect. Only when the patient has memorized the four steps should actual practice begin. Practice should start with fairly easy tasks, such as having a conversation or watching the news, and then proceeding with more difficult tasks, ranging from conversations where the patient is distracted to cooking a meal or driving a car (Box 7).

\section{Box 7}

$H B$ 's first experience with the strategy is a good example of how a fairly easy task, getting information from a travel agency, can be performed using the strategic adaptations. First, analysis of the task showed HB that several steps had to be taken to retrieve the required information. For example going to the agency, asking several questions and receiving elaborate information. Then $H B$ identified where and when time pressure might occur: he could imagine that being at the agency, where many people were talking and impatiently waiting for their turn, could lead to an overwhelming feeling of pressure and an urge to hurry up. In addition, asking several questions and receiving information at a fast rate could also be a problem and cause him to miss information or forget to ask some relevant questions. Second, HB made a plan of things that could be done before the actual task started, to prevent the occurrence of time pressure. For example going to the agency during a quiet hour, or asking to sit in a quiet room, but also making a list of the most important questions that could be checked during the conversation. Third, an emergency plan was made: asking for a pause, or asking the agent to write down the most important information. And finally, the last step would require $H B$ to perform the task and use the plan and emergency plan when necessary.

During training practice it is best for the patient to instruct himself aloud initially, guiding himself through the strategy he has just learned. This also allows the therapist to check that the patient applies the strategies properly, and to assist the patient, giving cues and asking questions. After each task, the therapist should discuss task performance and analyze how success or failure is linked to the use of (or failure to use) the strategy. Eventually, the patient should learn to relate the quality of his performance to the use of the strategies while performing the task (box 8). 
As a first practice, $H B$ was required to use the learned strategy during a conversation with his trainer. During the conversation he also had to deal with an unexpected situation (the telephone might ring telling him to come home to deal with an emergency). First, HB analyzed the task, asking himself what he was about to do and where time pressure might occur. Second, he made a plan of things he could do before the actual task began. When HB started to perform the task, the therapist interrupted, asking him if he had not forgotten anything and cueing him by asking him what to do in case of overwhelming time pressure. $H B$ understood the hint and made an emergency plan. On performing the task, it appeared that, although $H B$ was very well able to create a plan and emergency plan, he forgot to actually use it. After receiving feedback from the therapist, HB tried to perform the task again, now remembering to use both plans. $H B$ noticed that the strategy indeed could be of great use, leading to better task performance, and was very satisfied about his performance.

Some specific problems may arise when teaching the strategies (Box 9). The patients may:

- disagree with the therapist on the utility of the strategy;

- not recognize when they need to start enforcing the strategy;

- fail to anticipate problems with time pressure;

- not learn the strategies due to fatigue and overstimulation or secondary to cognitive deficits affecting memory and concentration.

Some ways of overcoming these difficulties are given.

\section{Box 9}

MA is a good example of someone who was not able to recognize that a problem would occur and the strategy should be applied. On analyzing a task (having a conversation as a teacher with agitated parents about the school achievements of a student) it appeared that MA was not foreseeing any problems with having that conversation. Even when the therapist explained to her that having a conversation with two people at the same time, both probably angry, and asking many questions, would require her to process much information in a short amount of time. MA saw no need in preparing the conversation and using the strategy.

It is important to persuade the patient that success is related to the use of strategies and that failure is likely when the strategies are not used. Only then will the patient be committed to use the strategy routinely. Elaborate practice and relevant feedback on the benefits of performing tasks while using a strategic approach is a first step to increase the probability that patients will actually apply what they have learned.

In addition, for patients to achieve compensatory behavior at a managing (tactical) level, they must be able to recognize a problem with time pressure when it happens, and subsequently initiate compensation [15]. However, some patients lack this "emergent awareness": they are able to recognize the deficit, and sometimes even explain that a strategy 
should be applied, but they do not recognize the need to initiate strategic behavior. They are not able to monitor the environment or to react to feedback from others. Therapists should focus on this during training. They should teach patients how to pick up (subtle) cues that can help them to realize that they are in a time pressure situation wherein strategic adaptations are needed. In addition the therapist and patient should identify situations where it is appropriate for the patient to use a strategy and then practice these situations repeatedly. For example, if a patient has difficulties following conversations, he should learn to detect the need to initiate the appropriate strategy as soon as he is no longer able to process the information adequately. He should learn to pick up internal (for example feelings of panic or a "full head") as well as external cues (e.g. other people asking him whether he can understand what they are saying). Therapists should teach patients that initiation of the strategy is then needed.

For patients who seem unable to learn to recognize time pressure situations, the therapist might choose to train what is called "situational compensation" - compensating behavior that is triggered by a specific type of circumstance. This behavior must become a habit and must be used in all situations that fall in a critical category. For example, the patient who has difficulties following conversations should learn to use conversations as a trigger to initiate the application of strategies, even if their use is not strictly necessary at that moment. A limited number of critical situations should be practiced time and again [15].

Third, to achieve compensation at a preventive (strategic) level, "anticipatory awareness" is necessary: patients must be capable to anticipate that a problem is going to occur and be aware that compensation reduces the chance that the problem will occur. Of course, this type of compensation is preferred in order to avoid and minimize problems. However, especially anticipatory awareness is often impaired in patients with acquired brain injury and can be very persistent [15]. Fasotti et al described in their paper on the effectiveness of TPM in TBI patients, that most patients only initiate compensation once the problem set in [10]. If patients lack the ability to anticipate, therapists may restrict themselves to teaching only managing strategies. It may be more efficient to spend the available training time on teaching them to make tactical or handling decisions, instead of spending time on teaching them strategic behavior or preventive steps that they will never use.

In this stage it is important to realize that some other factors, such as the nature of the patient's cognitive and learning deficits, also influence success of treatment: therapists need to make sure that patients get enough rest in between sessions, and should be aware that the response to training improves when patients are alert. To prevent overstimulation, distributed practice for short periods has been recommended not only in several studies on educational psychology and motor skill learning, but also in rehabilitation practice $[22,23]$.

In addition, therapists need to use the most effective teaching strategies. They should recognize when the patient is not responsive and when something else should be tried [16]. Not every patient can be expected to learn to use compensatory strategies [17]. As already reported, patients have to be able to conceptualize, to self-monitor, to recognize and realize shortcomings, and to understand the nature of the process by which improve- 
ment of performance can be achieved. This requires a substantial set of cognitive skills $[15,16]$. For patients who do not possess these skills, it is sensible to restrict training to for example procedural training or environmental support ${ }^{16}$. In those circumstances therapists can try to maximize functioning without being concerned whether the patient fully understands why a certain strategy should be used or whether generalization will occur.

\section{Stage 3: Generalization}

In the last stage of TPM training the focus is on generalization. Patients should understand that the aim of a rehabilitation program is to restore them to their greatest potential and maximum independence, hopefully resulting in independent functioning at home and in society. Occurrence of generalization in strategy training should not be taken for granted and the spontaneous transfer of skills is very unlikely $[16,24]$. Generalization therefore already should receive attention during the training period and measures can be taken to facilitate it. Some of the most important measures are described here.

A prerequisite for transfer is that patients should know what transfer is, and how it works. Therapists should persuade patients that, since they cannot possibly treat all the problems and tasks a patient will encounter in his own surroundings, transfer of skills and strategies from the rehabilitation setting to the home setting and from trained to non-trained tasks and situations is of great importance to the clinical success of a therapy program.

Second, in TPM, general strategies are taught and patients need to learn when and where they can be applied. A variety of tasks and situations should be trained to uncouple the connection between what is learned and the situation in which it is learned. Patients need to experience and be explicitly told that the TPM strategy is a general strategy that can be used in many different situations and tasks, even ones that were not trained. Although for each task the specific content of the plan and emergency plan has to be adapted, the same strategy can be applied in every situation in which time pressure is crucial, for instance cooking a meal or driving a car. This requires sufficient ability of abstract reasoning, because otherwise patients will only understand their problems at a concrete level, and in relation to particular circumstances [15]. If patients are thought to lack this level of abstract reasoning, therapists may choose to restrict training to situations that are important for the patient and that regularly lead to problems and risks. Finally, the training situation should be repeatedly modified to support new skills and behaviours. Practice of many different and more difficult tasks is needed, showing the patient that the strategy indeed can be used in these different tasks, and that the strategy is helpful and probably also will be in other, untrained, situations.

A final, somewhat unrelated, but equally important aspect for therapists is the recognition that some patients may feel embarrassed or even ashamed having to use strategies in situations that for other people are easy to handle. In order for patients to benefit from TPM it is important that therapists tackle these thoughts. Therapists must stress that everyone uses these strategies regularly and that TPM is just an extension of the strategies that non braininjured people use in their daily lives, such as diaries to support memory functioning.

In conclusion, TPM should be presented as a general strategy that can be used to tackle 
a wide range of problem situations. With sufficient awareness and motivation, elaborate practice, the proper feedback, and adjustment of the training to the individual level of the patient, even patients with severe deficits can learn to use the strategy (Box 10).

\section{Box 10}

$H B$ underwent a neuropsychological assessment at the start and at the end of the training (i.e. after ten hours of training, ten weeks later) and again three months later, using a mix of standard and experimental tests. This assessment was limited owing to the patient's physical disabilities and communication problems. His performance on the standard neuropsychological tests did not improve significantly, which was to be expected since TPM focuses on dealing with the consequences of time pressure, not on actually restoring speed of information processing. On the MSQ and MSOT however, $H B$ showed marked improvement: his complaints on the MSQ decreased with $41 \%$ (His total score decreased from 56 to 33 on a scale from 0 to 168). He reported the same complaints, although they were less frequent and less severe. In addition his performance on the MSOT improved. Although performance was still below average, he improved more than $100 \%$, his total score increasing from 5,2 to 16 on a scale from 0 to 40.

\section{Conclusions}

In this paper we have illustrated how to teach patients about Time Pressure Management (TPM), using two case examples from a randomized controlled trial on the effectiveness of TPM for patients with stroke. TPM is a cognitive strategy training that aims at teaching patients compensatory strategies to facilitate the handling of time pressure in daily life, that results from mental slowness due to acquired brain injury. From observations and clinical experience gathered in an RCT we infer that several factors may be prerequisites for patients to learn and use TPM. Other factors may complicate training patients in its use, and for some patients the TPM training may not work (Box 11).

\section{Box 11}

MA also underwent a neuropsychological assessment at the start and end of the training and again three months later. After a training period of ten weeks, MA's strategy use on the MSOT was almost the same as before the start of the training: when following instructions on a route or when obtaining train times by telephone she did not realize that the learned strategy would be needed for optimal performance. She did not take notes or did it insufficiently, i.e. without asking for a pause or repetition etc.. Consequently she showed no or only marginal improvement on the MSOT (her total score went from 32,5 to 35,1$)$.

First, each stage of the TPM training requires an adequate level of awareness of the patient. In the first stage, awareness of errors and deficits and of the relation between mental slowness, time pressure and task performance is needed. The second and third stage of TPM require 
conviction that successful task performance is related to use of the strategy. In addition, "emergent" and "anticipatory" awareness are needed, either to recognize a problem when it happens and then initiate compensation, or to anticipate that a problem is going to occur and then realize that compensation will reduce the chance that a problem will occur [15].

A second problem encountered is that patients may not be sufficiently motivated to learn the strategy. This problem does not only apply to TPM training, but is an important issue in every training in general. To increase a patient's motivation to learn, information and examples provided should be meaningful and personalized.

Third, TPM training should be adjusted to the patient's individual learning abilities. For some patients, more time and practice is required before they can proceed from one stage to another. Others need more rest in between sessions. And still others may require another training approach which is more suitable for their particular needs. For example, therapists might switch to 'procedural training' where by means of repetition and practice, the patient "overlearns" a few important skills [16].

In addition, therapists should understand the patient's cognitive deficits. To learn to use the strategy, patients have to be able to integrate past experiences and apply this information to real-world situations. They have to be able to memorize the steps of the strategy and they have to generalize what they have learned to other settings and new tasks. This requires a substantial set of cognitive skills that cannot be expected from every patient. Therapists should recognize when there is no response and next try something else.

In conclusion we think that even severe patients may benefit from TPM, if the training is adjusted to the patient's individual level of readiness, cognitive skill and awareness. However, this paper was not meant to discuss the effectiveness of TPM and right now we can only speculate about the effects of the training for patients at an individual level. This paper was meant only to give a framework on how the training is given and which considerations the therapist might be confronted with.

Fasotti et al already established the efficacy of TPM in a group of patients with traumatic brain injury [10]. Currently a randomized controlled trial with stroke patients is conducted. In this trial the effectiveness of TPM is compared with the effects of a "care as usual" approach to mental slowness in two groups of stroke patients. The case examples used in this paper were part of this RCT. The results of the trial will be presented in an ensuing paper.

\section{Clinical messages}

- Patients that learn to use TPM should:

- Have sufficient awareness of deficits and related problems

- Realize the strategy is helpful

- Have adequate motivation to learn the strategy

- Therapists that teach patients to use TPM should:

- Adjust the training to the patients' individual learning abilities and cognitive skills 


\section{References}

1. Gerritsen MJ, Berg IJ, Deelman BG, Visser-Keizer AC, Meyboom-De Jong B. Speed of information processing after unilateral stroke. J Clin and Exp Neuropsychol 2002; 25:1-13.

2. Rasquin SM, Lodder J, Ponds RW, Winkens I, Jolles J. Cognitive functioning after stroke: a one-year follow-up study. Dement Geriatr Cogn Disord 2004;18:138-144.

3. Stuss DT, Stethem LL, Hugenholtz H, Picton T, Pivik J, Richard, M.T. Reaction time after head injury: Fatigue, divided and focused attention, and consistency of performance. Journal Neurol Neurosurg Psychiatry 1989;52:742-748.

4. Ponsford JL, Kinsella G. Attentional deficits following closed head injury. J Clin Exp Neuropsychol 1992;14:822-838.

5. Winkens I, Van Heugten CM, Fasotti L, Duits AA, Wade DT. Manifestations of mental slowness in the daily life of stroke patients. Clin Rehabil 2006;20:827-34.

6. Milders M, Deelman B, Berg I. Rehabilitation of memory for people's names. Memory 1998;6(1):2136.

7. Kaschel R, Della Sala S, Cantagallo A, Fahlbock A, Laaksonen R, Kazen M. Imagery mnemonics for the

rehabilitation of memory: a randomized group controlled trial. Neuropsychol Rehabil 2002;12(2):127153.

8. Geusgens C, Van Heugten C, Donkervoort M, Van den Ende E, Jolles J, Van den Heuvel W. Transfer of training effects in stroke patients with apraxia: an exploratory study. Neuropsychol Rehabil 2006;16(2):213-229.

9. Levine B, Robertson IH, Clare L, Carter G, Hong J, Wilson BA et al. Rehabilitation of executive functioning: an experimental-clinical validation of goal management training. $J$ Int Neuropsychol Soc 2000;6(3):299-312.

10. Fasotti L, Kovacs F, Eling PATM, Brouwer WH. Time Pressure Management as a compensatory strategy training after closed head injury. Neuropsychol Rehabil 2000;10:47-65.

11. Michon JA. Dealing with danger. Summary report of a workshop in the Traffic Research Centre, State University Groningen, The Netherlands; 1979

12. Van Zomeren AH, Spikman JM. Tempo en aandacht (Speed and attention). In: Vandermeulen, JAM, Derix MMA, Avezaat CJJ, Mulder Th, Van Strien JW, Eds. Niet aangeboren hersenletsel bij volwassenen (Acquired brain injury in adults). Maarssen, the Netherlands: Elsvier Gezondheidszorg; 2003. 
13. Ylvisaker M, Hanks R, Johnson-Greene D. Perspectives on rehabilitation of individuals with cognitive impairment after brain injury: rationale for reconsideration of theoretical paradigms. J Head Trauma Rehabil 2002;17:191-209.

14. Winkens I, Van Heugten CM, Fasotti L, Wade DT. Reliability and validity of two new instruments for measuring aspects of mental slowness in the daily lives of stroke patients. Neuropsychol Rehabil. In press.

15. Crosson B, Barco PP, Velozo CA, Bolesta MM, Cooper PV, Werts D et al. Awareness and compensation in postacute head injury rehabilitation. J Head Trauma Rehabil 1989;4(3):46-54.

16. Sohlberg MM. Assessing and managing unawareness of self. Semin Speech Lang 2000;21(2):135-151.

17. Gross Y, Schutz LE. Intervention models in neuropsychology. In: Uzzell B Gross Y, Eds. Clinical neuropsychology of intervention. Boston: Martinus-Nijhof Publishers; 1986.

18. Wilson B, Herbert C, Shiel A. Behavioural approaches to neuropsychological rehabilitation. Hove, UK: Psychology Press;2003.

19. Siegert RJ, Taylor WJ. Theoretical aspects of goal-setting and motivation in rehabilitation. Review. Disabil Rehabil 2004;26(1):1-8.

20. Bergquist TF, Jacket MP. Awareness and goal setting with the traumatically brain injured. Brain Injury 1993;7(3):275-282.

21. Meichenbaum D. Cognitive behaviour modification. An integrative approach. New York: Plenum Press; 1977.

22. Mumford MD, Costanza DP, Baughman WA, Threlfall KV, Fleishman EA. Influence of abilities on performance during practice: effects of massed and distributed practice. J Educ Psychol 1994;86(1):134144.

23. Cepeda NJ, Pashler H, Vul E, Wixted JT, Rohrer D. Distributed practice in verbal recall tasks: a review and quantitative synthesis. Psychol Bull 2006;132(3):354-380.

24. Geusgens C, Winkens I, Van Heugten C, Jolles J, Van den Heuvel W. The occurrence and measurement of transfer in cognitive rehabilitation: a critical review. J Rehabil Med 2007;39(6):425-439. 

Chapter 6

\section{Efficacy of Time Pressure Management in stroke patients with slowed information processing: a randomized controlled trial}

Submitted for publication in Archives of Physical Medicine and Rehabilitation I. Winkens, C. Van Heugten, D. Wade, E. Habets, L. Fasotti 


\begin{abstract}
Objective. To examine the effects of a Time Pressure Management strategy taught to stroke patients with mental slowness, compared to the effects of care as usual. The strategy consists of a set of alternative cognitive strategies that allow stroke patients to compensate for their mental slowness in real-life tasks.

Methods. Thirty-seven stroke patients in rehabilitation programs were randomly assigned to the Time Pressure Management training group or a group receiving care as usual. Assessment of the complaints about mental slowness, performance of everyday tasks, and speed of information processing was conducted at baseline, immediately after the end of the treatment (i.e. after ten hours of treatment given over five to ten weeks), and three months after the end of the training. The primary outcome measures were a Mental Slowness Observation Test, and a Mental Slowness Questionnaire. Other measures of cognitive disabilities, personal activities of daily living, mood, fatigue and quality of life also were administered.

Results. Twenty stroke patients with a mean age of 49.5 years $(\mathrm{SD}=8.0)$ and a mean Barthel score at baseline of $19.7(\mathrm{SD}=1.3)$ received the training; 17 patients with a mean age of $53.9(\mathrm{SD}=11.1)$ and a mean Barthel score of $19.6(\mathrm{SD}=0.9)$ received care as usual. After ten hours of training, both groups showed a significant decline in number of complaints on the Mental Slowness Questionnaire (21\% decline for the trial group; $17 \%$ decline for the care as usual group). This decline was still present at three months. At three months the Mental Slowness Observation Test revealed significantly higher increases in speed of performance of the Time Pressure Management group in comparison with the care as usual group ( $18 \%$ difference versus $3 \%$ difference; $\mathrm{t}=-2.7, \mathrm{p}=0.01$ ).

Conclusion. Although the Time Pressure Management group and the care as usual group both showed less complaints after a three-months follow-up period, only the Time Pressure Management group showed improved speed of performance on everyday tasks. Use of Time Pressure Management training therefore is recommended when treating stroke patients with mental slowness.
\end{abstract}




\section{Introduction}

Mental slowness is a common complaint after stroke and traumatic brain injury [1,2]. Patients may present with a range of problems and complaints. There may be an externally observed slowness (patients may show slowed performance on neuropsychological tasks); they may have problems with everyday situations in which events proceed at a rate they cannot control. Conversations, driving a car and watching television are daily life tasks in which this may become apparent; and there may also be a subjective feeling within the person that things happen too quickly, that one can no longer keep up mentally with cognitive demands being made by external events. These problems in turn may lead to feelings of fatigue, altered mood, irritability etc $[3,4]$.

The frequency of these complaints and their impact on the lives of stroke patients, make mental slowness a prime target for cognitive rehabilitation.

One seemingly obvious rehabilitation method for cognitive deficits is the so called "direct stimulation approach": remediation interventions are aimed at specifically impaired cognitive processes. For mental slowness this means that patients are trained to perform reaction time tasks at a normal speed rate. The underlying ideas are that the target process can be improved by repetitive stimulation (a form of "mental muscle-building") and that this improvement generalizes to several related skills and to daily life. Both ideas appeared to be questionable given the great amount of remedial programs based on this approach and the modest results obtained, especially with regard to generalization $[5,6,7]$.

Fasotti et al [8] used a different approach towards mental slowness, namely Time Pressure Management (TPM). TPM consists of two sorts of cognitive strategies by which subjects learn either to "prevent" or to "manage" time pressure, and hence compensate for their slowness and deal with the task at hand, instead of trying to restore normal speed of information processing. The idea is that TPM training is applicable to a broad range of problems caused by mental slowness and hence might generalize more easily to nontrained tasks.

The rationale of TPM can be illustrated by Michon's task analysis [9] that was originally designed to describe traffic behaviour in hierarchically ordered levels. For any task, decision making can be hierarchically ordered into three levels, differing in the amount of time pressure present. The first level, the "strategic level", concerns decisions (and subsequent actions) that can be undertaken well beforehand. When driving a car for instance, decisions are made with regard to the route and time of departure. For these decisions there usually is enough time and no time pressure is experienced. The second level is the "tactical level", which relates to anticipating events and adapting behaviour before time pressure builds up. To stay with the example of car driving, the choice of driving speed and car following distance might be adaptations at the tactical level. At this level time pressure is present but usually still manageable. The third level is the "operational level", where immediate decisions and actions are required to prevent failure and risks. For example hitting the brakes and turning the wheel to avoid a collision, or reacting to sudden deviations and manoeuvring the car through traffic are all operational actions. Here much time pressure is felt. 
The basic idea is that the strategic and tactical decision levels are barely affected by mental slowness and that one can strongly reduce time pressure at the operational level by using the preserved ability to take strategic and tactical decisions. In other words, TPM training focuses on the reorganization of the execution of actions with time pressure. By breaking up such actions into subtasks and subsequently identifying the amount of time pressure in these subtasks, one can pinpoint decisions and actions that can prevent (strategic) or manage (tactical) time pressure. Patients are taught to move as many actions as possible from the impaired levels with high time pressure to the preserved levels with little or no time pressure. This should minimize the negative consequences of mental slowness and should lead to improvements in task performance. Returning to the driving example for instance, patients may be taught to take strategic decisions, such as leaving early, or tactical decisions, such as keeping ample distance and not driving too fast. This should give the patient enough time to react in tricky traffic circumstances and even prevent the occurrence of dangerous situations in the first place.

Fasotti et al evaluated the TPM treatment in a randomized controlled trial [8]. Twentytwo patients with severe to very severe closed head injury were randomly assigned to TPM training or concentration training in which verbal instruction was the key element. The results indicated that TPM training produced greater gains than concentration training for an information intake task and also appeared to generalise to other measures of speed and memory function. However, to date, there are no other studies, and no data on the treatment effects of this strategy training for stroke patients.

The goal of the present study was to determine in a randomized controlled trial the efficacy of TPM training for stroke patients with mental slowness.

\section{Methods}

Stroke patients who had sustained a stroke at least three months earlier and that had been referred for cognitive rehabilitation for mental slowness were included in the present study. Referral occurred on the basis of the clinical diagnosis of the treatment team (mostly through neuropsychological examinations and clinical interviews). Exclusion criteria were: 1) age under 18 years; 2) stroke occurred less than three months ago; 3 ) very severe or disabling premorbid or current (continuing) pathologies, such as psychiatric diseases (e.g. depression) or substance abuse for which the patient had been hospitalized, or other medical or neurological diseases (such as tumor or whiplash); 4) such severe cognitive, communication, physical or psychological problems that the patient was unable to perform the tasks, based on the clinical judgment of the treating team.

All patients received verbal and written information about the study and gave written consent to participate. The study protocol was approved by the ethics committee of all participating institutions. 


\section{Study design}

A multicenter, randomized, single blind, controlled trial design was used to compare the effect of TPM with the effect of care as usual. For each of the eight participating rehabilitation centers a random assignment list was created before the start of the trial. After selection and recruitment, an independent person used the list to assign the patients to the TPM training group or care as usual group.

Trainers were asked to give all patients ten hours of their allocated training, and were asked to record the exact amount of training hours. Training was given in sessions of one, one and a half or two hours per week (depending on the learning potential of the patient and usual practice in the particular rehabilitation center).

Baseline measurements were done immediately after inclusion. After the end of the ten hours treatment period, a second measurement took place, and the final measurement was a follow-up three months after the end of the treatment. Measurements were done by a research assistant (EH) who was blind to the allocation of the patients. Success of blinding was checked afterwards.

At the start of the study, every participating center decided which trainer was responsible for the TPM training. This trainer received a three-hour course in TPM. Other trainers were responsible for the care as usual.

\section{Time Pressure Management}

TPM training was given in three main stages $[10,11]$. The initial aim is to enhance the patient's awareness that mental slowness is a critical problem, that many activities are adversely affected by the inability to react to external events with adequate speed and that mental slowness may bring about secondary problems such as emotional changes, fatigue or forgetfulness.

The second stage focuses on the acceptance and acquisition of the TPM strategy. The patient is told that the speed of information processing is not expected to return to premorbid levels, but that there is a strategy called "let me give myself enough time", that might help deal with their slowness. The essence of this four-step strategy is shown in Table 1.

Table 1. The TPM strategy "Let me give myself enough time to do the task"

(Extracted from Fasotti et al. [8])

\begin{tabular}{|l|l|}
\hline Questions to be asked: & Main objective \\
\hline $\begin{array}{l}\text { 1. Are there two or more things to be done at } \\
\text { the same time? Could I be over whelmed or } \\
\text { distracted? }\end{array}$ & $\begin{array}{l}\text { To recognize time pressure in the task at } \\
\text { hand }\end{array}$ \\
\hline $\begin{array}{l}\text { 2. Which things can be done before the actual task } \\
\text { begins? Make a plan }\end{array}$ & $\begin{array}{l}\text { To prevent as much time pressure as } \\
\text { possible }\end{array}$ \\
\hline $\begin{array}{l}\text { 3. What to do in case of unexpected, overwhelming } \\
\text { time pressure? Make an emergency plan }\end{array}$ & $\begin{array}{l}\text { To deal with time pressure as quickly and } \\
\text { effectively as possible }\end{array}$ \\
\hline $\begin{array}{l}\text { 4. Plan and emergency plan ready? Then use it } \\
\text { regularly }\end{array}$ & $\begin{array}{l}\text { Urging the patient to monitor himself while } \\
\text { using the TPM strategy }\end{array}$ \\
\hline
\end{tabular}


In the last stage of TPM training the focus is on generalization. Patients are taught that therapists cannot possibly treat all the problems and tasks a patient will encounter in his own surroundings. Therefore transfer of skills and strategies from the rehabilitation setting to the home setting and from trained to non-trained tasks and situations is of great importance. In this stage, a variety of tasks and situations is trained under more distracting and difficult conditions (see Winkens et al. [11] for detailed description).

There are two classes of TPM strategies: 1) "preventive strategies" in which the patient learns to anticipate time pressure as much as possible by taking decisions while enough time is still available (optimization of task preparation and reduction of stress during task execution due to uncertainty); and 2) "management strategies" in which the patient learns to prevent the increase of time pressure or to deal with the existing level of time pressure during execution of the task. Patients in the TPM group learn to use both kinds of strategies while performing an information intake task (see below). When the patient is able to perform the information intake task while using the strategy, role plays and real-life situations are practiced.

\section{Care as usual}

The other group received care as usual. Since eight different centers participated in the study, content of the care as usual varied. Most centers restricted their cognitive training for slowed information processing to giving education about brain damage, speed of information processing and its possible consequences for daily functioning, and gave practical hints and advice how to deal with these consequences. One center gave actual practice training more similar to Time Pressure Management, training patients in performing tasks while using compensation strategies.

The essential difference between the two training methods is that Time Pressure Management is directly aimed at behavioural, cognitive change in training situations. The training starts with psychological education on mental slowness and time pressure and patients are clearly told that they will receive training to diminish time pressure. Then, during training, patients are constantly monitored and trainers are directly involved in the teaching of new strategies. Feedback is frequently given and possible errors are corrected on the spot. In the care as usual group, the focus is not on diminishing time pressure. In addition, patients usually are not constantly monitored while being trained in specific tasks. So, Time Pressure Management is not only more detailed and task-specific but also more directly aimed at improving task execution, whereas the control training assumes that an intermediate stage, in which the patient is supposed to transform instructions into actions, should take place spontaneously. 


\section{Measurements}

Six primary and thirteen secondary outcome measures were assessed by an independent, blinded research assistant.

\section{Information intake task [8]}

In this task, patients are told they are about to buy a waterbed and are required to ask for more information about this item. The shop assistant's answers are shown on a video. The instructions emphasize that the patients should remember as much information as possible and they are allowed to do anything to make this easier. At the end, the patient's reproduction score is calculated by adding up the reproduced items. The maximum score is 21 .

\section{Mental Slowness Observation Test (MSOT) [4]}

This test consists of four tasks that are commonplace for most people, are brief, and amenable to accurate timing. The tasks are specifically designed to measure performance in time pressure situations: patients are required to handle incoming information and to work within certain time limits. The tasks are: 1) following a route description, 2) sorting money, 3) making a telephone call, and 4) looking up telephone numbers. Two tasks have a preset maximum time, i.e. subtask 2 (sorting money, 5 minutes) and subtask 4 (looking up telephone numbers, 10 minutes): if the subject does not complete the task within this time period, the item is terminated. Otherwise the tester records the time needed to perform each task (Time score), and the number of elements correctly achieved (Elements score). The maximum score per task is 10 , the maximum total score is 40 .

For both the Mental Slowness Observation Test and the information intake task, the number of strategies used are counted (for example interrupting the video, reiterating the information etc.) and used as outcome measures.

\section{Mental Slowness Questionnaire (MSQ) [4]}

This Questionnaire consists of 21 items examining different kinds of daily activities that are likely to be related to mental slowness. Examples of the items are: "I have trouble following a conversation", or "I have trouble doing two things at the same time". Each item is scored on a five-point frequency scale ranging from 0 (this never happens) to 4 (this happens often). Each problem is also scored on a three-point severity scale ranging from 0 (not troublesome) to 2 (very troublesome). The score on the frequency scale is multiplied by the score on the severity scale. For this weighted scale the maximum total score is 168 .

In addition to the primary outcome measures described above, measures for personal activities of daily living, fatigue, depression and quality of life, and neuropsychological tests for speed of information processing, memory, attention and executive functioning also were administered.

Independence in personal activities of daily living was measured using the Barthel Index [12]. The researcher filled in the questionnaire on the basis of the patient's reports. The maximum score is twenty. A higher score means higher independence.

Fatigue was measured using the Fatigue Severity Scale [13], a self-report instrument used to 
assess levels of fatigue and its effect on daily functioning. It contains 9 items, each of which is scored on a 7-point scale. Then a mean score is calculated. Patients with higher scores are more fatigued.

Mood was measured using the Center for Epidemiologic Studies Depression Scale [14], a selfreport questionnaire screening for depression in stroke patients. It contains 20 items, each of which is scored in a 4-point scale ranging from less than one day per week to 5 to 7 days per week. Higher score means more depressive complaints.

Quality of life was measured using the EuroQol-5D [15] which consists of two parts, the selfclassifier or questionnaire, and the EQ-Vas or Thermometer. The EQ-5D self-classifier is a one-page questionnaire, which captures respondent descriptions of health problems on a 5-dimensional classification of mobility, self-care, usual activities, pain and discomfort and anxiety and depression. Each dimension is rated by respondents on a three-level scale from 1 (no problem) to 3 (unable or extreme problem). The EQ-Vas is a 20-centimeter visual analogue scale, portrayed as similar to a thermometer, on which the respondent rates his/her health state today between 0 (worst imaginable) to 100 (best imaginable).

Speed of information processing was measured using the Symbol Digit Modalities Test (SDMT). Patients are instructed to transcribe from symbols to numerals, in writing and verbally, using a key matching particular symbols to particular numerals. Subjects are required to complete as much of the task as possible within 90 seconds [16]. The number of correct responses is evaluated.

Speed of information processing was also measured using the Paced Auditory Serial Addition Task (PASAT) [17]. The task was presented at a pacing with a $3.2 \mathrm{sec}$. interstimulus interval. The number of correct responses is evaluated. Simple Reaction Time was measured on a pocket PC. Subjects touch the screen of the computer until a stimulus appears, then release the screen as fast as possible. Reaction times are measured.

Memory was measured using the Auditory Verbal Learning Test (AVLT) [18], which measures episodic memory. The total number of correct responses is calculated.

Attention was measured using the Trail Making Test A and B (TMT) [19]. Time and error rate are measured.

Executive functioning was measured using the Stroop Color Word Task [20]. The variable of interest is the time needed to complete each subtest.

\section{Statistical analysis}

Descriptive statistics were used to present patient characteristics and test results at baseline. Between group differences at baseline were investigated by Chi-square analysis, Fisher exact test or independent samples t-test as appropriate.

Intervention effects were examined with a Linear Regression Analyses. For the variables that turned out to be skewed, non-parametric Mann-Whitney u-tests were used. In order to evaluate 
outcome, change scores and $95 \%$ confidence intervals were calculated by subtracting baseline scores from post-treatment and follow-up scores respectively (to improve precision in controlling for influence of baseline score on outcome). Between group differences in change scores were investigated for all outcome measures. To further improve the power of the Linear Regression Analyses, outcome at baseline was included as a covariate in the analyses. A two-sided significance test (significance level 0.05) was used, as we did not have an assumption on the direction of these differences in advance. Analyses were carried out using SPSS 15.0 for Windows.

\section{Results}

Figure 1 shows the patient flow and follow-up to three months after the end of the training. Patients were recruited from November 2005 until October 2007. During the study, 40 patients with reduced speed of information processing were referred for training in the participating institutions; 37 were included

Figure 1. Flow chart of patients in the trial

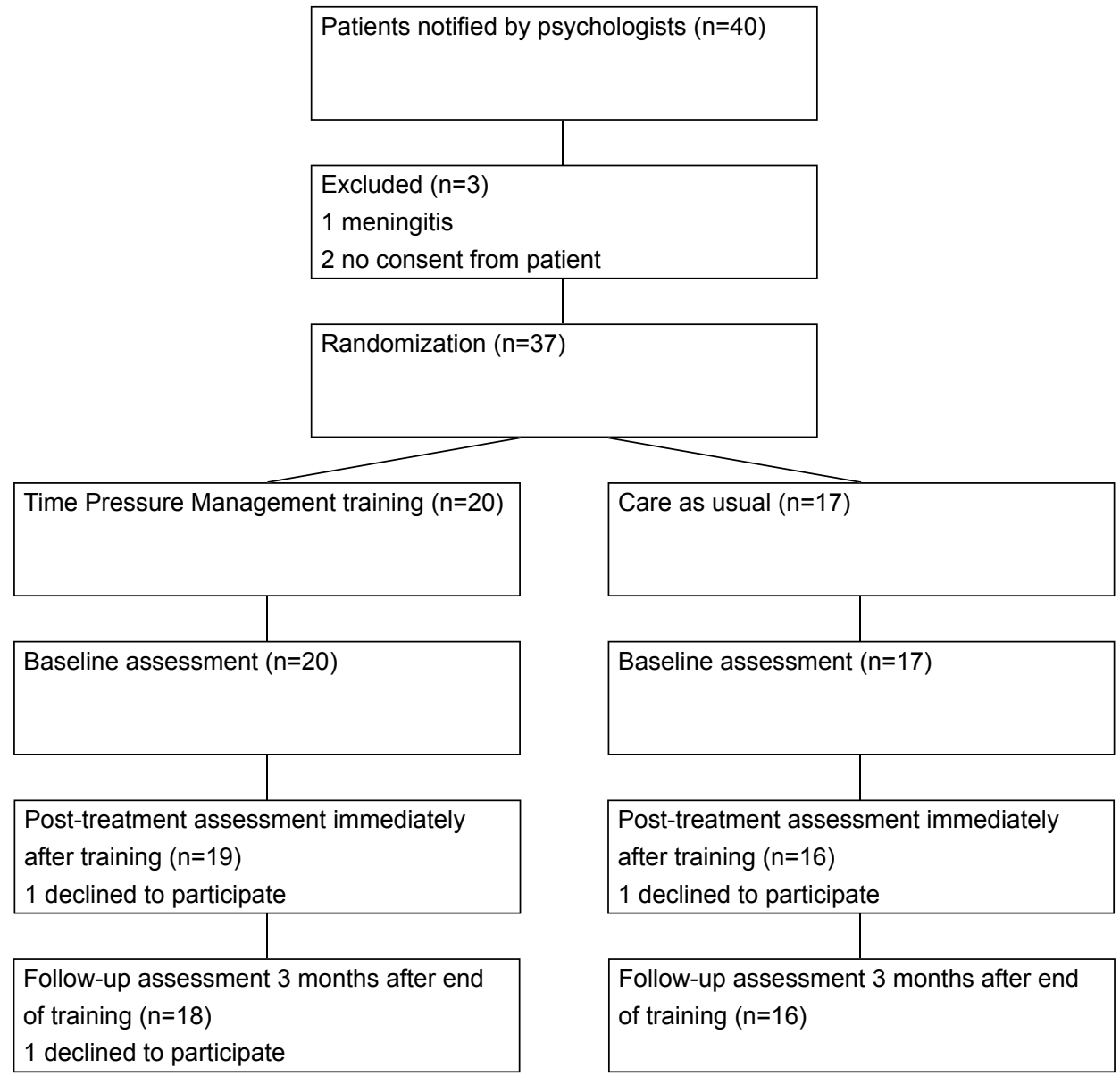


Of the twenty patients allocated to TPM training, one declined participation before the start of the training, three patients stopped training after one hour due to insufficient motivation and two patients stopped after seven hours of TPM training because both the patient and the trainer agreed that no further gains were to be achieved. Fourteen patients received exactly ten hours of training as indicated by the TPM protocol.

\section{Comparability}

Patient characteristics and baseline results are displayed in table 2. The results show that patients in both groups were relatively young for a stroke population and physically independent. In addition Table 2 shows that patients in both groups were not severely depressed or excessively tired.

At baseline the participants in both groups did not differ significantly on any of the observed variables (see Table 2). Although not statistically significant, we considered the difference in time since stroke between the two groups sufficient, clinically, to include time since stroke as a covariate in the analyses.

Table 2. Baseline characteristics for patients included in the study

\begin{tabular}{|c|c|c|}
\hline \multicolumn{3}{|l|}{ Demographics } \\
\hline & TPM $(n=20)$ & $\begin{array}{l}\text { Care as usual } \\
(n=17)\end{array}$ \\
\hline Age, mean (sd) & $49.5(8.0)$ & $53.9(11.1)$ \\
\hline $\begin{array}{l}\text { Gender, n (\%) } \\
\text { Male } \\
\text { Female }\end{array}$ & $\begin{array}{l}9 / 20(45 \%) \\
11 / 20(55 \%)\end{array}$ & $\begin{array}{l}12 / 17(71 \%) \\
5 / 17(29 \%)\end{array}$ \\
\hline $\begin{array}{l}\text { Education, n (\%) } \\
\text { Low } \\
\text { Middle } \\
\text { High }\end{array}$ & $\begin{array}{l}6 / 20(30 \%) \\
10 / 20(50 \%) \\
4 / 20(20 \%)\end{array}$ & $\begin{array}{l}3 / 17(18 \%) \\
8 / 17(47 \%) \\
6 / 17(35 \%)\end{array}$ \\
\hline Time since stroke in months, mean (SD) & $19.3(29.6)$ & $6.9(5.4)$ \\
\hline Barthel score, mean (sd) & $19.7(1.3)$ & $19.6(0.9)$ \\
\hline Hours of allocated treatment, mean (sd) & $\begin{array}{l}\text { Total group }(n=19) \text { : } \\
8.1(3.2) \\
\text { Group receiving training } \\
\text { according to protocol }(n=14) \text { : } \\
9.5(1.6)\end{array}$ & $9.3(3.0)$ \\
\hline Hours of additional treatment, mean (sd) & $21.1(17.3)(n=19)$ & $30.5(15.7)$ \\
\hline
\end{tabular}




\begin{tabular}{|c|c|c|}
\hline \multicolumn{3}{|l|}{ Primary outcome measures } \\
\hline $\begin{array}{l}\text { Information intake task (number of used strategies), } \\
\text { mean (sd) }\end{array}$ & $0.5(0.5)$ & $0.5(0.6)$ \\
\hline Information intake task (reproduction score), mean (sd) & $10.6(4.1)$ & $9.6(4.2)$ \\
\hline MSOT (number of used strategies), mean (sd) & $4.6(2.1)$ & $3.8(1.6)$ \\
\hline MSOT (number of correct elements), mean (sd) & $34.2(8.0)$ & $32.3(7.1)$ \\
\hline MSOT (time in seconds), mean (sd) & $861.0(255.0)$ & $871.4(172.3)$ \\
\hline MSQ (frequency x severity score), mean (sd) & $44.6(41.1)$ & $62.3(43.8)$ \\
\hline \multicolumn{3}{|l|}{ Secondary outcome measures } \\
\hline FSS score, mean (sd) & $30.0(16.3)$ & $32.7(10.7)$ \\
\hline CES-D score, mean (sd) & $9.0(7.7)$ & $13.6(6.9)$ \\
\hline EuroQOL VAS scale score, mean (sd) & $70.5(19.2)$ & $65.9(17.4)$ \\
\hline \multicolumn{3}{|l|}{ Neuropsychological tests } \\
\hline SDMT_writing (number correct), mean (sd) & $36.0(11.6)$ & $31.3(10.8)$ \\
\hline SDMT_reading (number correct), mean (sd) & $45.9(12.4)$ & $39.4(11.7)$ \\
\hline Simple reaction time test (time in seconds), mean (sd) & $0.31(0.10)$ & $\begin{array}{l}0.34(0.06) \\
(n=16)\end{array}$ \\
\hline PASAT (number correct), mean (sd) & $38.2(11.7)(n=19)$ & $\begin{array}{l}32.4(15.1) \\
(n=16)\end{array}$ \\
\hline AVLT (number correct), mean (sd) & $52.9(9.5)(n=19)$ & $\begin{array}{l}46.1(10.4) \\
(n=15)\end{array}$ \\
\hline TMT A (time in seconds), mean (sd) & $44.5(20.9)$ & $46.2(16.0)$ \\
\hline TMT B (time in seconds), mean (sd) & $90.7(38.4)(n=19)$ & $131.3(102.5)$ \\
\hline $\begin{array}{l}\text { Stroop Colour Word Test card } 1 \text { (time in seconds), } \\
\text { mean (sd) }\end{array}$ & $52.6(11.9)(n=19)$ & $62.9(26.3)$ \\
\hline $\begin{array}{l}\text { Stroop Colour Word Test card } 2 \text { (time in seconds), } \\
\text { mean (sd) }\end{array}$ & $67.0(14.7)(n=19)$ & $87.5(51.9)$ \\
\hline $\begin{array}{l}\text { Stroop Colour Word Test card } 3 \text { (time in seconds), } \\
\text { mean (sd) }\end{array}$ & $105.6(23.4)(n=19)$ & $\begin{array}{l}119.7(36.9) \\
(n=15)\end{array}$ \\
\hline
\end{tabular}

MSOT = Mental Slowness Observation Test; MSQ = Mental Slowness Questionnaire; FSS Fatigue Severity Scale; CES-D = Center for Epidemiologic Studies Depression Scale; SDMT = Symbol Digit Modalities Test; PASAT = Paced Auditory Serial Addition Task; AVLT = Auditory Verbal Learning 
The amount of training that patients received did not differ significantly between the two intervention groups $(\mathrm{t}=1.2, \mathrm{p}>0.05)$. Patients in the care as usual group had on average $9.3(\mathrm{SD}=5.4)$ hours of training. Patients in the TPM group had on average $8.1(\mathrm{SD}=3.2)$ hours of TPM training. However, when restricting the TPM group to the 14 patients that did not deviate from the TPM protocol, the TPM group had on average 9.5 $(\mathrm{SD}=1.6)$ hours of TPM training, which also did not differ significantly from the care as usual group $(\mathrm{t}=-.03, \mathrm{p}>0.05)$. Furthermore, the two intervention groups did not differ with respect to the total amount of hours spent in additional treatments, such as occupational therapy, physiotherapy, psycho-education, recreational therapy, social work etc.

The effectiveness of blinding of the research assistant (EH), who performed the outcome measurements, was checked post hoc. Analyses showed that she had guessed the allocation correctly in 24 of 37 cases (Cohen's Kappa $=.29, \mathrm{p}>.05$ ).

\section{Post-treatment outcome}

Table 3 shows the results immediately at the end of the treatment. The two groups differed significantly in the use of strategies on the trained information intake task: The TPM group showed an average improvement of 0.4 strategies while the care as usual group showed a decline of 0.3 strategies $(\mathrm{z}=-2.1, \mathrm{p}<0.05)$. On all other variables (primary as well as secondary outcome measures and neuropsychological tests) no significant between group differences were found. 


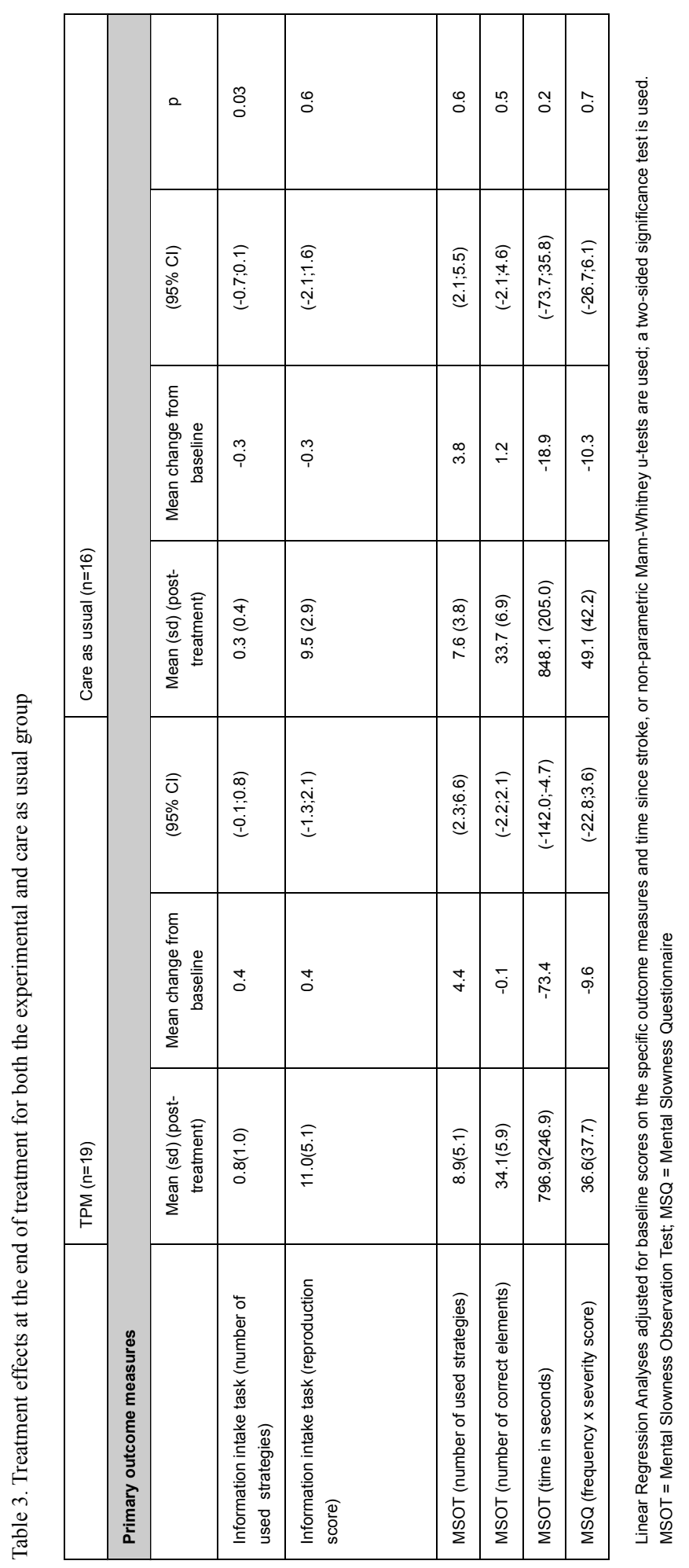


Both groups showed an improvement in the mean number of strategies used on the Mental Slowness Observation Test: the TPM group showed a mean increase of 4.4 strategies after training ( $98 \%$ improvement); the care as usual group showed a mean increase of 3.8 strategies after training (100\% improvement). And both groups showed a considerable decline in complaints on the Mental Slowness Questionnaire: the TPM groups showed an average decline of 9.6 points ( $21 \%$ decline); the care as usual groups showed an average decline of 10.3 points (17\% decline). In addition, the TPM group showed an average decline of 73.4 seconds needed to complete the Mental Slowness Observation Test compared to an average decline of 18.9 seconds in the care as usual group $(9 \%$ difference in the TPM group compared to $2 \%$ difference in the care as usual group). However, the differences in change scores between the two groups were not statistically significant.

\section{Outcome at follow-up}

Table 4 shows the follow-up versus baseline results for both intervention groups. At three months the two groups differed significantly on the time needed to complete the Mental Slowness Observation Test. The TPM group showed an average decline of 154.6 seconds in the time needed to complete the test compared to an average decline of 26.5 seconds in the care as usual group (18\% improvement in the TPM group versus only $3 \%$ improvement in the care as usual group); this was statistically significant $(\mathrm{t}=-2.7, \mathrm{p}=.01)$. After controlling for time since stroke, the larger decrease in the time needed to complete the test in the TPM group was still significant $(\mathrm{t}=-2.9, \mathrm{p}<0.01)$.

On all other variables (primary as well as secondary outcome measures and neuropsychological tests) no significant between group differences were found.

At the three-months follow-up period, the number of strategies used in both the information intake task and the Mental Slowness Observation Test had returned to baseline levels. However, the TPM group showed an average decline of 10.5 points on the number of complaints on the Mental Slowness Questionnaire (22\% decline), and the care as usual group showed an average decline of 10.3 points ( $28 \%$ decline). Between group differences, however, were not statistically significant.

A per protocol analysis was conducted, excluding all patients in the TPM group who were not treated according to the study protocol $(n=5)$. Results of the per protocol analysis were similar to the results of the intention to treat analysis. 


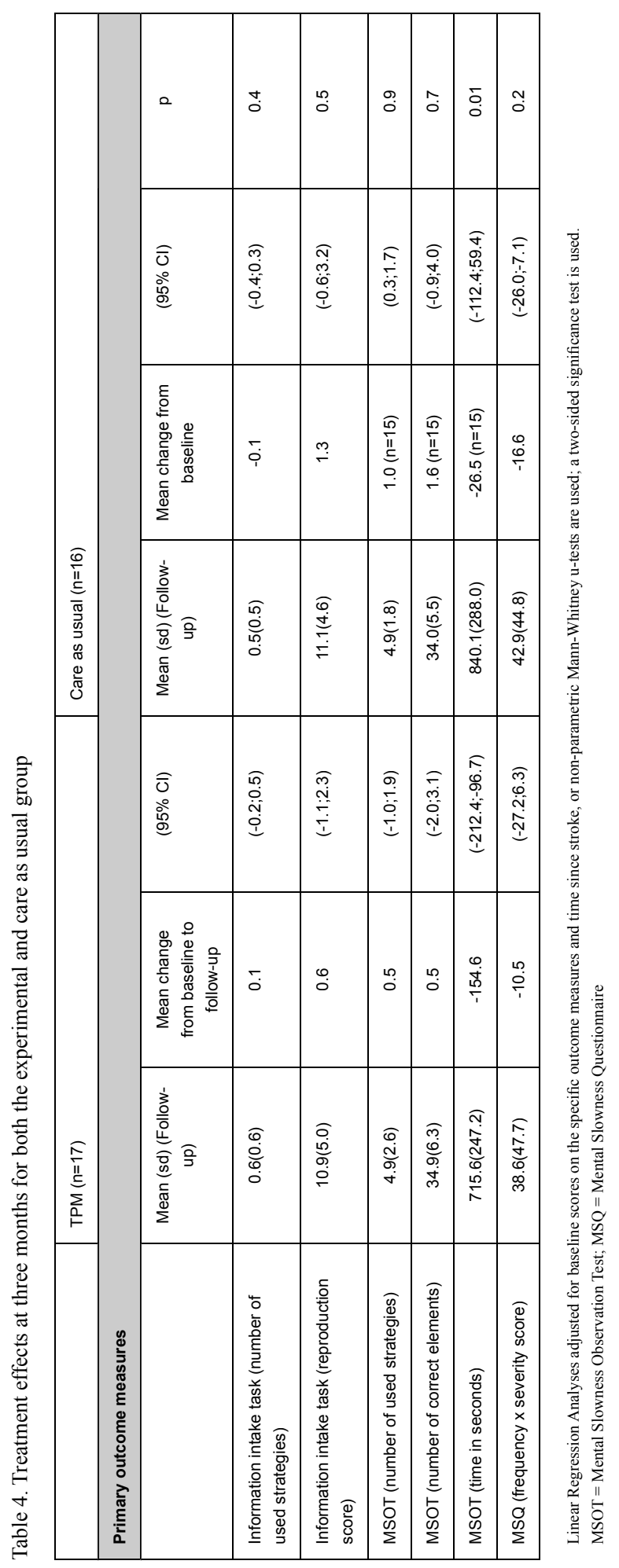




\section{Discussion}

In this trial, evidence was found for the long-term efficacy of TPM training in stroke patients with mental slowness, suggesting that strategy training benefits take some time to become evident.

Immediately after training, the patients in the experimental group showed a clinically significant decline in the number of complaints on the Mental Slowness Questionnaire, and a major decrease in the time needed to complete the Mental Slowness Observation Test. However, the results of the experimental group were not significantly different, statistically, from the results of the control group.

At three months however, the experimental group showed a statistically significant decrease in the time needed to complete the Mental Slowness Observation Test, compared to the care as usual group. Patients in the TPM group were more efficient in completing everyday tasks such as following a route description or making a telephone call; they needed less time without becoming less accurate.

This pattern of improvement in the experimental group, starting during training but continuing (and becoming statistically significant) thereafter, is likely to occur in a strategy training model, where one might expect some benefit as the strategy is implemented, but increasing benefit as it becomes increasingly automated and integrated into a wider range of behaviours [21]. Patients need time to accept and learn that the strategy is helpful and probably also will be in other situations than the ones that are trained.

For this study, 'dose' of treatment was fixed at a maximum of ten hours. Although some patients may need less (two patients finished after seven hours), some probably need more time to learn to use cognitive strategies such as the ones taught in TPM training. In several other studies patients receive training for at least 15 hours or more [22-24]. Given the small but significant effect in the everyday tasks, it is reasonable to predict that an expanded version of training would produce greater effects, at least in some patients. Extending TPM training over more sessions would give trainers the opportunity to incorporate more practice situations into the training, thereby increasing the chance for generalization to other non-trained tasks and situations to occur.

The results support previous findings of the only other study on the effects of TPM: in the study by Fasotti et al. [8], 12 patients with slowed speed of information processing after traumatic brain injury received TPM training, ten other patients received regular concentration training. The patients in the TPM group improved considerably in the use of strategies and remembered more information in an information intake task compared to the control group. In addition, the results in our study are consistent with positive results of other studies on different kinds of strategy training (e.g. for neglect, apraxia, memory impairment and attention deficits) [25]. 


\section{Limitations}

Some comments can be made concerning our study.

First, although the TPM training seems to be effective, the small study sample makes conclusions uncertain. Although eight centers participated in the study, recruitment was poor. Other impairments possibly but not necessarily related to slowness such as fatigue, memory or language problems might have had treatment priority.

Second, both intervention groups were selected groups consisting of relatively young, ADL independent people. As such, we have to be careful in generalizing the results found in this study to other groups of stroke patients, i.e. older and ADL dependent stroke patients. However, our experiences with the TPM training have given us no reason to assume that it is not possible to apply this training in different settings and to other patient groups. We do think that success of training is dependent on patients' awareness and severity of their cognitive deficits [11].

In this study a patient's level of awareness of deficits was not an exclusion criterion. However, patients with high awareness and motivation are most likely to benefit, whereas patients with severely compromised awareness and denial of their problems are least likely to benefit $[11,26]$ Although not measured objectively in this study, some trainers spontaneously reported that some patients were not able to appreciate their deficits and the benefits of using the strategy. Larger effect of TPM training possibly would have been found if patients had been selected on level of awareness.

\section{Conclusion and future studies}

Although both our study and the only other study on the effects of TPM training were small, results of the two studies are promising. First, there are indications for positive long-term effects of the strategies taught in the TPM training both for patients with traumatic brain injury as well as for stroke patients. Second, our multi-center study shows that the training can be taught to other therapists. More studies are needed to confirm the effects of TPM training and we recommend conducting new studies including a higher number of less selected patients. In addition, it would be worthwhile to use longer training periods and longer follow-up periods. The results in this study indicate that it takes a while for strategies to become incorporated into patients' everyday lives. It would also be interesting to see whether effects are still apparent after for example a year, or whether additional training is needed to prevent patients from forgetting what they have learned during training.

\section{Acknowledgements}

The authors thank all participants and their families, as well as the teams of the healthcare institutions that participated in this study: the rehabilitation centers Rehabilitation Foundation Limburg (Hoensbroek), Blixembosch (Eindhoven), Leijpark (Tilburg), Sint Maartenskliniek (Nijmegen), Groot Klimmendaal (Arnhem), Sophia (Den Haag and Gouda), Heliomare (Wijk aan Zee) and the Academic Hospital Maastricht. 


\section{References}

1. Hochstenbach J. The cognitive, emotional, and behavioural consequences of stroke [Dissertation]. Nijmegen, The Netherlands: Catholic University Nijmegen, 1999.

2. Visser-Keizer AC, Meyboom-de Jong B, Deelman BG, Berg IJ, Gerritsen MJ. Subjective changes in emotion, cognition and behaviour after stroke: factors affecting the perception of patients and partners. $J$ of Clin and Exp Neuropsychol 2002; 24: 1032-45.

3. Winkens I, Van Heugten CM, Fasotti L, Duits AA, Wade DT. Manifestations of mental slowness in the daily life of stroke patients. Clin Rehab 2006; 20: 827-34.

4. Winkens I, Van Heugten CM, Fasotti L, Wade DT. Reliability and validity of two new instruments for measuring aspects of mental slowness in the daily lives of stroke patients. Neuropsychol Rehab. Published online April 3rd, 2008.

5. Robertson HI. Does computerised cognitive rehabilitation work? A review. Aphasiology 1990; 4: 381-405.

6. Wilson BA. Assessment and management of memory problems. In: Von Steinbuechel N, Von Cramon DY, Poeppel E. (Eds.) Neuropsychological Rehabilitation, (pp. 194-202). Berlin : Springer Verlag, 1992.

7. Halligan PW, Wade DT. The effectiveness of rehabilitation for cognitive deficits. Oxford: University Press, 2005

8. Fasotti L, Kovacs F, Eling PATM, Brouwer WH. Time Pressure Management as a compensatory strategy training after closed head injury. Neuropsychol Rehab 2000; 10: 47-65.

9. Michon JA. Dealing with danger. Summary report of a workshop in the Traffic Research Centre. State University Groningen, the Netherlands, 1979.

10. Ylvisaker M, Szekeres SF, Henry K, Sullivan DM, Wheeler P. Topics in cognitive rehabilitation theory. In: Ylvisaker M, Gobble EM. (Eds.) Community re-entry for head injured adults (pp. 137-220). Boston: College-Hill Press, 1987.

11. Winkens I, Van Heugten C, Wade D, Fasotti L. Training patients in Time Pressure Management, a cognitive strategy for mental slowness. Clin Rehab. In press

12. Collin C, Wade DT, Davies S, Home V. The Barthel ADL Index: A reliability study. Int Disability Studies 1988; 10(2): 61-63.

13. Krupp LB, LaRocca NG, Muir-Nash J, Steinberg AD. The Fatigue Severity Scale: Application to patients with multiple sclerosis and systemic lupus erythematosus. Arch of Neurol 1989; 46: 1121-1123.

14. Shinar D, Gross CR, Price TR, Banko M, Bolduc PL, Robinson RG. Screening for depression in stroke patients: the reliability and validity of the Center for Epidemiologic Studies Depression Scale. Stroke 1986; 17: 241-245. 
15. Brooks R EuroQOL: the current state of play. Health Policy 1996; 37(1): 53-72.

16. Smith A. Symbol Digit Substitution Test (SDMT). Manual (Revised). Los Angeles, USA: Western Psychological Services, 1982.

17. Gronwall DMA, Sampson H. The psychological effects of concussion. Auckland: Auckland University Press, 1974.

18. Brand PA, Jolles J. Learning and retrieval rate of words presented auditory and visually. J of Gen Psychol 1985; 112: 201-210.

19. Reitan RM. Validity of the Trail Making Test as an indicator of organic brain damage. Perc and Motor Skills 1958; 8: 271-276.

20. Houx PJ, Jolles J, Vreeling FW. Stroop interference : aging effects assessed with the Stroop Color-Word Test. Exp Aging Res 1993; 19: 204-224.

21. Gray JM, Robertson I, Pentland B, Anderson S. Microcomputer-based attentional retraining after brain damage: A randomized group controlled trial. Neuropsychol Rehab 1992; 2(2): 97-115.

22. Donkervoort M, Dekker J, Stehmann-Saris FC, Deelman BG. Efficacy of strategy training in left hemisphere stroke patients with apraxia: A randomized controlled trial. Neuropsychol Rehabil 2001; 11: 549-566.

23. Kaschel R, Della Sala S, Cantagallo A, Fahlbock A, Laaksonen R, Kazen M. Imagery mnemonics for the rehabilitation of memory: A randomized controlled trial. Neuropsychol Rehabil 2002; 12: 127-153.

24. Pizzamiglio L, Antonucci G, Judica A, Montenero P, Razzano C, Zoccolotti P. Cognitive rehabilitation of the hemineglect disorder in chronic patients with unilateral right brain damage. J Clin Exp Neuropsychol 1992; 14: 901-923.

25. Cicerone KD, Dahlberg C, Malec JF, Langenbahn DM, Felicetti T, Kneipp S et al. Evidence-based cognitive rehabilitation: Updated review of the literature from 1998 through 2002. Arch Phys Med Rehabil 2005; 86: 1681-1692.

26. Levine B, Robertson IH, Clare L, Carter G, Hong J, Wilson BA, et al. Rehabilitation of executive functioning: An experimental-clinical validation of Goal Management Training. J of the Int Neuropsychol Society 2000; 6: 299-312. 
Chapter 7

\section{Occurrence and measurement of transfer in cognitive rehabilitation: a critical review}

Published in:

Journal of Rehabilitation Medicine 2007; 39: 425-439

C. Geusgens, I. Winkens, C. van Heugten, J. Jolles, W. van den Heuvel 


\begin{abstract}
Objective. To investigate the occurrence of transfer of cognitive strategy training for persons with acquired brain injury. To investigate the way in which transfer was measured. Methods. Electronic searches in PubMed, PsychINFO, Embase and CINAHL using combinations of search terms in the following categories: type of brain injury, transfer, type of disorder, type of intervention. A total of 39 papers was included in the review. The following aspects were judged: study design and participant characteristics, intervention characteristics and type of outcome measures used.

Results. Transfer outcome measures could be classified in three groups: non-trained items, standardised daily tasks and daily life. Most studies reported at least one type of transfer, however, the methodological quality of the studies was low. Cognitive strategy training in the evaluated studies focussed on seven domains of functioning: information processing, problem solving / executive functioning, memory / attention, language, neglect, apraxia and daily activities.

Conclusions. Transfer of training effects of cognitive strategy training has been evaluated in a relatively small number of studies. Outcome measures used in these studies could be classified in three groups. Most studies reported the occurrence of transfer of training effects, although some serious remarks can be made concerning the methodological quality of the studies.
\end{abstract}




\section{Introduction}

The exact meaning of the terms " transfer" and "generalization" lacks consensus. It is however agreed that both terms relate to the way in which prior learning affects new learning. In the context of rehabilitation, transfer of treatment effects is of great importance. The aim of a rehabilitation programme is to restore patients to their greatest potential and maximum independence, hopefully resulting in independent functioning, the return to their own home and participation in society [1]. To achieve this goal, transfer of training results is necessary. For patients to function as independently as possible at home, tasks which are taught in the rehabilitation setting should be transferred to the home setting. Moreover, therapists cannot possibly train a patient to handle all the difficulties and tasks he or she will encounter after discharge. Therefore transfer of skills from trained to nontrained tasks is of great importance to the clinical success of a therapy programme.

In recent years, strategy training has become a widely used treatment method in cognitive rehabilitation of patients with acquired brain injury (ABI). This type of therapy is based on the assumption that restoration of cognitive functions to their pre-injury structure and efficiency is not expected to occur and that rehabilitation should therefore concentrate on teaching compensatory strategies [1]. Cognitive strategy training is aimed at teaching patients new, general ways to compensate for problems in everyday life, resulting from a cognitive impairment [2]. Compensation can be achieved by teaching patients to use external as well as internal strategies and techniques to reach their goals in alternative ways. People with severe memory problems can, for example, use external memory aids like pagers or appointment books to enable them to remember their daily schedules. In addition people can be encouraged to use their residual, internal, skills more efficiently by applying rehearsal strategies or mnemonics [1].

In the recent literature on cognitive rehabilitation, it is often stated that the occurrence of transfer is expected in strategy training, as the training programme is not aimed at relearning specific tasks, but at teaching patients new ways to handle problems resulting from an impairment [3]. Therefore, patients are expected to be able to use the strategies in new settings and while performing new tasks, despite the lasting presence of the cognitive deficits. Therefore cognitive strategy training is not expected to transfer to neuropsychological test results, since the aim of the training is not to improve the impairment itself. However, Cicerone et al $[4,5]$ points out that relatively few studies have tried to evaluate the occurrence of transfer by directly evaluating the transfer of treatment effects to everyday situations or behaviours.

Therefore, the objective of this paper is to investigate the occurrence of transfer of cognitive strategy training to everyday situations and behaviours. Literature of educational psychology will be reviewed beforehand to clarify the concept of "transfer", as in rehabilitation research less attention has been paid to the definition. Next, we will discuss the results of a critical review of intervention studies evaluating transfer of cognitive strategy training. We will try to answer the following questions: 1) how was transfer measured in these studies? And 2) does transfer occur? Finally, we will reflect on the consequence of these results for clinical practice and we will give suggestions for the design of future studies aimed at evaluating transfer of treatment effects. 


\section{Transfer}

The term "transfer" is frequently used in spoken language and clinical practice. In addition, the term is commonly used in scientific research, in particular in contexts in which learning plays an important role, yet the exact meaning of this term lacks consensus. Nevertheless, it is agreed that "transfer" relates to the use of prior learning in new contexts, or, in other words, to the way in which prior learning affects new learning or performance [6-12].

Over the years, researchers have had trouble demonstrating the occurrence of transfer. This is rather unfortunate as it has often been stated that it is essential to all situations in which learning is concerned and as transfer is said to be the main goal of all learning $[6,8,10]$. At the same time, it is also rather peculiar as transfer seems to occur frequently in everyday life, as it is by transfer of earlier experiences that people can function adequately in new situations, which are encountered almost every day [8].

Despite the lack of evidence of the occurrence of transfer, educational psychology has paid much attention to the question how to promote transfer of learning. Based on literature, six prerequisites for the occurrence of transfer are:

- A person should know what transfer is and how it works $[8,13]$.

- A person should be aware of his own functioning before he will acknowledge that a strategy is needed to improve his functioning [14].

- A person should be able to judge when and where transfer can be applied $[10,15]$.

- General knowledge should be taught, as this type of knowledge is easier to transfer than specific knowledge [15].

- The connection between what is learned and the situation in which it is learned should be broken by practicing a strategy or skill while varying the practice situation as much as possible $[8,10,15,16]$.

- Transfer should be addressed during learning as it cannot be expected to occur automatically $[8,17]$.

We will now turn to the review of intervention studies evaluating transfer of cognitive strategy training.

\section{Methods}

A literature search was carried out in PubMed (1984 - April 2005), PsychINFO (1983 - April 2005), Embase (1989 - April 2005) and CINAHL (1982 - April 2005), using Silverplatter's Webspirs retrieval software [18]. Both controlled vocabulary words and free words in the article's title, abstract or keywords were combined in our searches. Details of the search are shown in Appendix I.

The first selection of papers was based on the title and the abstract. In some studies "transfer" was measured and discussed, but the term (or a synonym of it) was not mentioned in the title, abstract or keywords of the paper. As a result, these papers could not be retrieved in the data- 
bases. Therefore, the private libraries on cognitive rehabilitation of the authors were reviewed and papers that did mention strategy training and transfer of training effects were selected.

In addition to these two search methods, the reference lists of all included studies were scanned to further identify eligible studies.

Papers that were selected based on these three search methods were read by one of three reviewers (authors $\mathrm{CvH}$, IW and $\mathrm{CG}$ ). The following inclusion criteria were applied: 1) papers describe an intervention study; 2) papers evaluate a cognitive strategy training. Cognitive strategy training was defined as a training that aims at teaching patients new ways to execute daily activities by using either internal or external strategies to compensate for cognitive impairments [19]; 3) participants are adults, clinically diagnosed as acquired brain injury (ABI) patients; 4) outcome measures for transfer are used. Studies that evaluated transfer to new tasks as well as transfer to new situations were included. Studies that evaluated transfer of training effects to neuropsychological test results were not included in this review, as the aim of a strategy training is not to improve cognitive functioning, but to teach patients ways to function as independently as possible, despite the presence of the cognitive deficits ; 5) papers are written in English. If uncertainty about the compliance with the inclusion criteria still existed after the first reading, the paper was reread by one of the other two reviewers.

All included studies were judged on the following aspects, described in an adapted version of a rating list that is recommended by van Tulder et al. [20]: study characteristics (design, number of participants, used type of outcome measures, used statistics), participant characteristics (age, time post onset, type of injury) and intervention characteristics (intervention strategies used, duration of intervention, trainer characteristics).

\section{Results}

A total of 83 papers was read. After checking the inclusion criteria, 39 papers, describing 41 separate studies were included in the review. Forty-four papers that did not meet the inclusion criteria, were excluded for the following reasons: papers did not describe intervention studies $(n=18)$; studies did not use cognitive strategy training $(n=18)$; studies did not use transfer outcome measures $(n=5)$ and study participants were healthy adults $(\mathrm{n}=3)$.

Included papers were divided into six groups, based on the cognitive domains that the intervention focussed on (information processing, problem solving skills / executive functioning, memory / attention, language, neglect, apraxia). A seventh group of studies consisted of interventions that were aimed at the training of daily activities, not specifically aimed at a single cognitive disorder.

Table 1 displays characteristics and methodological aspects of all included intervention studies on transfer in cognitive strategy training, divided into the seven categories described above. 


\begin{tabular}{|c|c|c|c|c|c|c|}
\hline 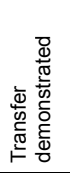 & & 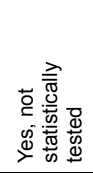 & 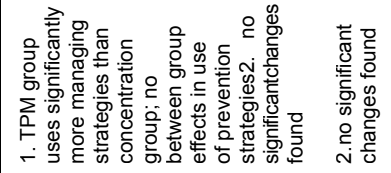 & & 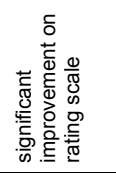 & 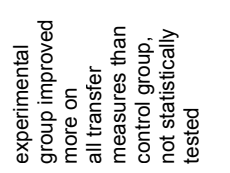 \\
\hline 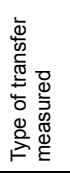 & & 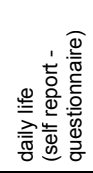 & 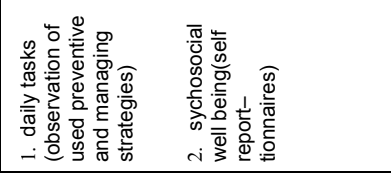 & & 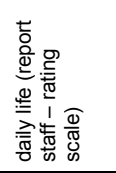 & 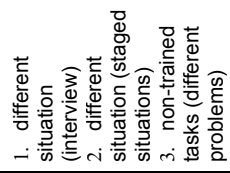 \\
\hline 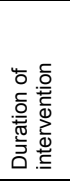 & & 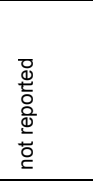 & 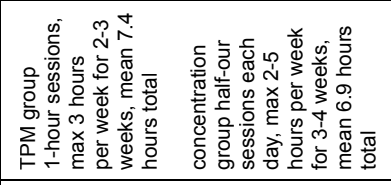 & & 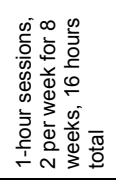 & 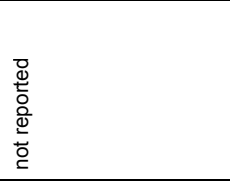 \\
\hline 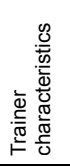 & & 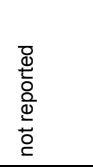 & 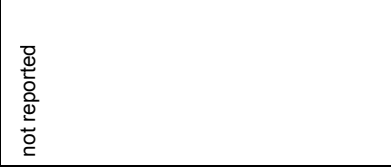 & & 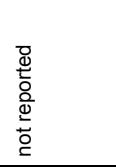 & 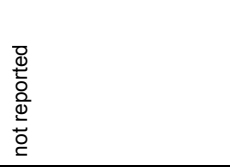 \\
\hline 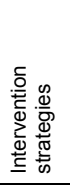 & & 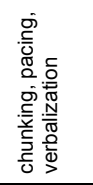 & 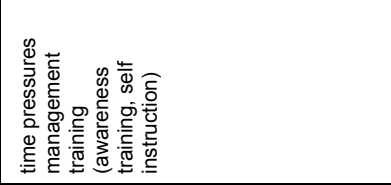 & & 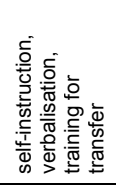 & 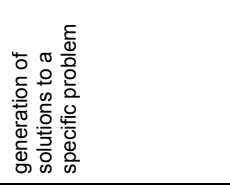 \\
\hline 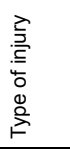 & & 完 & 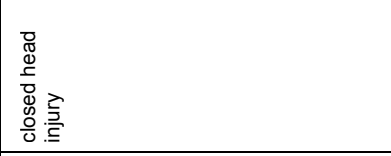 & & 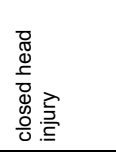 & $\bar{q}$ \\
\hline 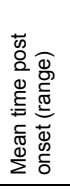 & & 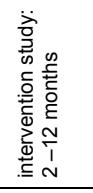 & 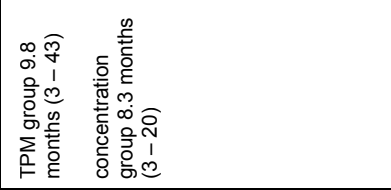 & & $\begin{array}{l}\stackrel{\infty}{\Phi} \\
\stackrel{\varpi}{\varpi} \\
\diamond\end{array}$ & 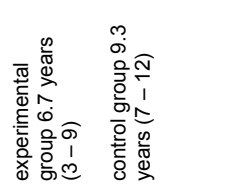 \\
\hline 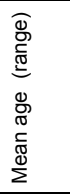 & & 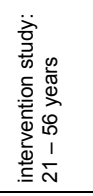 & 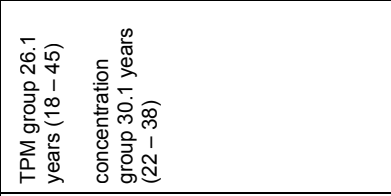 & & 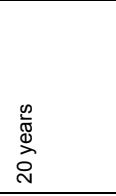 & 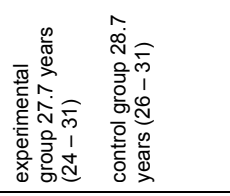 \\
\hline z & & $\stackrel{\circ}{\circ}$ & ส & & - & 0 \\
\hline $\begin{array}{l}\text { 도 } \\
\overline{0} \\
0 \\
\end{array}$ & & 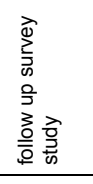 & 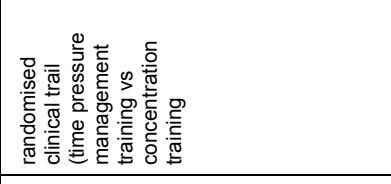 & & 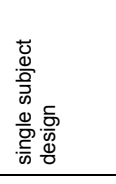 & 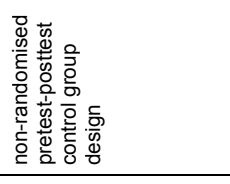 \\
\hline 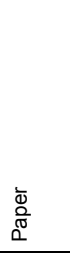 & 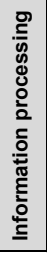 & 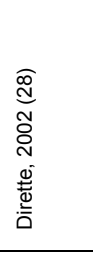 & 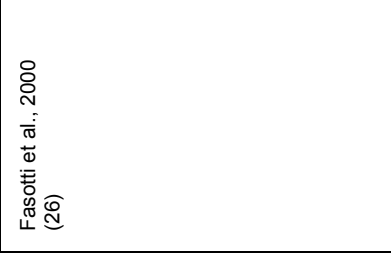 & 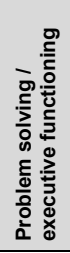 & 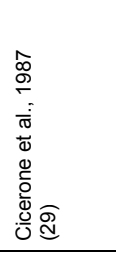 & 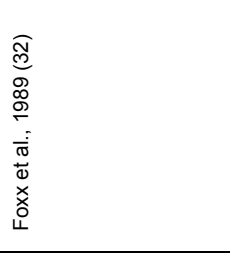 \\
\hline
\end{tabular}




\begin{tabular}{|c|c|c|c|c|c|}
\hline 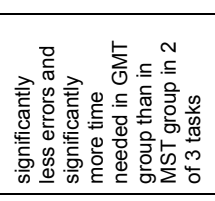 & 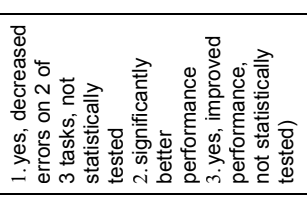 & 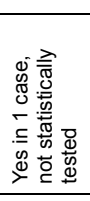 & 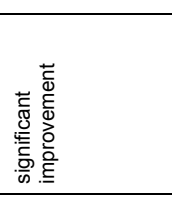 & & 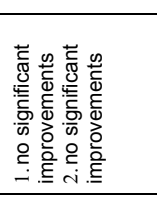 \\
\hline 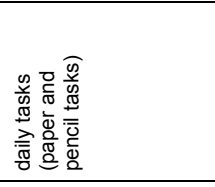 & 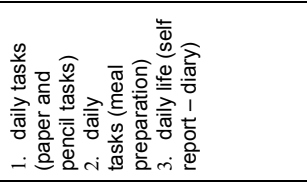 & 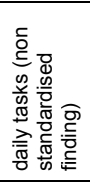 & 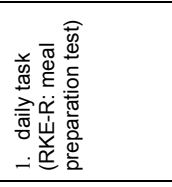 & & 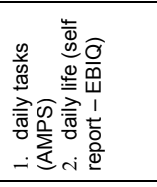 \\
\hline 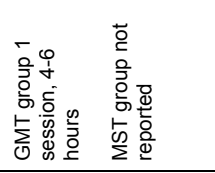 & 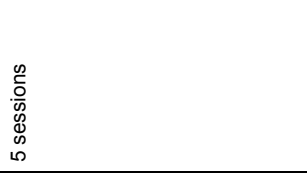 & 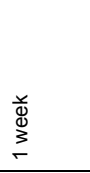 & 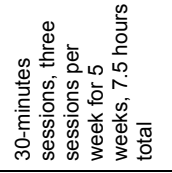 & & 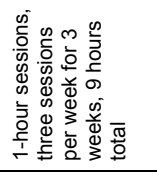 \\
\hline 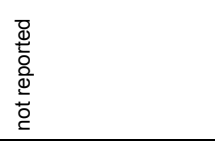 & 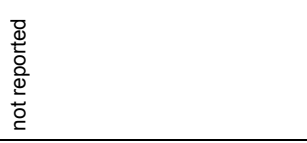 & 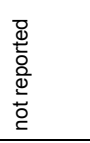 & 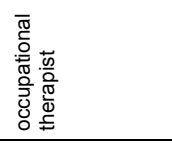 & & 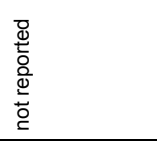 \\
\hline 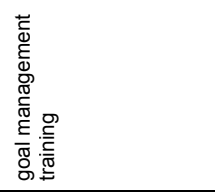 & 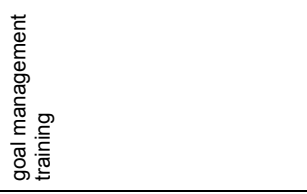 & 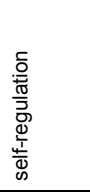 & 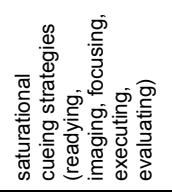 & & 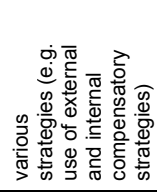 \\
\hline$\overline{\bar{g}}$ & 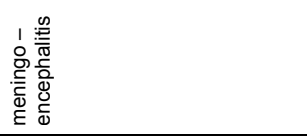 & $\frac{\stackrel{\circ}{\circ}}{\frac{\mathrm{g}}{\omega}}$ & $\begin{array}{l}\frac{n}{2} \\
\frac{0}{N D} \\
\end{array}$ & & 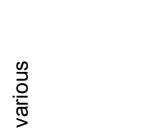 \\
\hline 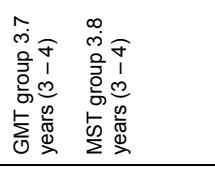 & 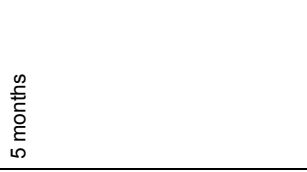 & 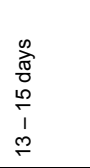 & 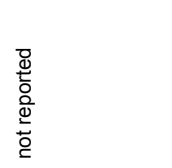 & & 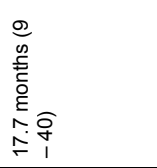 \\
\hline 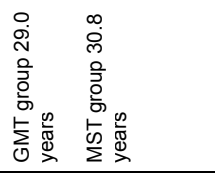 & 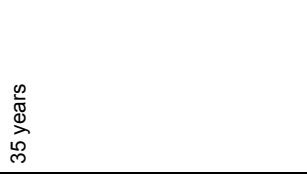 & 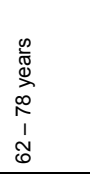 & 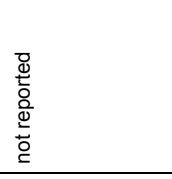 & & 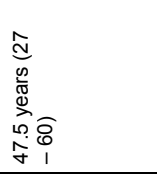 \\
\hline 요 & + & m & & & 우 \\
\hline 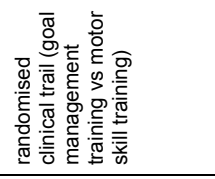 & 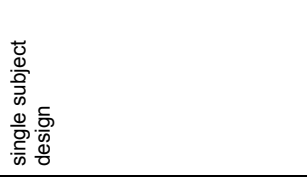 & 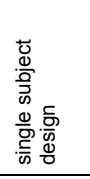 & 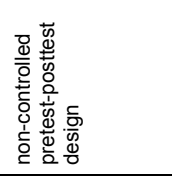 & & 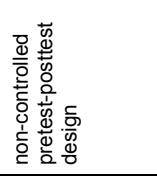 \\
\hline 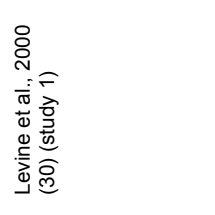 & 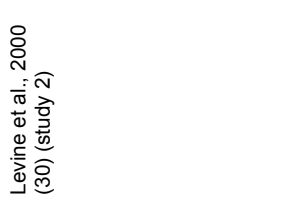 & 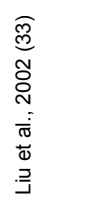 & 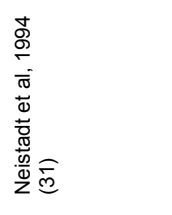 & 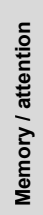 & 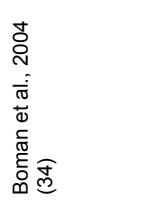 \\
\hline
\end{tabular}




\begin{tabular}{|c|c|c|c|}
\hline 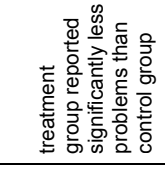 & 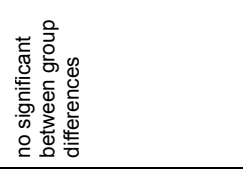 & 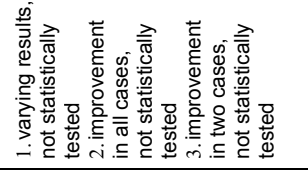 & 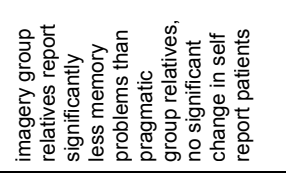 \\
\hline 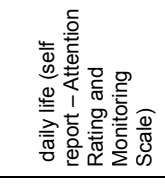 & 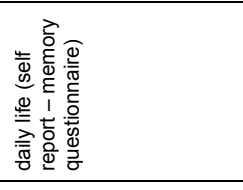 & 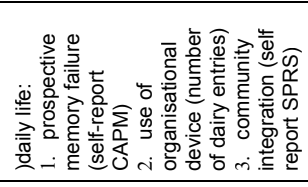 & 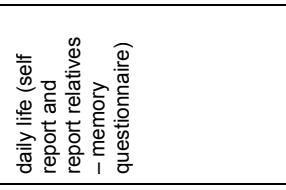 \\
\hline 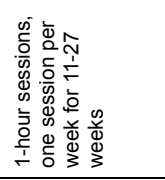 & 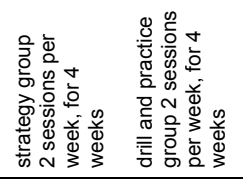 & 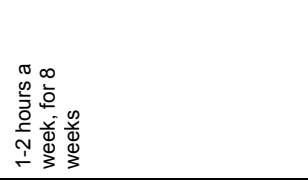 & 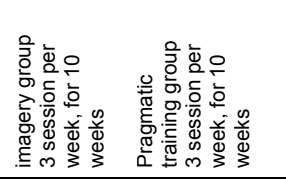 \\
\hline 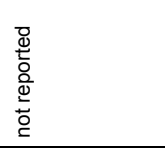 & 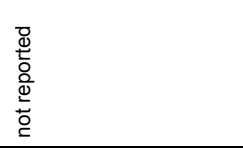 & 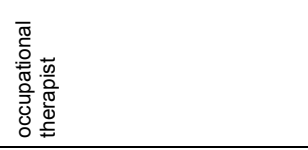 & 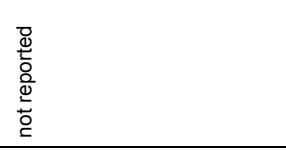 \\
\hline 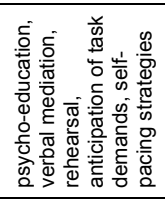 & 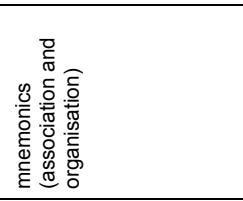 & 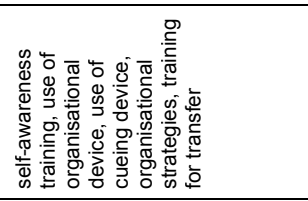 & 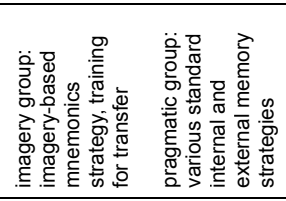 \\
\hline 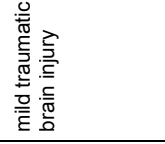 & $\frac{\frac{o}{5}}{\frac{\rho}{\omega}}$ & $\begin{array}{l}\frac{\text { on }}{2} \\
\text { 亳 }\end{array}$ & $\begin{array}{l}\text { 号 } \\
\frac{\mathrm{D}}{\mathrm{d}}\end{array}$ \\
\hline 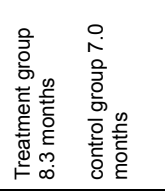 & 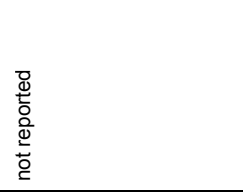 & 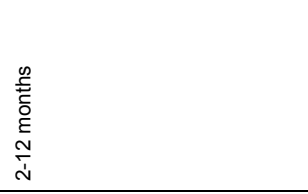 & 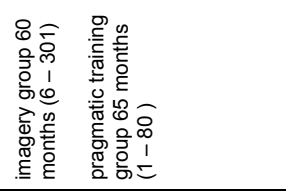 \\
\hline 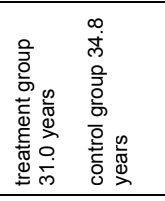 & 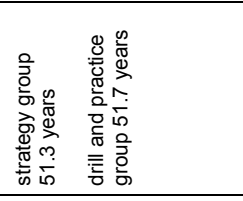 & 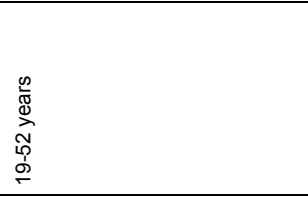 & 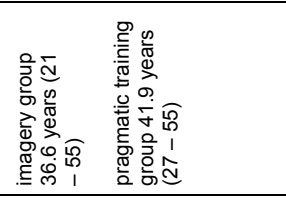 \\
\hline$\infty$ & $\simeq$ & m & $\bar{N}$ \\
\hline 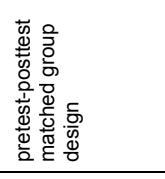 & 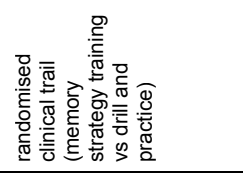 & 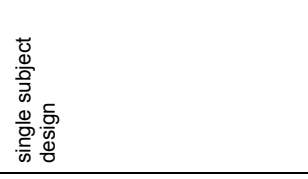 & 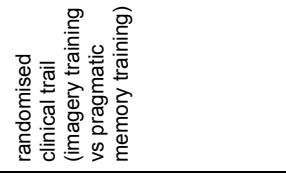 \\
\hline 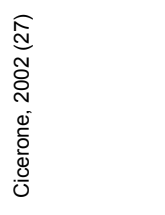 & 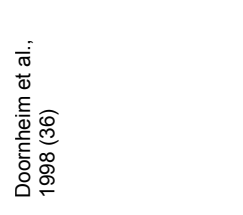 & 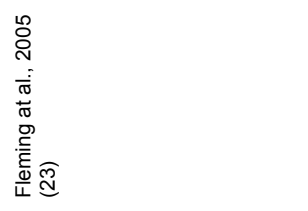 & 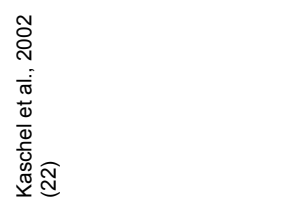 \\
\hline
\end{tabular}




\begin{tabular}{|c|c|c|}
\hline 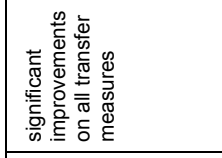 & 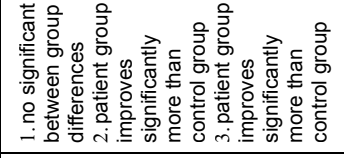 & 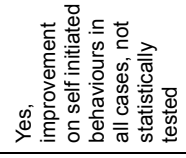 \\
\hline 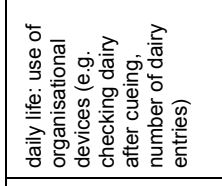 & 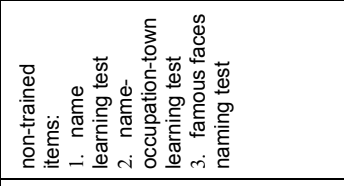 & 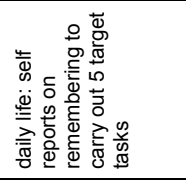 \\
\hline 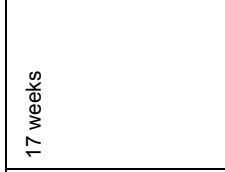 & 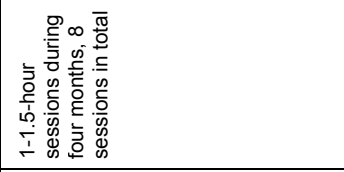 & 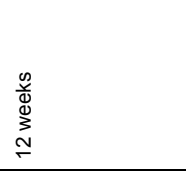 \\
\hline 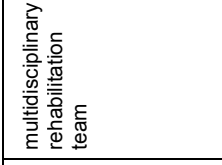 & 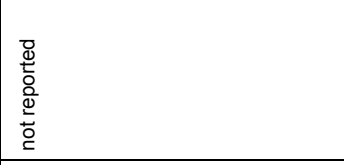 & 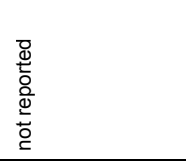 \\
\hline 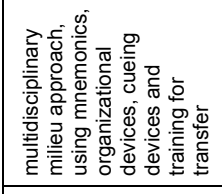 & 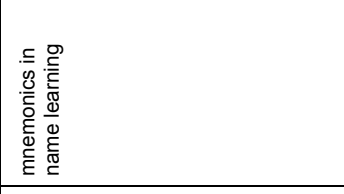 & 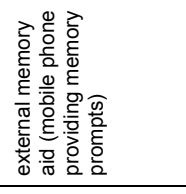 \\
\hline 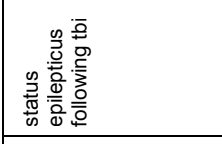 & 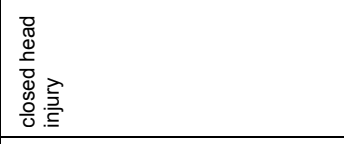 & $\begin{array}{l}\frac{\infty}{0} \\
\frac{0}{\omega N} \\
\\
\end{array}$ \\
\hline 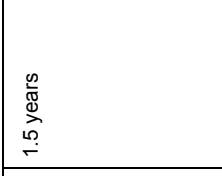 & 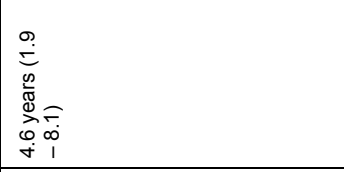 & 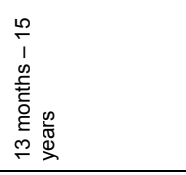 \\
\hline 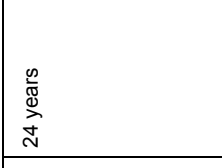 & 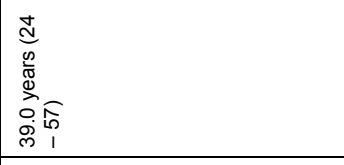 & 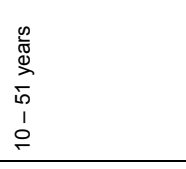 \\
\hline- & $\stackrel{8}{\circ}$ & ம \\
\hline 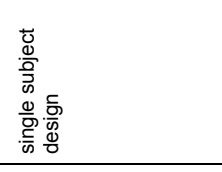 & 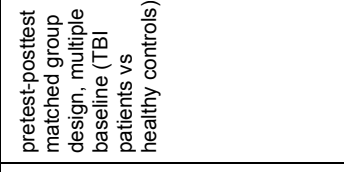 & 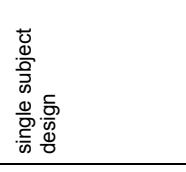 \\
\hline 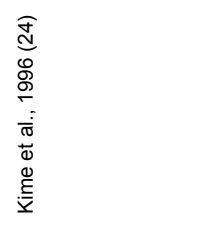 & 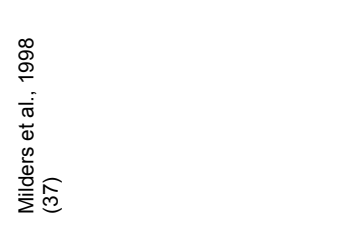 & 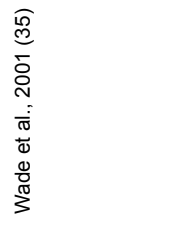 \\
\hline
\end{tabular}




\begin{tabular}{|c|c|c|c|}
\hline & 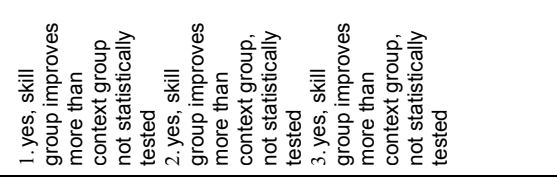 & 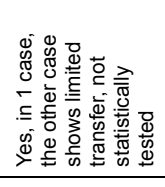 & 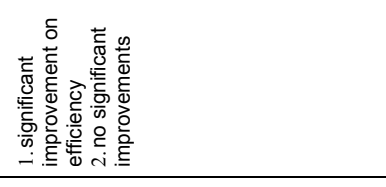 \\
\hline & 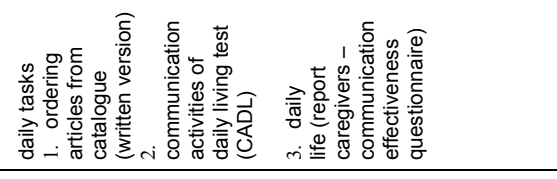 & 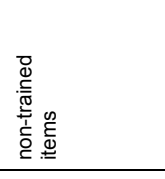 & 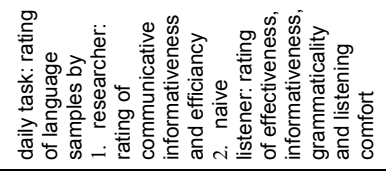 \\
\hline & 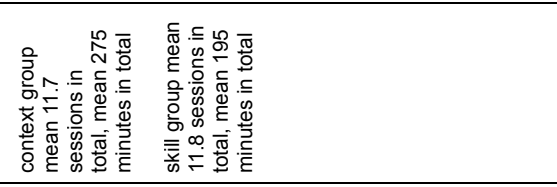 & 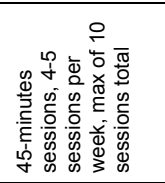 & 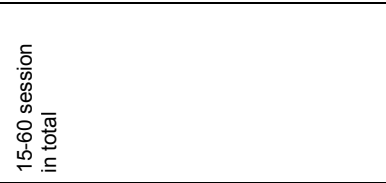 \\
\hline & 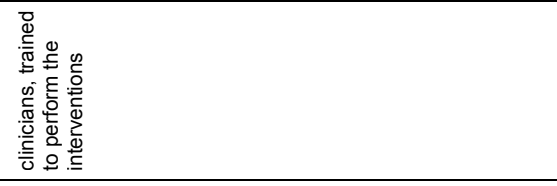 & 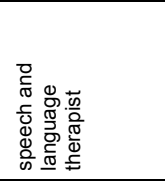 & 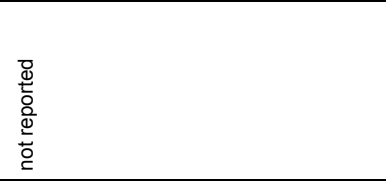 \\
\hline & 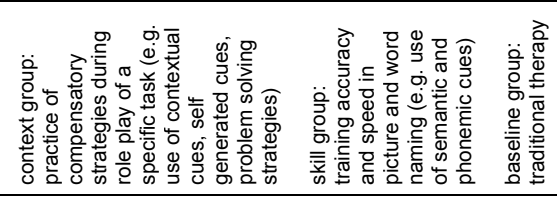 & 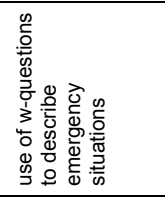 & 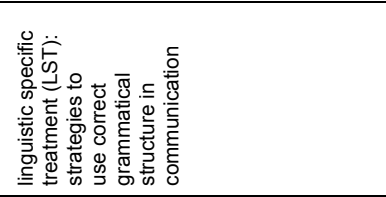 \\
\hline & $\frac{\stackrel{\circ}{\circ}}{\frac{\rho}{\omega}}$ & $\frac{\stackrel{\circ}{\circ}}{\frac{\mathrm{s}}{\omega}}$ & $\frac{\bar{\sigma}}{\bar{\sigma}}$ \\
\hline & 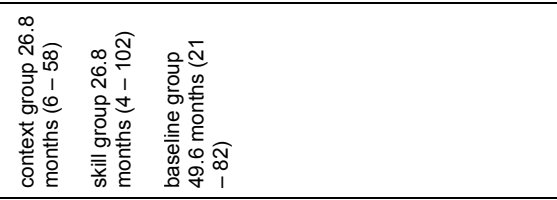 & 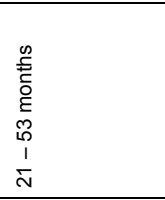 & 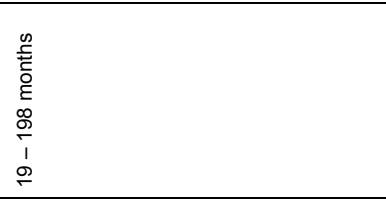 \\
\hline & 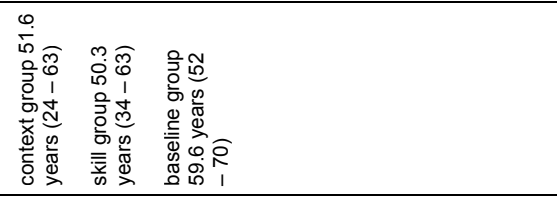 & 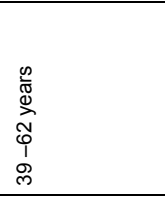 & 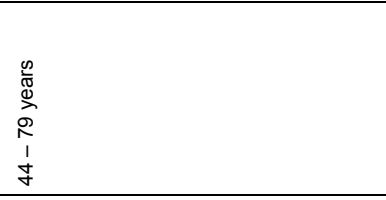 \\
\hline & 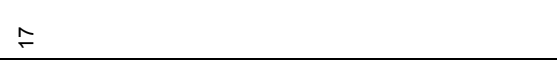 & N & مـ \\
\hline & 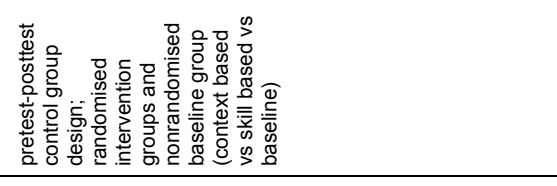 & 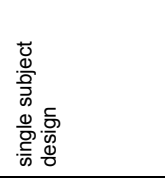 & 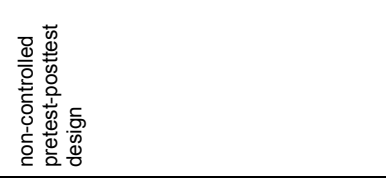 \\
\hline 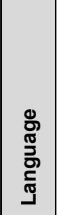 & 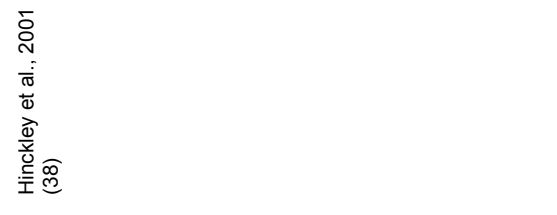 & 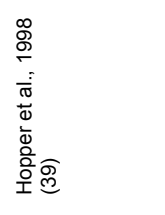 & 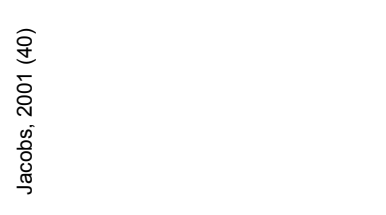 \\
\hline
\end{tabular}




\begin{tabular}{|c|c|c|c|}
\hline 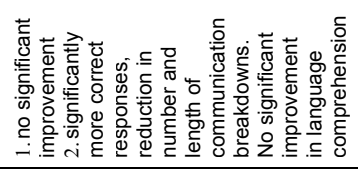 & 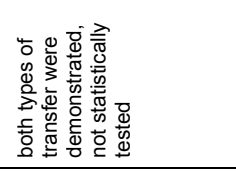 & 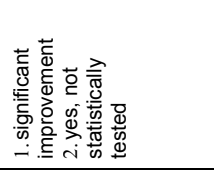 & 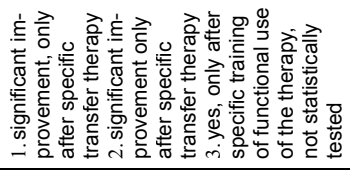 \\
\hline 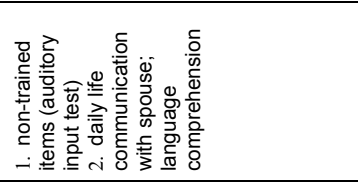 & 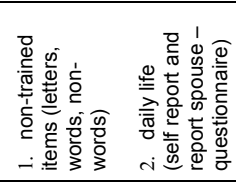 & 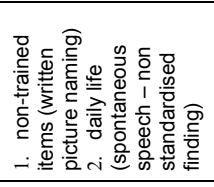 & 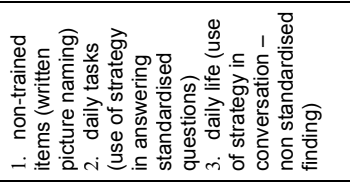 \\
\hline 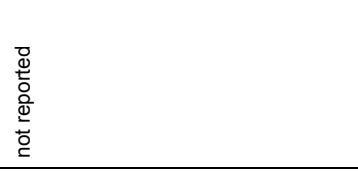 & 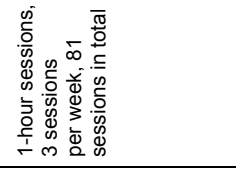 & 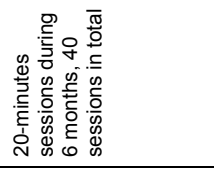 & 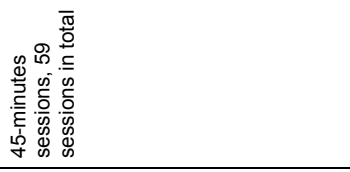 \\
\hline 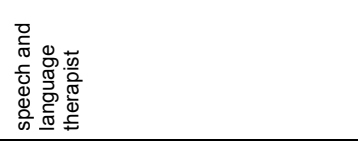 & 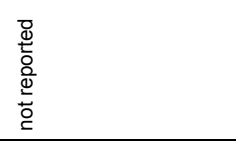 & 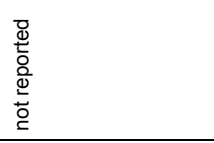 & 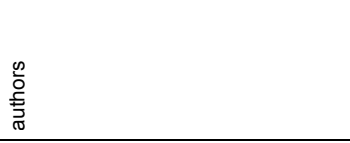 \\
\hline 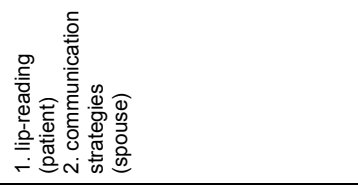 & 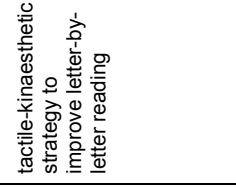 & 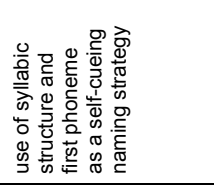 & 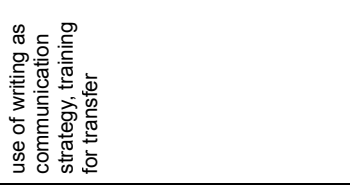 \\
\hline$\frac{\stackrel{0}{\circ}}{\frac{ \pm}{\omega}}$ & $\frac{\stackrel{\circ}{\circ}}{\frac{0}{\omega}}$ & 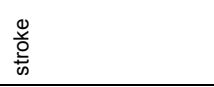 & $\frac{\Phi}{\frac{D}{0}}$ \\
\hline 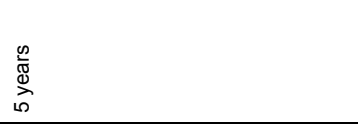 & 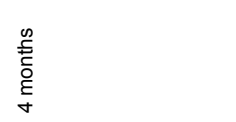 & 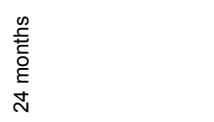 & 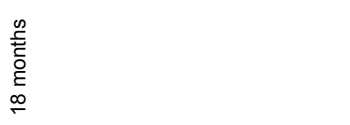 \\
\hline 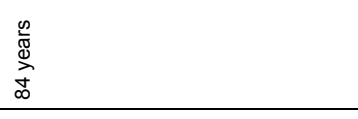 & $\begin{array}{l}\stackrel{\infty}{\pi} \\
\stackrel{\infty}{\pi} \\
\hat{\imath} \\
\end{array}$ & 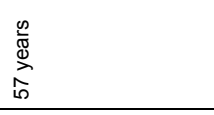 & 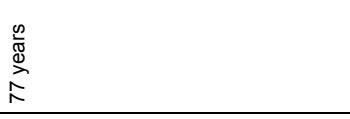 \\
\hline- & - & - & - \\
\hline 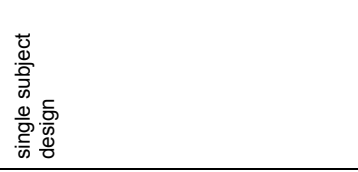 & 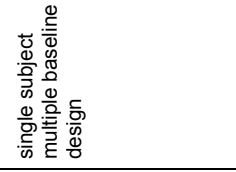 & 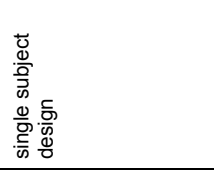 & 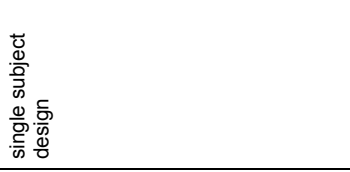 \\
\hline 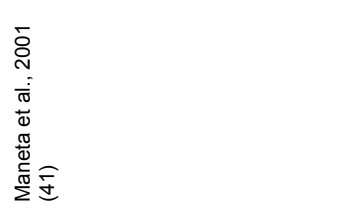 & 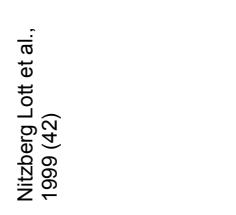 & 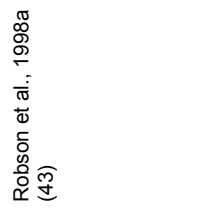 & 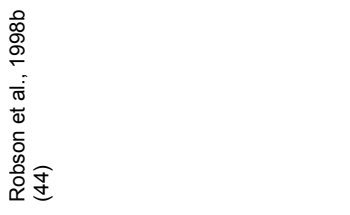 \\
\hline
\end{tabular}




\begin{tabular}{|c|c|c|c|}
\hline 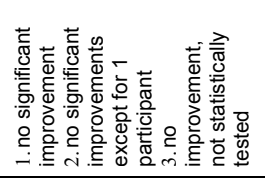 & 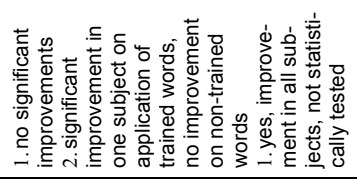 & 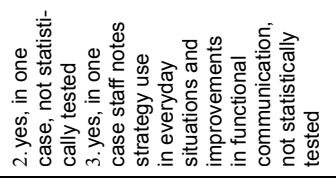 & 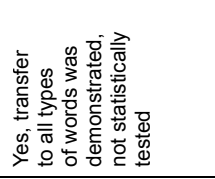 \\
\hline 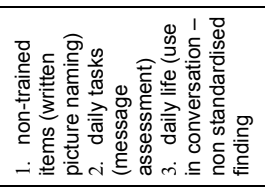 & 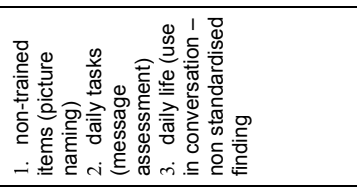 & 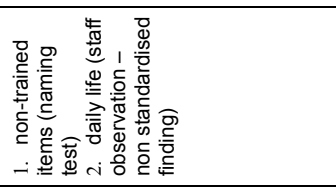 & 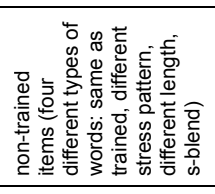 \\
\hline 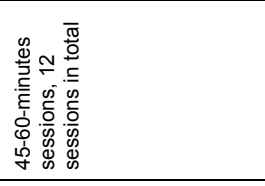 & 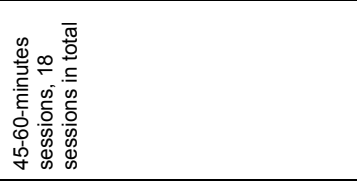 & 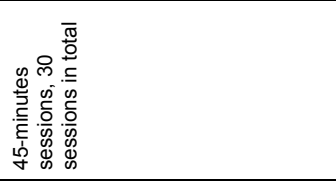 & 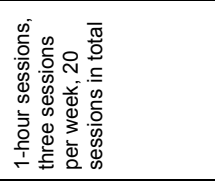 \\
\hline 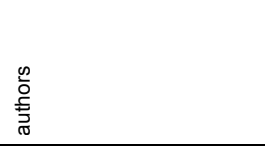 & $\begin{array}{l}\frac{\infty}{0} \\
\text { 竧 } \\
\end{array}$ & 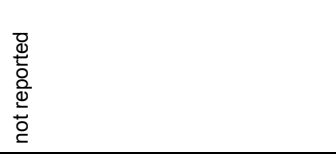 & 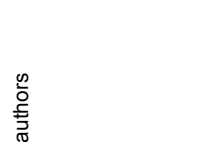 \\
\hline 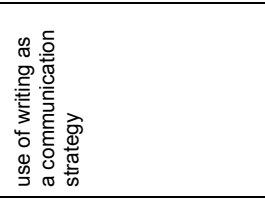 & 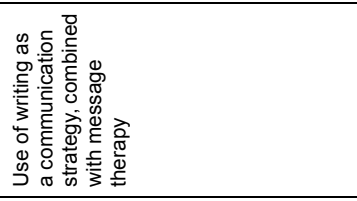 & 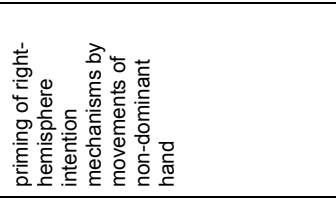 & 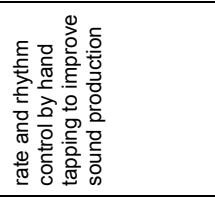 \\
\hline$\frac{\stackrel{o}{\circ}}{\frac{\rho}{\omega}}$ & $\frac{\frac{\rho}{s}}{\frac{\rho}{\omega}}$ & $\frac{\mathscr{o}}{\frac{\mathrm{s}}{\omega}}$ & $\frac{\stackrel{\circ}{\circ}}{\frac{0}{n}}$ \\
\hline 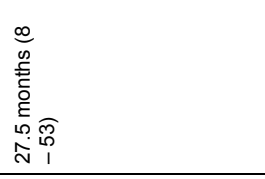 & 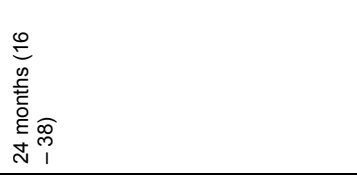 & 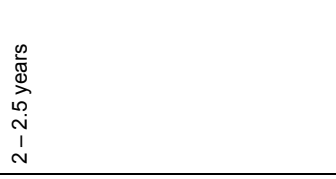 & 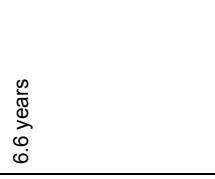 \\
\hline 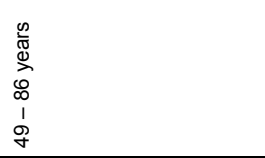 & 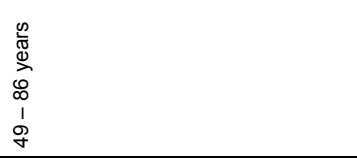 & 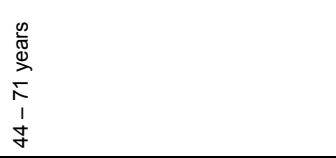 & 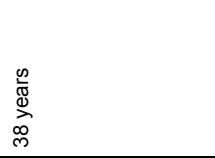 \\
\hline 0 & $\infty$ & m & - \\
\hline 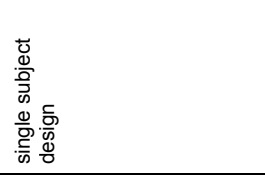 & 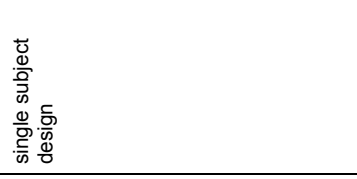 & 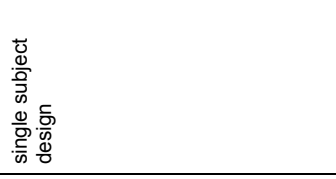 & 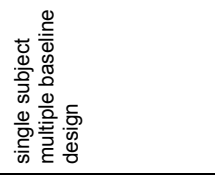 \\
\hline 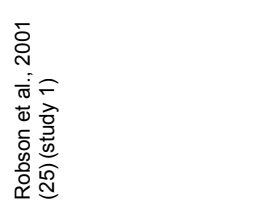 & 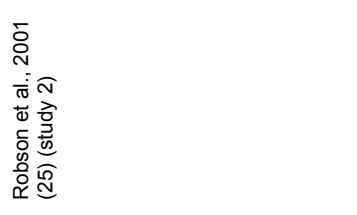 & 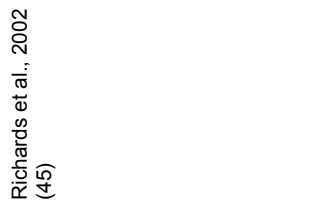 & 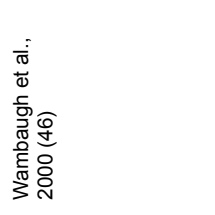 \\
\hline
\end{tabular}




\begin{tabular}{|c|c|c|c|c|c|}
\hline & 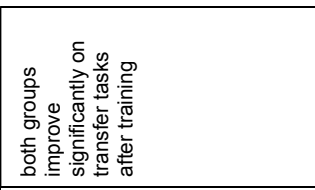 & 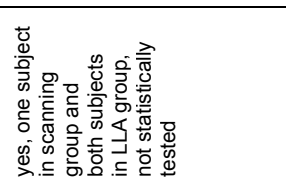 & 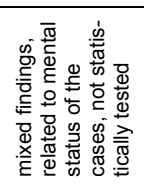 & 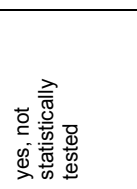 & 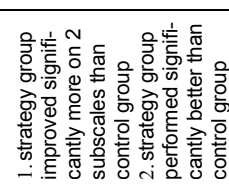 \\
\hline & 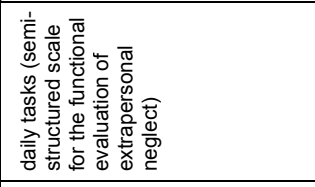 & 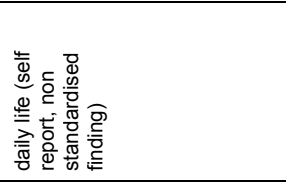 & 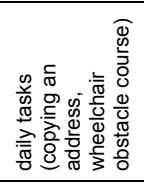 & 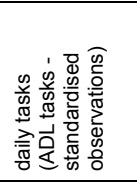 & 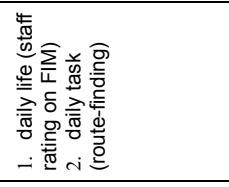 \\
\hline & 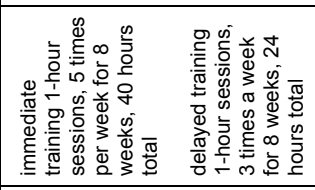 & 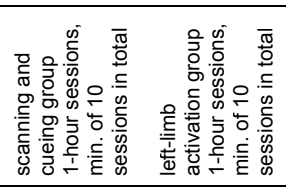 & 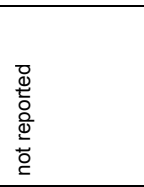 & 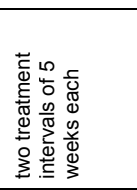 & 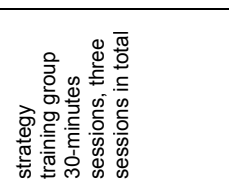 \\
\hline & 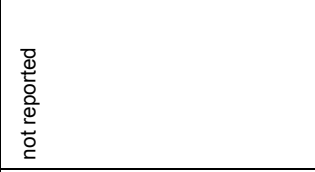 & 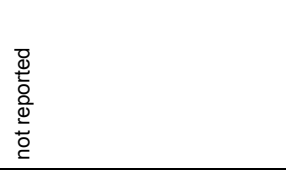 & 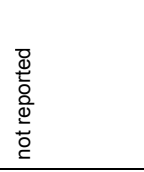 & 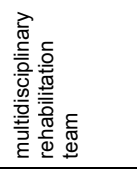 & 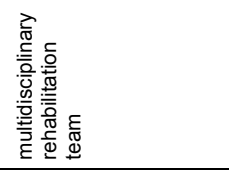 \\
\hline & 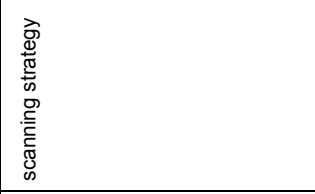 & 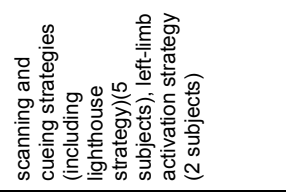 & 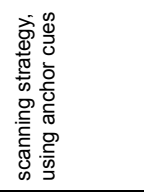 & 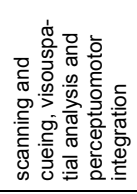 & 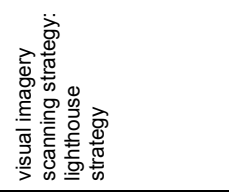 \\
\hline & $\frac{\%}{\frac{ \pm}{\omega}}$ & $\frac{\stackrel{\nu}{*}}{\frac{\mathrm{s}}{\omega}}$ & $\frac{\stackrel{\circ}{\circ}}{\frac{\mathrm{g}}{\omega}}$ & 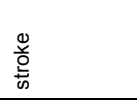 & 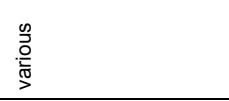 \\
\hline & 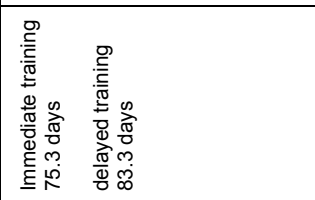 & 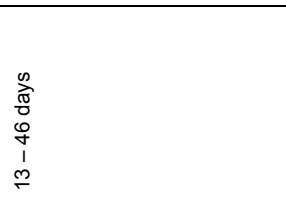 & 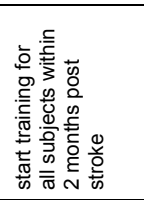 & 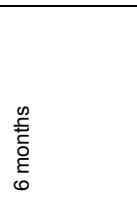 & 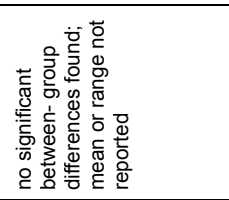 \\
\hline & 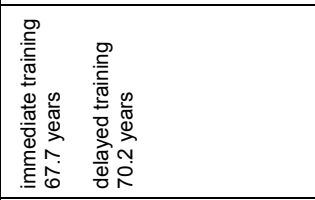 & 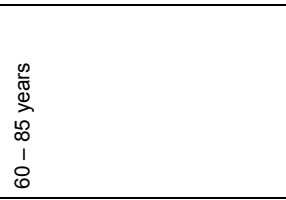 & 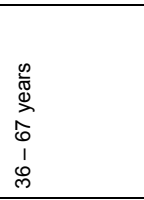 & 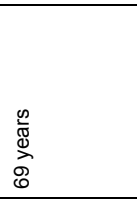 & 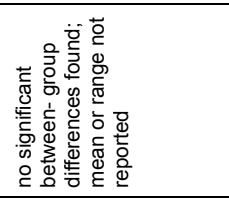 \\
\hline & ๙ & n & ๑ & - & $\stackrel{\sigma}{\circ}$ \\
\hline & 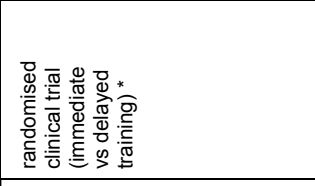 & 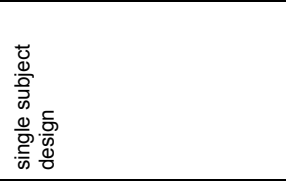 & 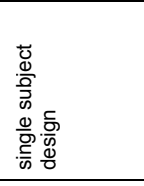 & 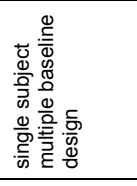 & 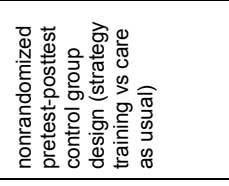 \\
\hline 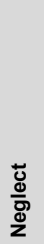 & 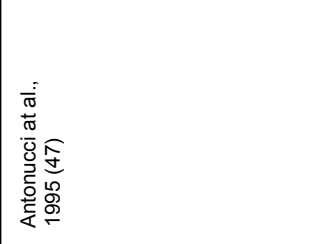 & 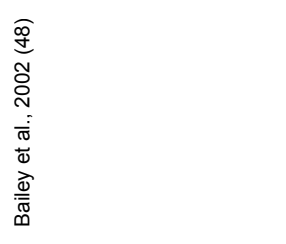 & 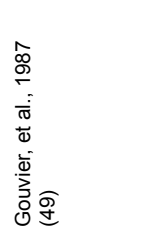 & 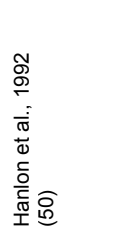 & 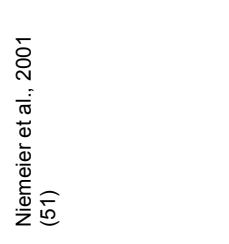 \\
\hline
\end{tabular}




\begin{tabular}{|c|c|c|c|c|}
\hline 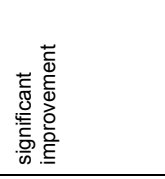 & 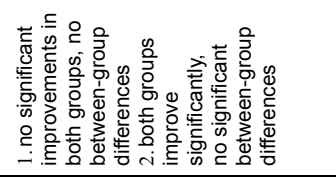 & 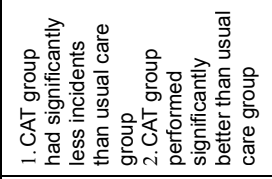 & & 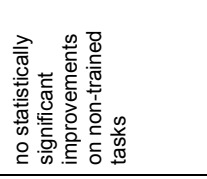 \\
\hline 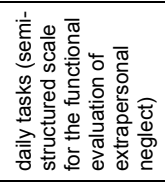 & 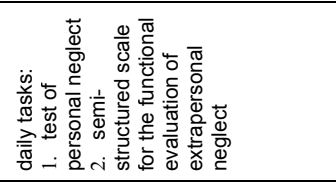 & 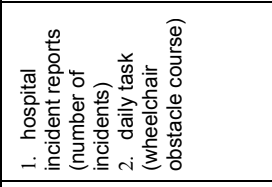 & & 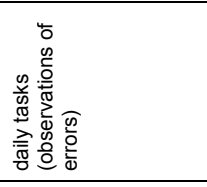 \\
\hline 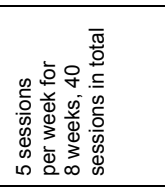 & 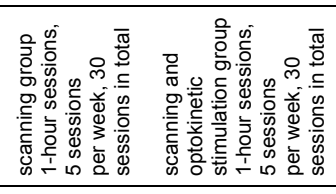 & 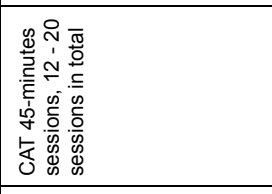 & & 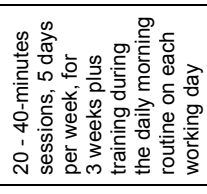 \\
\hline 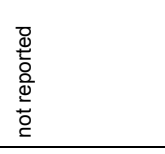 & 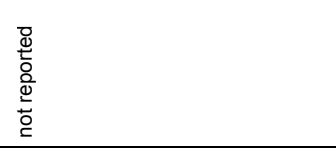 & 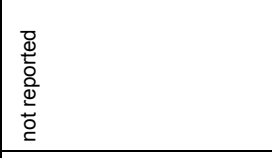 & & 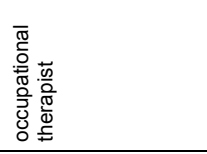 \\
\hline 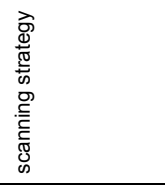 & 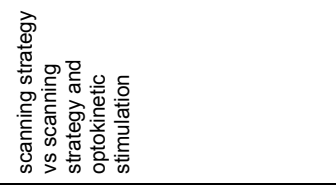 & 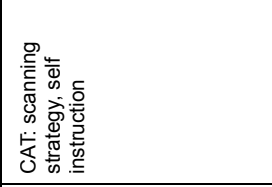 & & 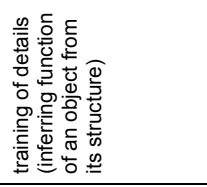 \\
\hline$\frac{\stackrel{\rho}{\circ}}{\frac{8}{\omega}}$ & 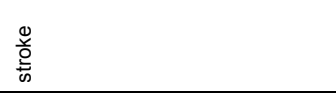 & 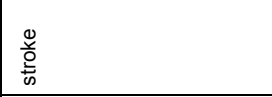 & & $\frac{\stackrel{o}{\circ}}{\frac{\rho}{\omega}}$ \\
\hline 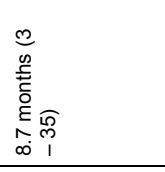 & 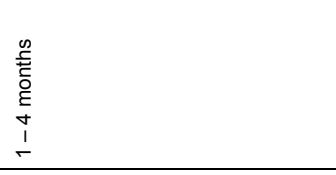 & 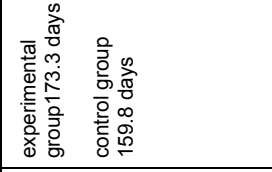 & & 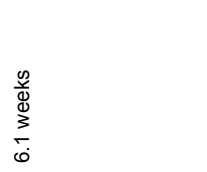 \\
\hline 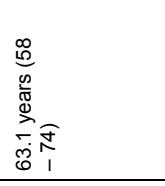 & 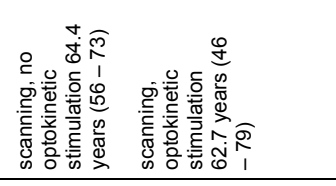 & 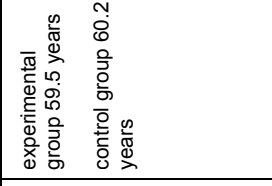 & & 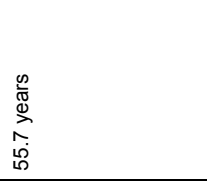 \\
\hline$\stackrel{\infty}{\square}$ & $\approx$ & g & & $\stackrel{\leftarrow}{\llcorner}$ \\
\hline 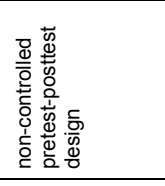 & 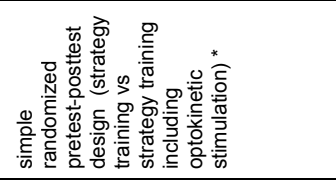 & 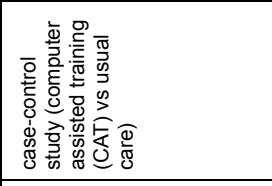 & & 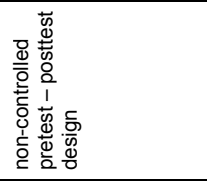 \\
\hline 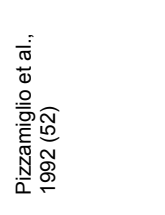 & 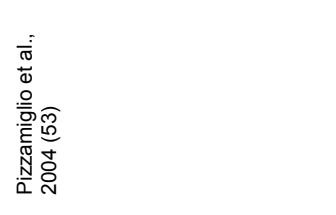 & 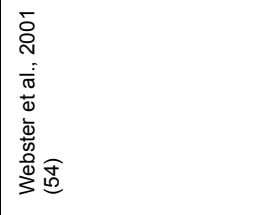 & 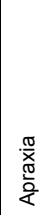 & 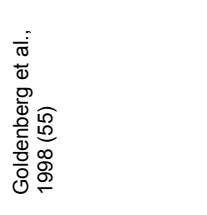 \\
\hline
\end{tabular}




\begin{tabular}{|c|c|c|c|c|c|}
\hline 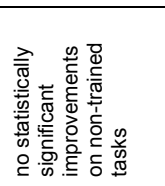 & 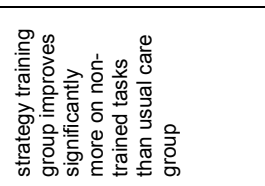 & & 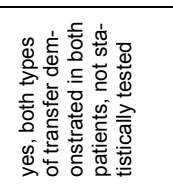 & 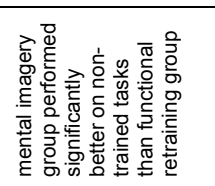 & 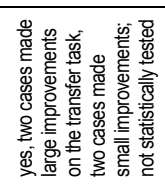 \\
\hline 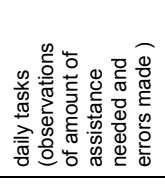 & 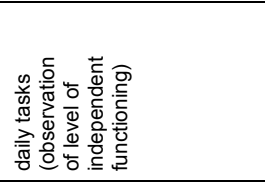 & & 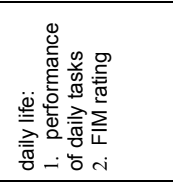 & 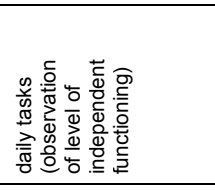 & 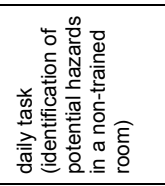 \\
\hline 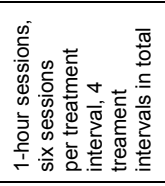 & 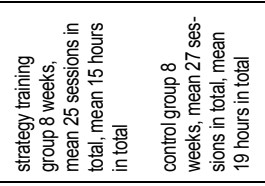 & & 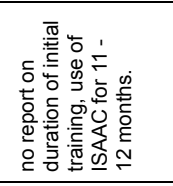 & 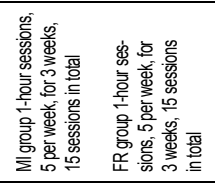 & 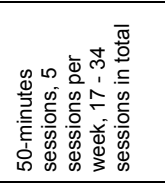 \\
\hline 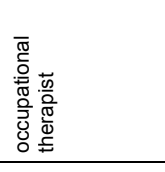 & 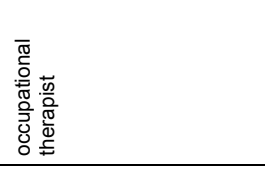 & & 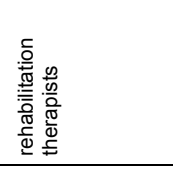 & 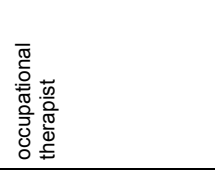 & 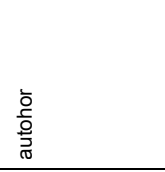 \\
\hline 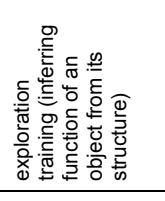 & 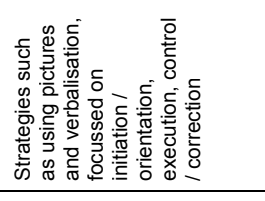 & & 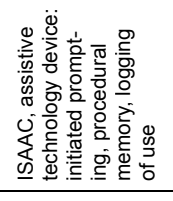 & 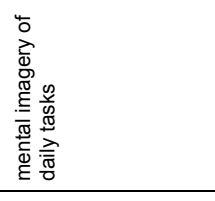 & 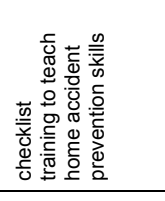 \\
\hline$\frac{\stackrel{o}{\circ}}{\frac{\mathrm{s}}{\omega}}$ & $\frac{\frac{o}{2}}{\frac{\rho}{\omega}}$ & & 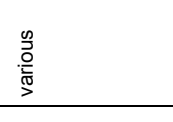 & 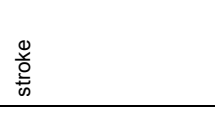 & $\overline{\underline{p}}$ \\
\hline 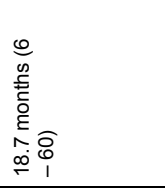 & 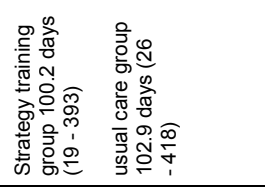 & & 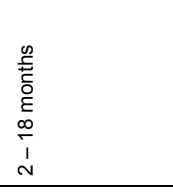 & 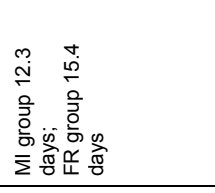 & $\begin{array}{l}\frac{\infty}{0} \\
\infty \\
\infty \\
\infty \\
1 \\
- \\
\end{array}$ \\
\hline 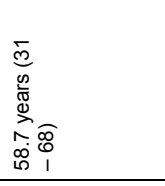 & 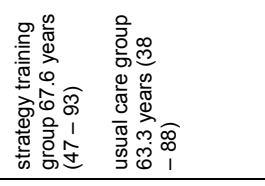 & & 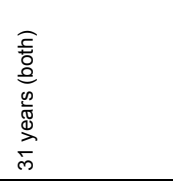 & 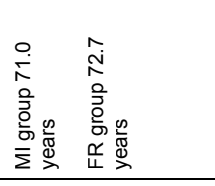 & 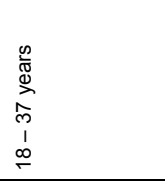 \\
\hline 0 & $\stackrel{m}{\rightleftharpoons}$ & & N & o & $\sigma$ \\
\hline 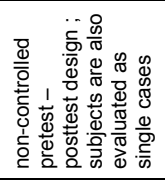 & 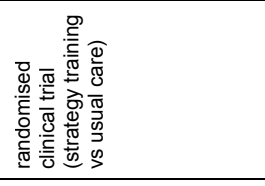 & & 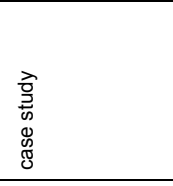 & 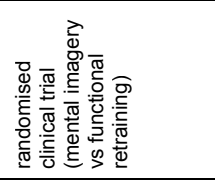 & 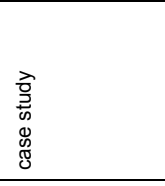 \\
\hline 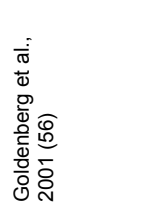 & 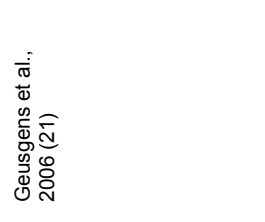 & 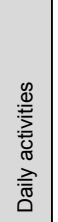 & 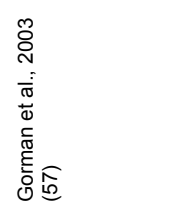 & 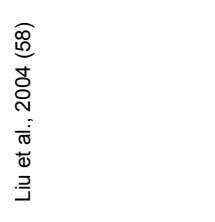 & 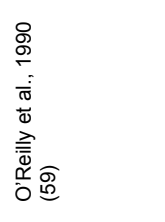 \\
\hline
\end{tabular}

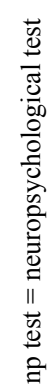




\section{Methods}

\section{Study design}

Most studies had single subject designs $(\mathrm{n}=20)$. Other designs that were used are randomised clinical trial designs $(\mathrm{n}=8)$, non controlled pretest-posttest designs $(\mathrm{n}=6)$ and nonrandomised group designs $(\mathrm{n}=6)$, of which three studies used matched groups. In one study, two randomised intervention groups and one non-randomised control group were used.

The sample sizes of the studies generally ranged from 1 participant to 46 participants, although most studies had a sample size less than 15 participants $(n=28)$. Only one larger study was found, in which 113 subjects participated [21].

\section{Participant characteristics}

The mean age of the participants reported in the studies falls into a broad range $(20-84$ years), which can be attributed to the different types of injuries that the studies focussed on. Most studies focussed on stroke patients $(\mathrm{n}=24)$. Overall, participants in these studies were older than 50 years. In contrast, TBI patients formed a much younger group, with a mean age under 40 years. The time post onset at the start of the therapy also had a broad range. It varied from fourteen days to twenty-five years. Time post onset also had large variations within studies itself, for example ranging from one month to 25 years in a randomised clinical trial [22].

\section{Intervention characteristics}

Most studies $(\mathrm{n}=23)$ did not report trainer characteristics. Studies that did mention who performed the intervention, reported varying disciplines, like occupational therapists, speech and language therapists and rehabilitation therapists. In three studies the entire rehabilitation team was reported to be involved with the cognitive training, whereas in five studies the training was reported to be conducted by the authors of the papers. The duration of the intervention ranged form one week to six months. Studies reported one to five training sessions per week. In most studies, training sessions lasted 30 to 60 minutes.

Three papers explicitly reported that during the intervention, "training for transfer" was used [23-25]. In addition, three papers reported that during training, attention was paid to the enlargement of the patient's awareness of his own deficits [23,26,27], which is an important prerequisite for the occurrence of transfer [14]. All other studies did not report using techniques to promote transfer.

The various intervention types can best be described based on the cognitive domains that the intervention focussed on.

\section{Information processing}

Two studies were found describing strategies aimed at information processing. One study used strategies aimed at self-instruction by verbalisation and at chunking and pacing the amount of information that had to be processed [28]. Strategies used in the other study were aimed at reducing the load on information processing capacity by generating a plan of action before the performance of a task and by verbalisation of the action plan during task performance [26]. 


\section{Problem solving / executive functioning}

Six studies were found describing strategies aimed at problem solving and executive functioning. In all studies self-regulation or self-instruction was used, aimed at either generating and adapting a plan of action before and during the performance of a task [29$31]$ or generating solutions to a specific problem [32,33]. In most studies, overt verbalisation of the action plan was a key feature at the start of the training, generally fading into internalised speech.

\section{Memory / attention}

Eight studies were found describing strategies aimed at memory and attention. Three different strategies could be identified:

1. Self-awareness training: information on the cognitive skills and on problems related to these skills is provided. Patients are helped to recognise the ways in which these problems affect their own situations [23,27].

2. External compensatory strategies: aimed at teaching patients to use a variety of external memory and planning aids, ranging from notebooks to cuing devices like pagers and mobile phones [22-24,34,35].

3. Internal compensatory strategies: aimed at teaching patients internal strategies to facilitate memory function, mostly using mnemonics like associating new information to old information and structuring and organising new information $[22,24,27,34,36,37]$.

Most studies used a combination of these strategies.

\section{Language}

Eleven studies were found describing strategies aimed at language deficits [25,38-46]. In these studies, a large variety of strategies was used. However, three types of strategies that were used in more than one study could be identified. Strategies used in the other studies are summarised in table 1.

1. Linguistic strategies: aimed at improving the grammatical structure of spoken language, hereby increasing the informativeness of the message [39,40].

2. External compensatory strategies: aimed at teaching patients and/or partners to use written language instead of spoken language $[25,41,44]$.

3. Internal compensatory strategies: aimed at teaching patients to use self-cueing strategies like tactile-kinaesthetic information to improve letter by letter reading or deriving a word from it's first phoneme [38,42,43].

\section{Neglect}

Nine studies were found describing strategies aimed at visuo-spatial or perceptual neglect. In all studies one or a combination of the following strategies was used:

1. Scanning strategies: aimed at teaching the patients to move their heads all the way from left to right. This strategy was used in all nine neglect studies [47-54], sometimes combined with one of the following strategies:

a. Self instruction: patients verbalise the command to turn their heads all the way to the left and move them all the way to the right.

b. Mental imagery: patients are taught to imagine their eyes are a lighthouse, scanning the sea all the way from left to right. 
2. Cueing strategies: aimed at guiding the patients attention to an anchor cue on the left of the visual field [48-50]. Patients are instructed to start scanning from the anchor cue. In one study, this strategy was internalised by teaching the patient to turn his head till the tip of his chin was in line with the top of his left shoulder and to move his head until the tip of his chin was in line with the top of his right shoulder [51].

\section{Apraxia}

Three studies were found describing strategies aimed at apraxia. Two strategies were aimed at teaching patients to infer the function of an object from its structure $[55,56]$. The other study was aimed at teaching strategies like verbalisation and the use of pictures to improve the internal concept of a the task, the execution of a task, or the control over a task. One of these three interventions was chosen, depending on the type of problems a patient was experiencing [21].

\section{Daily activities}

Three studies were found describing strategies specifically aimed at improving the performance of daily activities [57-59]. No overall strategies could be identified as the studies used widely differing interventions, namely checklist training, the use of an assistive technology device and the use of mental imagery of daily tasks.

\section{Measurement of transfer}

A variety of outcome measures was used to asses transfer. All outcome measures could be classified in one of the following three outcome types:

1. Non-trained items $(\mathrm{n}=11)$ : transfer of treatment is measured by assessing performance on items similar to the items that were used during training.

2. Daily tasks ( $\mathrm{n}=23)$ : transfer of treatment is measured by using standardised observations of a simulated performance of daily tasks in a laboratory environment.

3. Daily life $(n=21)$ : transfer to daily life situations is measured. In this type of transfer measurement, three different perspectives can be distinguished:

a. Patients (self reports): the patient judges his or her own functioning. Outcome measures are questionnaires (focussed on quality of life, the use of compensatory strategies or experienced problems due to the cognitive deficit), diary entries and non standardised remarks.

b. Caregivers: people living with the patient judge the patient's functioning. Outcome measures are questionnaires focussed on experienced problems due to the cognitive deficit and non standardised remarks based on coincidental observations.

c. Staff: members of the rehabilitation team judge the patient's functioning. Outcome measures are standardised rating scales and non standardised remarks based on coincidental observations.

Most studies used a combination of these three outcome types. 


\section{Outcome}

At least one type of transfer was demonstrated in 36 of the 41 evaluated studies. However, in 15 of these studies, the transfer effect was not statistically tested. As was mentioned before, most studies evaluated more than one type of transfer. Table 2 displays the data, arranged in the three types of transfer.

In a relatively large number of studies, transfer to daily life was evaluated $(n=22)$. This type of transfer was demonstrated in eighteen of the twenty-two studies. However, transfer effects were not statistically tested in twelve of the eighteen studies that demonstrated transfer to daily life.

Transfer to daily tasks was the most often evaluated type of transfer. Twenty-three studies evaluated this type of transfer and it was demonstrated in nineteen of these studies. Fifteen of these studies did statistically test the positive research findings; four did not.

Transfer to non-trained items was demonstrated in eight studies, three of which used statistical testing.

Only twelve evaluations of all types of transfer combined did not demonstrate transfer. Ten of these negative findings were statistically corroborated, two were not. No similarities could be identified in the studies reporting negative findings.

Table 2. Number of studies that evaluated and demonstrated the three types of transfer.

\begin{tabular}{|l|c|c|c|}
\hline Type of transfer & $\begin{array}{c}\text { Total number of } \\
\text { studies (transfer } \\
\text { demonstrated) }\end{array}$ & $\begin{array}{c}\text { Transfer demonstrated } \\
\text { - statistically tested }\end{array}$ & $\begin{array}{c}\text { Transfer demonstrated } \\
\text { - not statistically tested }\end{array}$ \\
\hline Non-trained items & $11(8)$ & 3 & 5 \\
\hline Daily tasks & $23(19)$ & 15 & 4 \\
\hline Daily life & $22(18)$ & 6 & 12 \\
\hline
\end{tabular}

A total of 39 papers, describing 41 studies was included in this review; several studies evaluated more than one type of transfer.

\section{Discussion}

We carried out a literature search to inventory studies evaluating transfer effects of cognitive strategy training, resulting in the identification of 41 studies. This is a small amount of studies, compared with the large number of studies on cognitive rehabilitation that was reviewed by Cicerone et al. [4,5]. Many different strategies and many different outcome measures were used in the studies. However, most strategies could be classified as the classical intervention strategies used in cognitive rehabilitation [60]. Outcome measures could be classified in three groups: non-trained items, daily tasks and daily life. The stud- 
ies we evaluated include the cognitive domains that were also identified by the review of Cicerone et al. [4,5]. In addition, a seventh group of studies was identified, consisting of strategies that were aimed at the training of daily activities, not specifically aimed at a single cognitive disorder. In accordance with Cicerone et al [4,5], we found relatively large numbers of studies evaluating transfer of training effects in the domains of neglect, memory and language, compared with the other domains. This reflects the fact that the domains of neglect, memory and language are in general more often studied than other cognitive domains.

\section{Limitations of the review}

We acknowledge that we could have missed articles that did measure "transfer" if the term was not mentioned in the abstract or keywords of the paper. We therefore reviewed an independent sample of articles that were included in the updated review of Cicerone et al. [5] containing all recently published studies on cognitive rehabilitation. Our sample consisted of $15 \%$ of the studies that were included in the updated review, that is, 13 of the 87 studies that were included by Cicerone et al. [5]. Studies were selected from each category in proportion to the number of studies Cicerone et al. included in the different categories they distinguished. Of these 13 studies, 3 turned out to be included in our review and two studies were retrieved by our search strategy, but were not included in our review as they did not meet with our inclusion criteria. Seven studies could be excluded, based on our exclusion criteria. Thus, the conclusion of this sample is that we missed one out of thirteen studies. To our opinion, this is an acceptable result.

\section{Limitations of the evaluated studies}

\section{Methodological issues}

Many studies used single subject designs or had a small sample size. Furthermore it should be noted that many positive results were not statistically tested. This especially was the case in studies that evaluated transfer to daily life. In six studies the demonstration of transfer to daily life was based on coincidental observations of people living with the patient, or on coincidental remarks the patient made. In these studies, identifying transfer to daily life was not formulated as an aim of the study beforehand and therefore, it was not measured in a standardised way.

\section{Choice of outcome measures}

A type of transfer we excluded from this review is transfer to neuropsychological tests, measuring transfer effects of cognitive strategy training to cognitive functions. The aim of a strategy training is not to improve cognitive functioning, but to teach patients ways to function as independently as possible, despite the presence of the cognitive deficits. Therefore, little change in cognitive deficits is expected in cognitive strategy training [2]. However, thirteen studies we included in our review, did evaluate transfer effects of strategy training to neuropsychological test results besides one of the other types of transfer we distinguished [22,23,26,27,29,31,34,36,47,48,50-52]. Eleven studies did report transfer to neuropsychological test results. Two of these studies do report that their findings are surprising, since cognitive functioning was not expected to improve $[23,26]$. Two other studies distinguished between neuropsychological tests in which the trained strategy could not be used versus tests in which the strategy could be used, because the 
components of the test reflected the focus of the training [22,29]. In this way, the fact that in most neuropsychological tests subjects are not allowed to use the strategies they learned to use, is annulled.

Evaluation of the effectiveness of a rehabilitation programme should be attuned to the results that are to be expected of this programme. When evaluating the effectiveness of a rehabilitation programme, the study should ideally be aimed at assessing transfer to daily life, as teaching patients to function as independently as possible in their own home and in society is considered to be the primary goal of rehabilitation practice $[1,61]$. Unfortunately, it seems hard to evaluate this type of transfer in a standardised way. Most studies that we identified measuring transfer to daily life, made use of self reports of the patients by analysing questionnaires, diary entries and coincidental remarks the patient made. The standardisation of the latter two methods can obviously be doubted. However, one can also argue about the reliability of a self report questionnaire filled out by an ABI patient [62]. Apparently there is a lack of reliable, standardised instruments to measure this type of transfer, making it very hard to evaluate the effectiveness of a rehabilitation programme.

Although, of course, demonstrating transfer to daily life is the most ideal way to prove the clinical effectiveness of a rehabilitation programme, demonstrating transfer to (simulated) daily tasks, performed in standardised laboratory settings can be seen as "the next best thing". We identified 23 studies evaluating this type of transfer, fifteen of which statistically demonstrated it.

\section{General conclusions}

Transfer of training effects of cognitive strategy training has been evaluated in a relatively small number of studies. Outcome measures used in these studies could be classified in three groups: non-trained items, daily tasks and daily life. Most studies reported positive results with regard to the occurrence of transfer of training effects, although some serious remarks can be made concerning the methodological quality of the studies.

\section{Recommendations for future research}

To be able to evaluate the effectiveness of cognitive strategy training more studies are needed, specifically designed for measuring transfer effects. In accordance, a workshop organised by the National Center for Medical Rehabilitation Research in the USA recommends that more attention should be paid to the investigation of transfer of rehabilitation programmes; particularly to transfer of functionally important tasks in meaningful task environments [63].

While designing a study to measure transfer effects of cognitive strategy training, two important factors should be taken into account. First, before starting the study, measuring transfer should be set as the primary aim of the study, hence making sure that transfer effects can be measured and statistically tested in a standardised way. Second, outcome measures should be chosen carefully, taking into account what the aim of the therapy is and whether reliable, standardised instruments exist to evaluate this aim. Studies aimed at evaluating transfer should use measures of activities as their primary outcome, demon- 
strating whether or not the strategy actually reduces limitations on activities, thus measuring transfer effects to daily tasks. In the studies we included in our review, this type of transfer was assessed by using standardised observations of a simulated performance of daily tasks in a laboratory environment. However, standardised observations of the simulated performance of daily tasks can also be made in daily settings, for example by observing a participant who performs a specific task in his own home environment. This outcome measure provides more information on the participant's functioning in daily settings, although, of course, it is not an exact reflection of the participant's performance in everyday life.

In addition, studies investigating whether and in what way transfer itself can be trained, could provide valuable information for clinical practice. The prerequisites for the occurrence of transfer derived from educational psychology that were described in the introduction of this paper, could be considered to be a good starting point for answering this question.

In clinical practice several of these prerequisites for the occurrence of transfer are already being applied. Three of these recommendations were actively used in the studies we described. First, three studies explicitly described that during training attention was paid to the enlargement of the patient's awareness of his own deficits $[23,26,27]$. This is an important prerequisite for the occurrence of transfer as someone must acknowledge that there is a need to adapt his behaviour [14].

Next, it was stated that general knowledge is by definition easier to transfer than specific knowledge [15]. This distinction corresponds to the distinction between strategy training and task specific training. Strategy training is said to be more general applicable than task specific training [3]. All studies included in this review evaluated transfer effects of cognitive strategy training.

Lastly, a small number of studies specifically used "training for transfer" [23,24,44], corresponding with the statement that transfer does not occur automatically and that it takes place during learning, not afterwards [8,17]. However, three recommendations of educational psychology do not reappear in the strategies that were described in the papers. Possibly, they have been used during training, but were not described in the papers.

The aim of this paper was to investigate the occurrence of transfer of cognitive strategy training for ABI patients. We hope that by means of this paper, clinical practitioners as well as researchers working in rehabilitation settings become more aware of the importance of transfer for the clinical success of a rehabilitation programme, and of the way in which transfer of training effects should be evaluated. We are certain that this awareness will make a vast difference while applying and studying rehabilitation practice. 


\section{References}

1. Wilson BA. Compensating for cognitive deficits following brain injury. Neuropsychology Review 2000;10(4):233-243.

2. Fasotti 1, Kovacs F. Slow information processing and the use of compensatory strategies. In: Chamberlain MA, editor. Traumatic brain injury rehabilitation: services, treatments and outcomes. London: Chapman \& Hall; 1995.

3. Ben-Yishay Y, Diller L. Cognitive remediation in traumatic brain injury: Update and issues. Archives of Physical Medecine and Rehabilitation 1993;74:204-213.

4. Cicerone KD, Dahlberg C, Kalmar K, Langenbahn DM, Malec JF, Bergquist TF, et al. Evidence-based cognitive rehabilitation: recommendations for clinical practice. Archives of Physical Medicine and Rehabilitation 2000;81(12):1596-615.

5. Cicerone KD, Dahlberg C, Malec JF, Langenbahn DM, Felicetti T, Kneipp S, et al. Evidence-based cognitive rehabilitation: Updated review of the literature from 1998 through 2002. Archives of Physical Medecine and Rehabilitation 2005;86:1681-1692.

6. Singley MK, Anderson JR. The transfer of cognitive skill. Cambridge: Harvard University Press; 1989.

7. Marini A, Genereux R. The challenge of teaching for transfer. In: McKeough A, Lupart J, Marini A, editors. Teaching for transfer: Fostering generalization in learning. Mahwah: Lawrence Erlbaum Assocoates; 1995. p. 1-20.

8. Haskell RE. Transfer of learning: Cognition, instruction, and reasoning. San Diego: Academic Press; 2001.

9. Annett J. Motor skills. In: Mackintosh NJ, Colman AM, editors. Learning and skills. London: Longman; 1995. p. 56-75.

10. Byrnes JP. Cognitive development and learning in instructional contexts. Boston: Allyn and Bacon; 1996.

11. Gagne ED, Walker Yekovich C, Yekovich FR. The cognitive psychology of school learning. New York: HarperCollins College Publishers; 1993.

12. Cormier SM, Hagman JD. Introduction. In: Cormier SM, Hagman JD, editors. Transfer of learning. Contemporary research and applications. San Diego: Academic Press; 1987. p. 1-8.

13. Campione JC, Shapiro AM, Brown AL. Forms of transfer in a community of learners: Flexible learning and understanding. In: McKeough A, Lupart J, Marini A, editors. Teaching for transfer: Fostering generalization in learning. Mahwah: Lawrence Erlbaum Associates; 1995. p. 35-68.

14. Crosson B, Barco PP, Velozo CA, Bolesta MM, Cooper PV, Werts D, et al. Awareness and compensation in postacute head injury rehabilitation. Journal of Head Trauma Rehabilitation 1989;4(3):46-54.

15. Salomon G, Perkins DN. Rocky roads to transfer: Rethinking mechanisms of a neglected phenomenon. Educational Psychologist 1989;24(2):113-142. 
16. Pinnington LL, Ward CD. Learning and skill acquisition. In: Greenwood RJ, Barnes MP, McMillan TM, Ward CD, editors. Handbook of neuropsychological rehabilitation. Hove: Psychology Press; 2003.

17. Perkins DN, Salomon G. Teaching for transfer. Educational Leadership 1988;46:22-32.

18. OvidTechnologies. Silverplatter's information retrieval system for the world wide web. In. 5.1 ed. Sandy, Utah: Ovid Technologies; 2005.

19. Berg IJ. Memory rehabilitation for closed-head injured patients. Amsterdam: Vrije Universiteit; 1993.

20. Van Tulder MW, Assendelft WJJ, Koes BW, Bouter LM. Method guidelines for systematic reviews in the Cochrane collaboration Back review group for spinal disorders. Spine 1997;22:2323-2330.

21. Geusgens C, van Heugten C, Donkervoort M, van den Ende E, Jolles J, van den Heuvel W. Transfer of training effects in stroke patients with apraxia: An exploratory study. Neuropsychological Rehabilitation 2006;16(2):213-229.

22. Kaschel R, Della Sala S, Cantagallo A, Fahlbock A, Laaksonen R, Kazen M. Imagery mnemonics for the rehabilitation of memory: A randomized group controlled trial. Neuropsychological Rehabilitation 2002;12(2):127-153.

23. Fleming JM, Shum D, Strong J, Lightbody S. Prospective memory rehabilitation for adults with traumatic brain injury: A compensatory training programme. Brain Injury 2005;19(1):1-10.

24. Kime SK, Lamb DG, Wilson BA. Use of comprehensive programme of external cueing to enhance procedural memory in a patient with dense amnesia. Brain Injury 1996;10(1):17-25.

25. Robson J, Marshall J, Chiat S, Pring T. Enhancing communication in jargon aphasia: A small group study of written therapy. International Journal of Language and Communication Disorders 2001;36(4):471-488.

26. Fasotti L, Kovacs F, Eling PATM, Brouwer WH. Time pressure management as a compensatory strategy training after closed head injury. Neuropsychological Rehabilitation 2000;10(1):47-65.

27. Cicerone KD. Remediation of 'working attention' in mild traumatic brain injury. Brain Injury 2002;16(3):185-195.

28. Dirette D. The use of cognitive strategies by adults with acquired brain injuries: Results of a two-year post-treatment survey. The Journal of Cognitive Rehabilitation 2002;20(4):6-10.

29. Cicerone KD, Wood JC. Planning disorder after closed head injury: A case study. Archives of Physical Medecine and Rehabilitation 1987;68:111-115.

30. Levine B, Robertson IH, Clare L, Carter G, Hong J, Wilson BA, et al. Rehabilitation of executive functioning: an experimental-clinical validation of goal management training. J Int Neuropsychol Soc 2000;6(3):299-312. 
31. Neistadt ME. A meal preparation treatment protocol for adults with brain injury. The American Journal of Occupational Therapy 1994;48(5):431-438.

32. Foxx RM, Martella RC, Marchand-Martella NE. The acquisition, maintenance, and generalization of problem-solving skills by closed head-injured adults. Behavior Therapy 1989;20:61-76.

33. Liu KPY, Chan CCH, Lee TMC, Li LSW, Hui-Chan CWY. Self-regulatory learning and generalization for people with brain injury. Brain Injury 2002;16(9):817-824.

34. Boman I, Lindstedt M, Hemmingsson H, Bartfai A. Cognitive training in home environment. Brain Injury 2004;18(10):985-995.

35. Wade TK, Troy JC. Mobile phones as a new memory aid: a preliminary investigation using case studies. Brain Injury 2001;15(4):305-320.

36. Doornhein K, de Haan EHF. Cognitive training for memory deficits in stroke patients. Neuropsychological Rehabilitation 1998;8:393-400.

37. Milders M, Deelman B, Berg I. Rehabilitation of memeory for people's names. Memory 1998;6(1):2136.

38. Hinckley JJ, Patterson JP, Carr TH. Differential effects of context- and skill-based treatment approaches: Preliminary findings. Aphasiology 2001;15(5):463-476.

39. Hopper T, Holland A. Situation -specific training for adults with aphasia: an example. Aphasiology 1998;12(10):933-944.

40. Jacobs BJ. Social validity of changes in informativeness and efficiency of aphasic discourse following linguistic specific treatment (LTS). Brain and Language 2001;78:115-127.

41. Maneta A, Marshall J, Lindsay J. Direct and indirect therapy for word sound deafness. International Journal of Language and Communication Disorders 2001;36(1):91-106.

42. Nitzberg Lott S, Friedman RB. Can treatment for pure alexia improve letter-by-letter reading speed without sacrificing accuracy. Brain and Language 1999;67:188-201.

43. Robson J, Marshall J, Pring T, Chiat S. Phonological naming therapy in jargon aphasia: Positive but paradoxal effects. Journal of the International Neuropsychological Society 1998;4:675-686.

44. Robson J, Pring T, Marshall J, Morrison S, Chiat S. Written communication in undifferentiated jargon aphasia: A therapy study. International Journal of Language and Communication Disorders 1998;33(3):305328.

45. Richards K, Singletary F, Gonzalez Rothi LJ, Koehler S, Crosson B. Activation of intentional mechanisms through utilization of nonsymbolic movements in aphasia rehabilitation. Journal of rehabilitation Research and Development 2002;38(4):445-454. 
46. Wambaugh JL, Martinez AL. Effects of rate and rhythm control treatment on consonant production accuracy in apraxia of speech. Aphasiology 2000;14(8):851-871.

47. Antonucci G, Guariglia C, Judica A, Magnotti L, Paolucci S, Pizzamiglio L, et al. Effectiveness of neglect rehabilitation in a randomized group study. Journal of Clinical and Experimental Neuropsychology 1995;17(3):383-389.

48. Bailey MJ, Riddoch MJ, Crome P. Treatment of visual neglect in elderly patients with stroke: A single-subject series using either a scanning and cueing strategy or a left-limb strategy. Physical Therapy 2002;82(8):782-797.

49. Gouvier WD, Bua BG, Blanton PD, Urey JR. Behavioral changes following visual scanning training: Observantions of five cases. The International Journal of Clinical Neuropsychology 1987;9(2):74-80.

50. Hanlon RE, Dobkin BH, Hadler B, Ramirez S, Cheska Y. Neurorehabilitation following right thalamic infarct: Effects of cognitive retraining on functional performance. Journal of Clinical and Experimental Neuropsychology 1992;14(4):433-447.

51. Niemeier JP, Cifu DX, Kishore R. The lighthouse strategy: Improving the functional status of patients with unilateral neglect after stroke and brain injury using a visual imagery intervention. Topics in Stroke Rehabilitation 2001;8(2):10-18.

52. Pizzamiglio L, Antonucci G, Judica A, Razzano C, Zoccolotti P. Cognitive rehabilitation of the hemineglect disorder in patients with unilateral right brain damage. Journal of Clinical and Experimental Neuropsychology 1992;14(6):901-923.

53. Pizzamiglio L, Fasotti L, Jehkonen M, Antonucci G, Magnotti L, Boelen D, et al. The use of optokinetic stimulation in rehabilitation of the hemineglect disorder. Cortex 2004;40:441-450.

54. Webster JS, P.T. M, Rapport LJ, Morill B, Roades LA, Abadee PS. Computer-assisted training for improving wheelchair mobility in unilateral neglact patients. Archives of Physical Medecine and Rehabilitation 2001;82:769-775.

55. Goldenberg G, Hagmann S. Therapy of activities of daily living in patients with apraxia. Neuropsychological Rehabilitation 1998;8(2):123-141.

56. Goldenberg G, Daumuller M, Hagmann S. Assessment and therapy of complex activities of daily living in apraxie. Neuropsychological Rehabilitation 2001;11(2):147-169.

57. Gorman P, Dayle R, Hood C, Rumrell L. Effectiveness of the ISAAC cognitive prosthetic system for improving rehabilitation outcomes with neurofunctional impairment. NeuroRehabilitation 2003;18:57-67.

58. Liu KP, Chan CC, Lee TM, Hui-Chan CW. Mental imagery for promoting relearning for people after stroke: A randomized controlled trial. Archives of Physical Medecine and Rehabilitation 2004;85:1403-1408. 
59. O’Reilly MF, Green G, Braunling-McMorrow D. Self-administered written prompts te teach home accident prevention skills to adults with brain injuries. Journal of Applied Behavior Analysis 1990;24:431446.

60. Wilson BA. Neuropsychological rehabilitation: Theory and practice. Lisse: Swets \& Zeitlinger; 2003.

61. Carney N, Chesnut RM, Maynard H, Mann NC, Patterson P, Helfand M. Effect of cognitive rehabilitation on outcomes for persons with traumatic brain injury: A systematic review. Journal of Head Trauma Rehabilitation 1999;14(3):277-307.

62. Lezak MD. Neuropsychological Assessment. 3 ed. New York: Oxford University Press; 2004.

63. Fuhrer MJ, Keith RA. Facilitating patient learning during medical rehabilitation. American Journal of Physical Medecine and Rehabilitaion 1998;77(6):557-561. 
Appendix 1. Details of literature search

Controlled vocabulary words (combinations of these terms)

\begin{tabular}{|l|l|}
\hline Category & Terms \\
\hline Type of brain injury & $\begin{array}{l}\text { Brain injury TBI, cerebrovascular accident, CVA, brain contusion, } \\
\text { brain concussion }\end{array}$ \\
\hline Transfer & $\begin{array}{l}\text { Transfer (psychology), transfer (learning), generalization } \\
\text { (psychology), generalization (learning), learning, transferability, } \\
\text { learning environment - clinical, activities of daily living }\end{array}$ \\
\hline Type of disorder & $\begin{array}{l}\text { Neurobehavioral manifestations, cognitive impairment, cognitive } \\
\text { defect, cognition disorders, cognition (OMAHA) }\end{array}$ \\
\hline Type of intervention & $\begin{array}{l}\text { Rehabilitation, cognitive rehabilitation, neuropsychological } \\
\text { rehabilitation, rehabilitation - community based, home rehabilitation, } \\
\text { education }\end{array}$ \\
\hline
\end{tabular}

Free text words (combinations of these terms and in combination with controlled vocabulary words)

\begin{tabular}{|l|l|}
\hline Category & Terms \\
\hline Type of brain injury & $\begin{array}{l}\text { "traumatic brain injury", stroke, contusion, CVA, "cerebro vascular } \\
\text { accident" }\end{array}$ \\
\hline Transfer & $\begin{array}{l}\text { Transfer, generalisation, generalization, "environmental validity", } \\
\text { "environmental valid", "activities of daily living", ADL }\end{array}$ \\
\hline Type of disorder & "Cognit" disorder", "cognitive impairment" \\
\hline Type of intervention & $\begin{array}{l}\text { Rehabilitation, remediation, compensation, strategy, "compensatory } \\
\text { strategy", "compensation training", "compensatory training", } \\
\text { "strategy training", "cognitive training", "cognitive retraining", } \\
\text { "cognitive rehabilitation", "cognitive remediation", "remediation } \\
\text { strategy" }\end{array}$ \\
\hline
\end{tabular}


Chapter 8

General discussion 

Slowness of information processing is one of the most common cognitive deficits after stroke. Many stroke patients show longer than normal execution times in a broad range of neuropsychological tests, and rate slowness of information processing high on a list of cognitive complaints $[1,2,3,4]$.

More importantly, slow speed of information processing is thought to influence adversely many daily life activities. Theories on speed of information processing predict that slowness especially will affect non-automatic, novel, and/or time-pressure tasks $[5,6,7]$. Such tasks require fast and continuous conscious processing of incoming information, have to be completed before situations change, and/or are often constrained within externally determined time limits. These characteristics apply to many everyday situations. Continuous and fast processing is needed, for example, when driving a car through heavy traffic, when cooking a meal, when having an important conversation, when listening to a teacher and simultaneously making notes, and even when reading subtitles on television. Patients with slow information processing may miss important information and/or may make errors when they are involved in such tasks.

In addition it is plausible that patients will experience an unpleasant subjective feeling of time pressure when they feel that they will probably not be able to finish a task within a given time limit, or they will experience low mood or agitation when they perceive their performance as less satisfactory or when they recognize they may be failing.

Few studies however have focused on the everyday consequences of slowness of information processing and how these may affect patients' lives. In addition, little is known about the effects of cognitive rehabilitation aimed at these consequences in stroke patients. This thesis has focused on these questions. In this final chapter, the main findings and conclusions of the thesis are summarized and discussed. In addition, the implications for clinical practice and future research will be considered.

\section{Main findings}

This thesis investigated the consequences of slow information processing in the daily lives of stroke patients, and the effects of a strategy training aimed at reducing these consequences. The main findings will be discussed in turn. However, the findings have prompted reconsideration of the theories that underlie and inform research, and thus we start with a discussion of the nature of "mental slowness", drawing on our research to illustrate this.

\section{The concept of mental slowness}

In the first study of this thesis (Chapter 2) we found that patients with slow speed of information processing reported a wide range of disabilities in daily life. Not only did they complain of a slowing in reaction time or in processing incoming information, but they also complained of problems in decision making, memory, learning new skills, etc. In addition, these problems sometimes seemed to produce fatigue or agitation when the patient felt that things happened too quickly, or even panic, and these responses in turn led to even worse performance. 
These results suggest that the consequences of slowness of information processing are multidimensional.

However, as described above, studies on slowness of information processing, or on mental slowness, - both frequently used terms in the field of neuropsychology - usually do not focus on patients' perceived consequences or performance in daily activities. In the scientific literature the terms "slow information processing" and "mental slowness" usually refer to either the time required to execute a cognitive task or the amount of work that can be completed within a finite period of time [8]. But there is still a lack of agreement on a clear conceptual basis and on the aspects that are or are not captured within these terms. This has led us to reconsider the concept of "mental slowness". This reconsideration was described in chapter three of this thesis.

We have developed a possible model of the concept and related aspects, shown in Figure 1. A person's environment, or the person himself, often imposes demands on his information processing capacity. As described above, fast and accurate processing is required in many situations. We think that any discussion on slowness or inaccuracy of a person's information processing system should consider at least all of the following aspects: first, the patient may show slowed performance on a variety of specific cognitive tasks in laboratory settings; second, the patient may be observed (either by his partner, employer or therapist) to have difficulty or reduced effectiveness in performing everyday tasks that require fast and accurate information processing, such as having a conversation or driving a car; third, the patient may experience himself as being slow; and finally, patients may experience secondary effects such as fatigue and tiredness arising from the extra effort required to achieve the desired output, and/or increased agitation or low mood when they experience they may be failing or performing less well.

In addition the figure shows that therapists should be aware that several rehabilitation treatments may be available targeting different aspects of "mental slowness". For example a strategy training teaching patients to cope successfully with the consequences of slowness may be very effective and may contribute to improvement in a variety of domains: it may improve performance on daily activities in terms of being more accurate and making fewer errors; it may reduce patients' feelings of being under pressure; it may decrease fatigue and tiredness, and it may even improve patients' mood. The results of the randomized controlled trial on the effects of a strategy training for mental slowness, discussed later on in this chapter, support at least part of this hypothesis.

We are aware that this model may be preliminary and incomplete. For one, some of the problems described may have been caused by other factors than slowness alone, such as memory or attention problems, fatigue, or depression. Nevertheless, this theoretical consideration is an important first step towards explaining the multidimensional concept of mental slowness. Our model is in line with the ICF model of functioning and disabilities, in which human functioning is described from three perspectives - the human organism (body function/structure), human acting (activities), and the human participating in the environment (participation)-, and where contextual factors (both personal and environmental factors) are taken into account [9]. According to the ICF model, outcomes of 
interventions should be evaluated by recording performance in the individual's real-life environment. We think that our model helps acknowledging that there is more to mental slowness and to measuring the effects of treatment of mental slowness than considering performance on cognitive tests alone. It may help clinicians and researchers to be more specific about their observations and treatment objectives.

Figure 1. Conceptual model of mental slowness and its treatments

Aspect of mental
slowness

Possible treatment for mental slowness

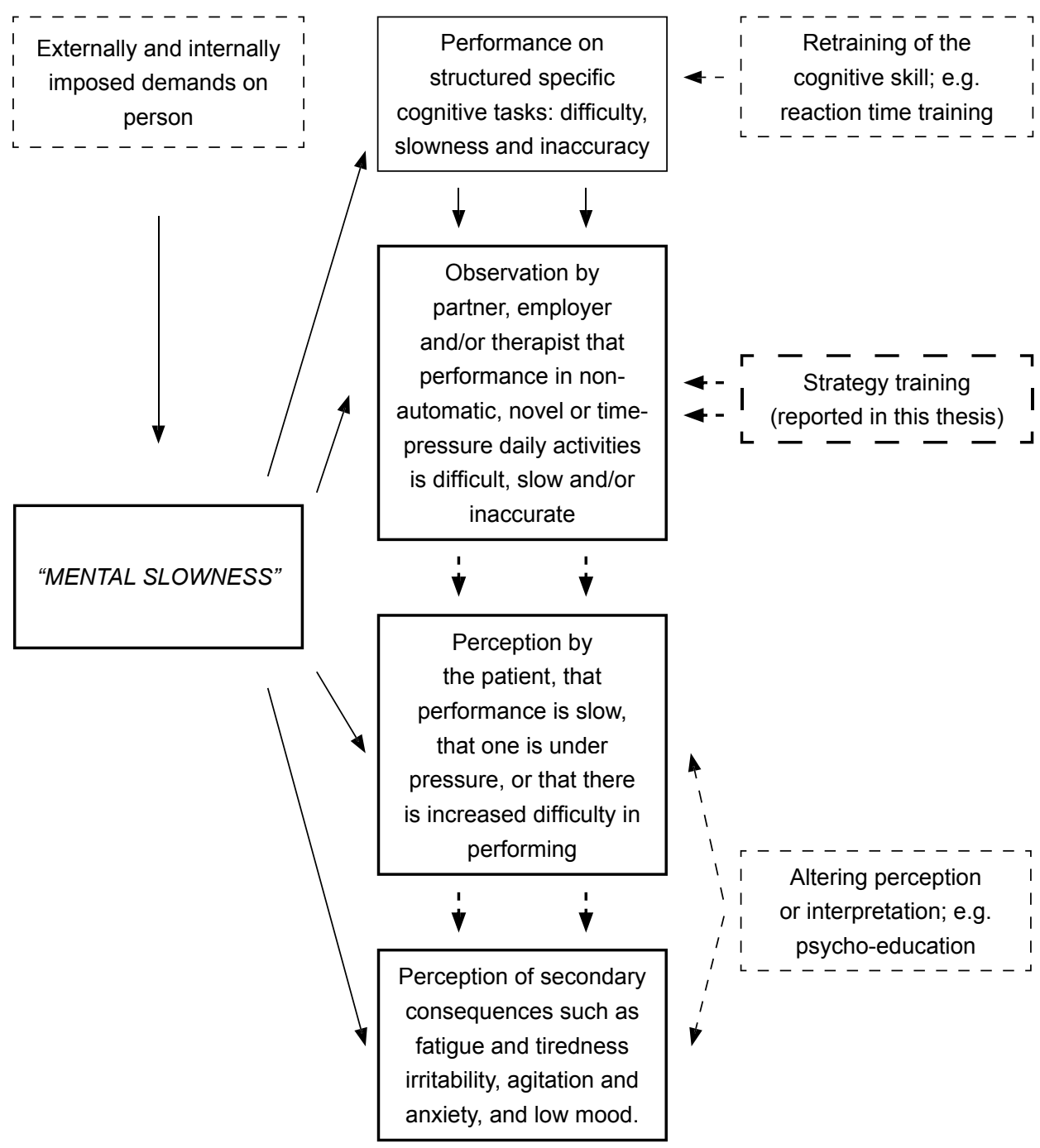




\section{Measuring mental slowness}

The model illustrated in Figure 1 highlights that the term "mental slowness" may cover a variety of phenomena. Thus it emphasizes that measurement needs to focus on one or other component. We found that the majority of measures were neurophysiological or neuropsychological tests (Chapter three). Few studies have actually focused on either the perception by a person that his mental processes are slower, or on related secondary consequences such as fatigue, or on the actual effects mental slowness has on functional activities in daily life.

Consequently we have developed two new measures. One, the Mental Slowness Observation Test, is a set of observations that measure the speed and accuracy of performance of daily activities susceptible to the effects of slow processing of cognitive information. The other, the Mental Slowness Questionnaire, is a questionnaire focused on the perceived consequences (by the patient) of slow information processing (Chapter 4).

The reliability and validity of both instruments is reasonable and we believe both instruments meet our goal of devising practical, rehabilitation based instruments, useful for evaluating the effectiveness of treatments in terms of the everyday consequences of mental slowness and the patients' perception of the impact of mental slowness. The set of observations not only showed reasonable statistical validity and reliability, but they also closely resemble tasks that patients are likely to encounter in their daily lives, and are directly aimed at measuring activities, thereby giving them good ecological validity. The questionnaire showed good reliability.

Construct validity however appeared low. Patients' scores on the questionnaire did not correlate with the scores on neuropsychological tests for speed of information processing such as the Paced Auditory Serial Addition Task, a simple reaction time task, or the Symbol Digit Modalities Test. Earlier studies on the validity of self-report memory questionnaires also have found low or no correlations between memory questionnaires and laboratory memory tasks [10]. The low relationship between absolute measured speed on cognitive tasks and performance on our new measure of perceived mental slowness may arise because patients compare their performance against their own perceived previous performance and not against a population normal. They may perform within the normal range on neuropsychological tests for memory or speed, and still feel that they forget things more easily than before, or feel that they have become slower than before.

In addition, fatigue may arise because it requires more effort for patients to be as accurate or as fast as they used to be [11]. Or patients may develop a low mood when they experience that they are slow (related to their previous speed). This may explain the correlations we found between the scores on the Mental Slowness Questionnaire and measures for fatigue and depression.

The results seem to support our idea that the two sets of data measure different aspects of the construct of mental slowness described in figure 1 that until now had been neglected: one measures the subjective perception that mental processing is slow, leading to a sense of time pressure, to a feeling that more effort is needed, and also to complaints of fatigue 
etc; the other measures observed difficulties in performing daily activities with a significant time pressure component.

Treatment of mental slowness: effects of a Time Pressure Management strategy training The model illustrated in figure 1 shows that "mental slowness" consists of many aspects. Outcomes of interventions should be evaluated in terms of these same aspects.

Several earlier studies have investigated the effects of treatment programs for (consequences of) slowness of information processing (restoration as well as compensation treatments) in older people and clinical populations, evaluating outcome in terms of one or more of the components described in our model. Edwards et al [12] for example, evaluated the effects of retraining cognitive skills for performance on timed instrumental activities of daily living. They used a computerized speed of processing training protocol, based on the Useful Field Of View concept, developed and described by Ball and Owsley [13]. The Useful Field of View measures the speed at which one can rapidly process multiple stimuli in the visual field. One hundred and twenty-six older adults were randomly assigned to the speed of processing training or a social- and computer-contact control group. Subjects in the experimental group practiced three types of tasks (simple speed of processing, divided attention, and selective attention) in ten sessions of one hour.

Al-though the results revealed positive training effects for performance on timed instrumental activities of daily living, nothing is known about the long-term effects of this training and about the effects for patients with acquired brain injury such as stroke.

In 1988 Ponsford and Kinsella evaluated a computer-mediated cognitive training program aimed at improving the cognitive skill of (speed of) information processing in ten patients with severe traumatic brain injury [14]. The study employed a multiple baseline across subjects design. The effectiveness of computer training alone was compared with that combined with therapist feedback and reinforcement in separate training phases. Results suggested that the patients showed little response to the interventions in terms of scores on a rating scale of attentional behaviour as observed in day-to-day activities, and performance on a clerical task measuring effects of the training on distractibility and sustained attention. However, considerable individual differences in patients' responses to aspects of the program were observed and the small study group may explain why significant effects were not found.

These two studies on the effects of restoration treatment programs for slowed speed of information processing have focused on other components than structured specific cognitive tests alone. They also investigated performance in daily activities, and/or the patient's perception of being slow. Although the results seem promising, the effects of the treatments for patients with acquired brain injury remain uncertain for several reasons. In the first study the long-term effects and the effects for patients with acquired brain injury were not investigated, in the second, the study sample was small. 
In comparison to the restoration treatments, strategy treatments are especially thought to aim at daily life functioning.

Fasotti et al [15] studied the effects of Time Pressure Management training for mental slowness in patients with traumatic brain injury. Time Pressure Management training is a strategy training that teaches patients to compensate for the consequences of slowed information processing. In theory the training is thought to be applicable to every problem caused by mental slowness and hence to generalize more easily to non-trained tasks. Patients showed considerable improvement in the use of strategies and the amount of information remembered in a trained information intake task, compared to patients receiving regular concentration training. However, effects on other, non-trained, daily activities were not evaluated.

Besides the study by Fasotti et al [15] we know of only one other study with brain injured patients on the effects of a strategy training aimed at reducing problems caused by slowed processing speed. In 2002 Cicerone [16] presented the effects of an uncontrolled study of an intervention emphasizing conscious and deliberate use of strategies to allocate attentional resources effectively and to manage the rate of information during task performance. Initial treatment sessions were directed toward providing the participants with an interpretation of their deficits and a rationale for the intervention. The impact of slow speed of processing was discussed. Subsequent sessions were directed at facilitating the participants' conscious and deliberate use of strategies to allocate attentional resources effectively and to manage the rate of information. Four patients with mild traumatic brain injury showed clinically significant improvement on measures of attention and reduction of self-reported attentional difficulties in their daily functioning. The principal effect was on the ability to maintain and manipulate information during task performance, with no direct effect on processing speed. The results suggest that the benefits of this treatment are due to patients' improved ability to compensate for deficits and adopt strategies for more effective allocation of remaining attentional resources. However, since this was an uncontrolled study including only four patients, the interpretation of the results is limited.

In a randomized controlled trial we investigated the long term effects of Time Pressure Management training in stroke patients (Chapter six). Thirty-seven stroke patients were randomly assigned to the experimental training or "care as usual". Primary outcome measures in this study were the Mental Slowness Observation Test and the Mental Slowness Questionnaire.

Evidence was found that the long-term effects of Time Pressure Management training in stroke patients with mental slowness were beneficial, compared to the effects of care as usual. As the model in figure 1 would predict, we found that teaching a strategy did improve actual performance on activities under time pressure, without altering the underlying cognitive processing speed. Moreover, the effect seemed to increase over time. These findings are consistent with the theoretical basis of our work that underlying slowness itself is only one factor determining successful functioning. Other factors such as the use of compensatory strategies also influence performance. 


\section{Theoretical considerations following the effect study}

The results from the intervention study raise various issues that may inform theories underlying rehabilitation and cognitive functions.

\section{Long-term effects of Time Pressure Management training}

An important finding in this study was that in the Time Pressure Management group improvement could be seen to start during training but to continue and become statistically significant thereafter. Such a pattern of an increasing effect is likely to occur in a strategy training model, where one might expect some benefit as the strategy is implemented, but increasing benefit as it becomes increasingly automated and integrated into a wider range of behaviours [17,18]. Maintenance and generalization of benefits are most likely when training is provided for appropriately longer periods of time, when efforts are made by the clinician and patient to identify and apply interventions to personally relevant areas of functioning, when patients have adapted to a new way of life, and when patients are able to assume responsibility for using compensatory strategies in their everyday functioning. Patients need time to accept and learn that the strategy is helpful and probably will also be helpful and usable in situations other than the ones that have been trained.

Following this it is reasonable to predict that an extended version of training would produce more substantial effects, at least for some patients. Extending the training over more sessions would give trainers the opportunity to incorporate more practice situations into the training, thereby increasing the chance that generalization to other, non-trained tasks and situations will occur.

\section{Speed-accuracy trade-off}

Another remarkable finding in this study was that after three months the experimental group needed less time to complete the everyday observation tasks, without becoming less accurate. This is remarkable since usually a so-called speed-accuracy trade-off is found meaning that, although processing speed is significantly impaired in clinical groups, they can often perform similarly to healthy adults, but at the cost of needing more time [8]. Faster performance, on the contrary, will lead to more mistakes. The results of our study show that using a strategy like the one taught in the Time Pressure Management training can prevent this trade-off: patients' performance becomes faster, but not less accurate. Since the strategy is specifically aimed at teaching patients to take more time to perform tasks, in first instance the finding that they become faster may seem contradictory. Apparently however, using a strategy that takes time, eventually causes patients to become more efficient in performing tasks. When following a route description for example, patients learn immediately to write information down or to ask for repetition. Consequently, after training patients will perform a task successfully at once, compared to before training, when they had to start the task over and over again, or when they were not even able to complete the task at all. Patients may still need more time than healthy adults, but they will be faster than before.

\section{Relevance for theories of information processing}

When trying to relate the effects of the strategy training to the three theories of speed of information processing described in the introductory chapter of this thesis, it is difficult to decide which of the three best explains the findings. Both Shiffrin and Schneider's model 
and connectionist models of information processing hypothesize that practice can lead to faster task performance. When 'using a new strategy' is seen as performing a novel task or situation, it is imaginable that by means of practice, use of the strategy can become automatized and hence faster. In addition it is also likely that the network of nodes representing 'performance of tasks while using the strategy' becomes stronger, leading to faster processing, and hence faster task performance.

According to Salthouse however, two mechanisms are responsible for the relation between speed and task performance. In one, information processing is too slow to be successfully completed in the available time. This is especially relevant when there are external time limits. Time Pressure Management can teach patients to avoid working under external time limits: for example, they learn to ask for more time when performance is likely to outrun the available time, or they learn to take more time in the first place and to begin on time.

In the second mechanism, slow processing reduces the amount of information available for higher processing. Information may decrease in availability over time as a function of decay or displacement, or information may no longer be accurate by the time it becomes available because of rapidly changing circumstances. Time Pressure Management first teaches patients to prevent decay or displacement of information from occurring: patients for example learn to write information down, or to rehearse it. Second, the strategy teaches patients to deal with rapidly changing conditions: patients for example learn to take the initiative and control as much of the environment as possible. They may ask others to slow down, or make sure they can not be distracted or disturbed. In conclusion, Time Pressure Management may help patients to compensate for the consequences of both mechanisms.

\section{Study limitations}

Throughout this thesis we have already discussed several factors that cast some doubts on the conclusions of our studies on mental slowness. Some of these factors will be repeated here shortly, and some new ones will be added.

First, in all of our studies we used selected samples. In the Netherlands only $10 \%$ of the total stroke population is admitted to a rehabilitation setting. These patients are usually younger than 65 years of age, able to follow an intensive rehabilitation program and expected to return to the home situation after a period of rehabilitation [19]. This means the patients have sufficient learning ability and are sufficiently motivated. This does not allow us to generalize the study results to all patients with stroke, especially those with less favourable prognosis, or those who are not referred to a rehabilitation center. Nonetheless there is no special reason for believing that this technique could not be applied to most patients.

In addition, in our study on the effects of Time Pressure Management, the study sample was only small. To increase numbers, during the study we increased the number of 
participating centers from four to eight. Still however, in the end only 37 patients were included in the study.

Third, the patients included in the efficacy study came from eight different rehabilitation centers. We are aware that the type of center could have had an effect on the ultimate results. First, the trainer in one particular center simply could have been more motivated in giving the care as usual, while trainers in other centers might have been less convinced of the experimental training, thereby reducing the possible positive effects of the experimental training. However, since we had such a small study sample we decided not to include centre as a confounding variable in the statistical analysis. Furthermore, given the small number of patients in each centre, it is unlikely that the positive finding arises simply from patients in one or two centers, and in fact the inclusion of many centers increases the likelihood that our findings are generally applicable to any centre.

The most important limitation of this study is that transfer of training effects to real life performance has not been measured. Generalization of the training effects to patients' everyday life is an important aspect of the Time Pressure Management training and the third and last phase of the training is especially aimed at this. In our literature review done to evaluate the occurrence of transfer of treatment effects in cognitive strategy training for stroke patients (described in Chapter seven), we conclude that it is important to investigate transfer to functionally important tasks in meaningful task environments.

Al-though in our RCT we used standardized observations of simulated performance of daily tasks, and hence some conclusions on transfer to everyday functioning can be drawn, the conclusions are limited. Observations can also be made in daily settings, for example by observing a patient who performs a specific task in his own home setting. The long term goal of a rehabilitation program is to maximize independent functioning at home and in society, and in tasks that are meaningful and relevant to the patients, and we should measure outcome there if possible.

\section{Implications for clinical practice}

Mental slowness is a common complaint after stroke and has a negative impact on patients' daily life functioning. The evidence in this thesis strongly suggests that mental slowness is a multidimensional concept, and clinicians and researchers should be aware that it contains several aspects which should all be taken into account when discussing or investigating mental slowness.

It is important to have standardized, valid and reliable measures to assess these different aspects of mental slowness $[8,18]$. The selection of outcome measures will vary depending on level of analysis and rationale for specific interventions. Primary outcome measures should be identified in relation to specific hypotheses and directly related to intended effects of treatment. First, there are several neuropsychological tests measuring speed of information processing. These tests are often unrelated to daily life functioning or their value for predicting daily life functioning has not been investigated. However, they can be very informative and can help identify the impairment underlying the observed 
problems. This is important since one first has to know what primary deficit causes the problems, and what deficit the intervention should aim at.

There are only a few tasks published in the literature that focus on patients' perception of slowness and their performance in everyday life. Few are standardized and little is know about their methodological qualities. Therefore we recommend using the two new instruments we developed when treating patients with mental slowness because they measure two other important aspects of the problem: patient perceptions of slowness, and actual performance of specific activities. In addition we recommend measuring patients' performance in real life settings if this is practical, either by observation or, more practically, through self-report or reports of partners or family. We also recommend considering the extent of fatigue and emotional disturbance. One might also ask patients about their experience of mental slowness, time pressure and related aspects.

We believe that the results from our randomized controlled trial and results from an earlier study [15] on the Time Pressure Management training have shown that the protocol is useful and effective and ready for implementation in clinical practice. Chapter five of this thesis describes how the training can be done and the RCT study in eight different rehabilitation centers shows that it can be taught to other therapists. Although in rehabilitation settings there is a tendency to protocolize treatment programs, it is important to understand that brain injured patients present a complex profile of impairments and comorbidities, and simply applying a standard treatment protocol is hardly ever appropriate. Individual adjustments are usually necessary, and where scientific prove is absent, clinicians should base their practice on evidence rather than simply reproducing a fixed approach. The challenge for the future lies in the development of protocols for cognitive rehabilitation which specify how treatments can be individually tailored to each patient's particular problems and needs.

Although not recorded formally, during the study we noticed that trainers adjusted the Time Pressure Management program to the patient's learning abilities and cognitive skills. In addition, the patient's awareness of cognitive deficits has been shown to be fundamental if he is expected to benefit from a strategy training such as this, and to implement new strategies independently [20]. Furthermore, patients will be more motivated to learn the strategies if they are aware of their deficits and acknowledge that these new strategies are necessary to improve their functioning. Therefore, increasing awareness remains an important starting point of Time Pressure Management training.

According to Crosson et al [21], three hierarchical levels of awareness can be identified. First, intellectual awareness relates to the knowledge that a particular function is impaired. Second, emergent awareness is the ability to recognize a problem when it occurs. And third, anticipatory awareness relates to the ability to recognize that a problem is likely to occur in a specific situation. For patients to independently implement compensatory strategies this third level of awareness is needed. Chapter six of this thesis describes these and other factors that facilitate treatment and how they can be achieved. 


\section{Recommendations for future research}

Although the results described in this thesis are promising, further research into the theoretical understanding of mental slowness, and the complex inter-relationship between cognitive function, emotional state, and perceived performance is needed. In addition, there is a need to investigate whether much more rehabilitation should concentrate upon teaching strategies to adapt to impairments rather than trying to reverse impairments.

Concerning the efficacy of Time Pressure Management training, some obvious points can be concluded from what is described in this chapter. We recommend conducting new studies including more patients, using longer and/or more flexible training periods and practices, and using measurements directly aimed at investigating transfer effects to daily life functioning. These studies should confirm that the strategy is effective and also confirm that it can be applied to the generality of patients.

Second, it would be worthwhile to investigate what characteristics identify patients who benefit most from Time Pressure Management training. This of course applies to all treatments, not just Time Pressure Management. The presence and interaction of physical, cognitive and emotional factors appear related to treatment effectiveness [18]. Although attempts to control for these factors by methods such as randomized allocation of subjects to treatment conditions do have merit, greater practical and clinical value may accrue from identifying subject variables and other prognostic factors that contribute to treatment efficacy and to adjust interventions accordingly.

As described in this thesis it is hypothesized that unawareness of deficits and specific cognitive impairments is one of the factors that could hinder the process of learning new strategies, but this needs investigation. In addition, cognitive skills and abstract reasoning are probably important prerequisites for generalizing these new skills to other, non-trained situations, but again this needs investigation. Based on the knowledge retrieved from further research, distinctions perhaps could be made between patients that are expected to benefit from Time Pressure Management training and perhaps even show transfer to other, non-trained, real-life situations, and patients who are expected not to benefit from Time Pressure Management. For these latter patients, different rehabilitation programs could be indicated, for example focusing on specific skills training that teaches patients how to perform specific functional tasks in the environment in which they will later have to be able to perform these tasks. This might prevent much frustration to occur for both patient and trainer.

\section{Conclusion}

This thesis has suggested that a phrase "mental slowness" includes at least four components - slow information processing, slowness or difficulty in performing some activities, perception of slowness and time pressure, and the development of fatigue and mood disturbance, secondary to the extra effort needed and the perception of poor performance. It suggests each component needs measurement, and two specific measures of performance 
and perceived difficulties have been developed. Finally this thesis suggests that teaching patients a strategy to ameliorate the effects of cognitive impairment is effective and has an increasing effect over time. Although further research is needed to confirm the findings, we believe that our theoretical and practical advances should be useful in many areas of rehabilitation. 


\section{References}

1. Hochstenbach J, Mulder T, Van Limbeek J, Donders R, Schoonderwaldt, H. Cognitive decline following stroke: a comprehensive study of cognitive decline following stroke. J Clin Exp Neuropsychol 1998; 20: 503-17.

2. Rasquin SM, Lodder, J, Ponds, RW, Winkens, I, Jolles, J, Verhey, FR. Cognitive functioning after stroke: a one-year follow-up study. Dement Geriatr Cogn Disord 2004; 18: 138-144

3. Hochstenbach J. The cognitive, emotional and behavioural consequences of stroke. Doctoral dissertation. Nijmegen: Catholic University Nijmegen (The Netherlands), 1999.

4. Visser-Keizer AC, Meyboom-de Jong B, Deelman BG, Berg IJ, Gerritsen MJ. Subjective changes in emotion, cognition and behaviour after stroke: factors affecting the perception of patients and partners. $J$ Clin Exp Neuropsychol 2002; 24: 1032-45.

5. Anderson JR. Rules of the mind. Hillsdale: Lawrence Erlbaum, 1993.

6. Shiffrin RM, Schneider W. Controlled and automatic human information processing; II: Pereceptual learning, automatic attending and a general theory. Psychol Review 1977; 84: 127-190.

7. Salthouse TA. The processing-speed theory of adult age differences in cognition. Psychol Review 1996; 103(3): 403-428.

8. DeLuca J, Kalmar JH. Information processing speed in clinical populations. Psychology Press, 2007.

9. Wade DT, Halligan P. New wine in old bottles: The WHO ICF as an explanatory model of human behaviour. Clin Rehab 2003; 18: 349-54.

10. Ponds RWHM. Forgetfulness and cognitive aging. Prevalence, characteristics, and determinants. Doctoral dissertation. Maastricht: Maastricht University (The Netherlands), 1998.

11. Christodoulou C, DeLuca J, Ricker JH, Madigan NK, Bly BM, Lange G, et al. Functional magnetic resonance imaging of working memory impairment after traumatic brain injury. J Neurol Neurosurg Psychiatry $2001 ; 71: 161-168$.

12. Edwards JD, Wadley VG, Myers RS, Roenker DL, Cissell GM, Ball KK. Transfer of a speed of processing intervention to near and far cognitive functions. Gerontology 2002; 48: 329-340.

13. Ball K, Owsley C. Increasing mobility and reducing accidents of older drivers. In: Schaie KW, Pietrucha M. (eds). Mobility and transportation in the elderly. New York: Springer, 2000.

14. Ponsford JL, Kinsella G. Evaluation of a remedial program for attention deficits following closed head injury. J of Clin and Exp Neuropsychol 1988; 10(6): 693-708.

15. Fasotti L, Kovacs F, Eling PATM, Brouwer WH. Time Pressure Management as a compensatory strategy training after closed head injury. Neuropsychol Rehabil 2000; 10(1): 47-65. 
16. Cicerone KD. Remediation of "working attention" in mild traumatic brain injury. Brain Injury 2002; 16(3): 185-95.

17. Gray JM, Robertson I, Pentland B, Anderson S. Microcomputer-based attentional retraining after brain damage: A randomized group controlled trial. Neuropsychol Rehab 1992; 2(2): 97-115.

18. Cicerone KD, Dahlberg C, Malec JF, Langenbahn DM, Felicetti T, Kneipp S, et al. Evidence-based cognitive rehabilitation: Updated review of the literature from 1998 through 2002. Arch of Phys Med and Rehab 2005;86:1681-1692.

19. Transmuraal Zorgmodel CVA Regio Heuvelland. Een model voor de verbetering van kwaliteit van zorg voor CVA-patiënten in de regio Heuvelland, 1996.

20. Toglia JP, Kirk U. Understanding deficits following brain injury. NeuroRehabilitation 2000; 15(1): 5770.

21. Crosson B, Barco PP, Velozo CA, Bolesta MM, Cooper PV, Werts D, et al. Awareness and compensation in postacute head injury rehabilitation. J Head Trauma Rehabil 1989; 4(3): 46-54. 
Summary 

Stroke usually is associated with (a high level of) permanent disability. Often this is caused by motor problems, but cognitive problems are also important. One of the most common cognitive deficits after stroke is slowness of information processing.

Standardized neuropsychological tests specifically aimed at the cognitive impairment itself, are generally accepted methods of investigating slowness of information processing and effects of treatments. Treatments also traditionally have focused on the impairment. This study did not target at slowness of information processing as an impairment, but was particularly aimed at the consequences of this impairment from the patient's perspective. The focus was on the disabilities that patients experience in their performance in everyday activities due to their slowness, and on the subjective experience and consequences of being mentally slow, such as fatigue.

The main goal of this thesis was to evaluate the effects of a cognitive compensatory strategy training for stroke patients with mental slowness, the so-called Time Pressure Management training. To achieve this aim, several related studies have been undertaken along the way. The consequences of mental slowness in the daily lives of stroke patients have been explored, and the concept of "mental slowness" has been revised critically. A literature review to evaluate the current state of the assessment of mental slowness has been done, and two new instruments measuring real life aspects of mental slowness have been developed. This was all done so that a randomized controlled investigation of the strategy training could be completed.

Chapter 1 first highlights the importance of cognitive difficulties after stroke, with special emphasis on the prevalence of slow information processing after stroke. Three general theories for speed of information processing in the healthy human brain are reviewed and used to hypothesize how deficits may occur after acquired brain injury. Recovery curves of these deficits are discussed and following this, two types of treatment approaches used in cognitive rehabilitation are described. Several reasons are given why cognitive strategy training was used in the treatment study described in this thesis. And finally, the research questions to be addressed in this thesis and the outline of the thesis are presented.

Chapter 2 describes an exploratory study on the consequences of slow information processing in the daily lives of patients with stroke. A convenience sample of thirteen stroke patients with mental slowness completed semi-structured interviews. Patients were asked to report the difficulties they experienced in daily life, in particular in relation to mental slowness. The results show that patients experienced mental slowness while performing a wide range of activities. Not only did patients experience slow and diminished cognitive functioning, they also had a set of related psychological and emotional complaints (e.g. low mood, agitation) and somatic complaints (e.g. fatigue, headaches). It is concluded that mental slowness is an important problem needing rehabilitation, and that successful coping may reduce (part of) the problems mentioned above.

To measure the effects of learned compensatory strategies on limitations in daily activities and related consequences, adequate instruments are needed. Chapter 3 describes a systematic review on outcome measures used to evaluate these two aspects of mental 
slowness - limitations in activities and patients' perceived experiences of slowness - after acquired brain injury. It was found that measures used to evaluate mental slowness can be classified into four categories: 1) standardized neuropsychological tests measuring specific impairments related to mental slowness; 2 ) tests or questionnaires measuring general cognitive impairment; 3 ) measures that are sensitive to the everyday consequences of mental slowness; and 4) measures of general everyday functioning. Of the 253 studies that were included in the review, only five used measures from category three, which focus on actual or perceived limitations in everyday functioning. However, it is likely that the lack of a clear conceptual basis underlying the construct of mental slowness was the main reason for finding so few useful instruments. It made the search for relevant instruments difficult, and may even have discouraged the development of measures of mental slowness. It is concluded that a critical reconsideration of the concept is needed, and the remainder of this chapter describes a first attempt towards this.

The lack of instruments suitable for immediate use in a study on the effects of a strategy training for mental slowness, has led to the development of two new instruments for mental slowness. Chapter 4 describes these two instruments. The Mental Slowness Observation Test is a set of observations aimed at performance on tasks, the Mental Slowness Questionnaire is a questionnaire evaluating perceived consequences of mental slowness. Thirty-seven stroke patients and 33 matched controls were studied to investigate internal consistency and construct validity. Of a subgroup of ten patients and 22 controls data were used to determine inter-rater reliability of the set of observations. A subgroup of 18 patients completed the questionnaire twice to determine its test-retest stability. The results show that the internal consistency was acceptable for the observation test and good for the questionnaire. The Mental Slowness Observation Test showed good inter-rater reliability, while test-retest reliability was very good for the questionnaire. And finally the results show positive correlations between scores on the Mental Slowness Observation Test and scores on several neuropsychological tests for speed of information processing. The questionnaire correlated most strongly with scores on tests for ADL functioning, fatigue and depression. It is concluded that these new instruments come close to the goal of measuring the everyday consequences of mental slowness in terms of decreased performance and a wide variety of complaints such as a sense of time pressure and fatigue. These new instruments are practical, rehabilitation based instruments that are ready for use in an evaluation of a strategy training for mental slowness.

Chapter 5 provides a framework for teaching patients Time Pressure Management, the cognitive strategy training that aims to reduce disabilities arising from mental slowness due to acquired brain injury. Application of the training in clinical practice is illustrated using two case examples from a randomized controlled trial on the effectiveness of Time Pressure Management for patients with stroke. The chapter describes the rationale behind Time Pressure Management, and explains the content of the training. It is described in detail how the training should be administered. It is concluded that several prerequisites are needed for patients to learn to use Time Pressure Management, that other factors may complicate training patients in its use, and that for some patients the training may not work. First, both the patient and the trainer need to have sufficient awareness of the deficits and problems the patient may experience. Second, patients have to realize that 
the strategy is helpful. Third, adequate motivation is needed to learn the strategy. And finally, therapists should adjust the training to the patients' individual learning abilities and cognitive skills.

In Chapter 6 the results of the multi-center randomized controlled trial into the efficacy of Time Pressure Management training in stroke patients with mental slowness are presented. In total 37 stroke patients were randomly assigned to the Time Pressure Management training group or a group receiving care as usual. Assessments took place at baseline, immediately after the end of a 10-hours treatment period (given over five to ten weeks), and three months after the end of the training. The primary outcome measures were the Mental Slowness Observation Test and the Mental Slowness Questionnaire. In this trial evidence was found for a long term beneficial effect of Time Pressure Management: although after three months both the experimental group and the care as usual group showed significantly less complaints on the questionnaire, only the experimental group showed significant improvement in speed of performance on everyday tasks. This study shows promising results and suggests an increasing benefit over time as would be expected from this type of intervention which needs some time for patients to accept the learned strategies and incorporate them into their daily lives and habits. However, further studies on a larger number of patients and patients with a wider range of difficulties are recommended, coupled with longer training periods adapted flexibly to the patient's needs, and longer follow-up periods.

One of the most important assumptions of a cognitive strategy training such as Time Pressure Management, is that generalization of treatment effects to other, non-trained tasks and situations is expected. In Chapter 7 a critical literature review on the occurrence and measurement of transfer of treatment effects in cognitive rehabilitation is presented. Thirty-nine papers describing 41 studies were included in the review. Results show that only a relatively small number of studies evaluated transfer of training effects. In these studies, transfer was evaluated in three ways: 1) by assessing performance on nontrained items similar to the ones that were used during training; 2 ) by using standardized observations of a simulated performance of daily tasks; and 3) by using self-reports of functioning in daily life situations, or by using questionnaires, rating scales and nonstandardized remarks based on coincidental observations by caregivers or staff. Most studies reported positive results with regard to the occurrence of transfer. However, some remarks concerning the methodological quality of the studies are made. First, in almost half of the studies reporting transfer effects, no statistical tests were used. This was especially true for the studies that claimed to have demonstrated transfer to daily life: in three out of four studies the results were not statistically tested. Second, measuring transfer of treatment effects to daily life is difficult, since adequate tests and instruments are lacking. And, third, in several studies the evaluation of transfer effects had not been formulated as an aim of the study beforehand. The studies were anecdotal, uncontrolled, and did not investigate transfer in a systematic way. It is concluded that more studies specifically designed for measuring transfer of treatment effects are needed to evaluate the effectiveness of cognitive strategy training. 
Chapter 8 gives an overview of the main results of the study and various theoretical and methodological considerations are discussed. Based on the results presented in this thesis first it is concluded that mental slowness is a multidimensional concept and that any discussion on slowness should not only consider slow performance on cognitive tasks in laboratory settings, but also reduced effectiveness in performing everyday tasks, patients' perception of being slow, and their experience of secondary effects such as fatigue, increased agitation or low mood. When treating patients with mental slowness, it is recommended to use two new reliable and valid instruments developed in the course of this research project because they measure two of these aspects: patients' perception of slowness, and actual performance of specific activities. Further it is suggested that long term effects of Time Pressure Management training have been demonstrated in this study. Therefore, the use of the training is recommended, although more research is needed to evaluate the occurrence of transfer effects of this training to daily life functioning. Furthermore, more research is needed to investigate what characteristics identify patients that benefit from Time Pressure Management training. Several factors, such as a patient's learning and/ or cognitive skills and unawareness of deficits, may influence treatment effectiveness. Insight into the impact of these factors may lead to greater practical and clinical value of rehabilitation treatments and would help clinicians to better adjust treatments to individual patients. 
Samenvatting 

Een beroerte gaat doorgaans gepaard met (een hoge mate van) blijvende beperkingen. Dit betreft vaak fysieke, maar niet in de laatste plaats ook cognitieve beperkingen. Eén van de meest voorkomende cognitieve stoornissen na beroerte is traagheid van informatieverwerking.

Gestandaardiseerde neuropsychologische tests specifiek gericht op de cognitieve stoornis zelf, zijn algemeen geaccepteerde methoden om traagheid van informatieverwerking en effecten van behandeling te onderzoeken. In dit proefschrift ligt het accent niet zozeer op vertraagde informatieverwerking als stoornis, maar vooral op de gevolgen van die stoornis vanuit het perspectief van de patiënt. De focus ligt op de beperkingen die patiënten ervaren in dagelijkse activiteiten, en op het subjectief ervaren van het mentaal traag zijn en gerelateerde gevolgen zoals vermoeidheid.

De belangrijkste doelstelling van dit proefschrift was het evalueren van de effecten van een cognitieve strategietraining voor patiënten met mentale traagheid na beroerte. Om deze doelstelling te bereiken zijn eerst enkele andere stappen uitgevoerd. De gevolgen van mentale traagheid in het dagelijks leven van patiënten zijn geïnventariseerd, en het concept "mentale traagheid" is kritisch herzien. Een review van de bestaande literatuur over het meten van mentale traagheid is uitgevoerd, en twee nieuwe meetinstrumenten voor twee aspecten van mentale traagheid zijn ontwikkeld.

Hoofdstuk 1 licht kort het belang van cognitieve revalidatie na beroerte toe; specifiek wordt ingegaan op de prevalentie van vertraagde informatieverwerking na beroerte. In het licht van drie algemene theorieën over snelheid van informatieverwerking in het gezonde brein wordt achtergrondinformatie gegeven over het ontstaan van vertraagde informatieverwerking na verworven hersenletsel. Vervolgens worden herstelcurves besproken. Dit hoofdstuk beschrijft verder twee verschillende typen behandelingen die in de cognitieve revalidatie worden gebruikt en onderbouwt de keuze voor het gebruik van een van beide typen behandelingen in de effectstudie van dit proefschrift. Tot slot worden de doelstellingen en de opzet van dit proefschrift beschreven.

Hoofdstuk 2 beschrijft een exploratieve studie naar de gevolgen van vertraagde informatieverwerking op het dagelijks leven van patiënten met een beroerte. Bij dertien patiënten werd een semi-gestructureerd interview afgenomen. Gevraagd werd aan te geven welke moeilijkheden patiënten ervaren in hun dagelijks leven, met name in relatie tot de vertraagde informatieverwerking. De resultaten laten zien dat patiënten bij het uitvoeren van een breed scala aan activiteiten mentale traagheid ervaren. Patiënten ervaren niet alleen een vertraagd en verminderd cognitief functioneren, maar hebben vaak ook psychologische en emotionele klachten (bv. sombere stemming en agitatie) en fysieke klachten (bv. vermoeidheid en hoofdpijn). Vertraagde informatieverwerking is derhalve een belangrijk doel voor cognitieve revalidatie. Toepassen van compensatie strategieën zou (een deel van) deze problemen en klachten kunnen verminderen.

Om de effecten van geleerde compensatie strategieën op beperkingen in dagelijkse activiteiten en gerelateerde gevolgen te kunnen meten, zijn geschikte meetinstrumenten nodig. 
Hoofdstuk 3 beschrijft een systematische review naar uitkomstmaten gericht op deze twee aspecten van mentale traagheid - beperkingen in activiteiten, en subjectieve ervaringen van mentale traagheid - die gebruikt kunnen worden bij patiënten met verworven hersenletsel. De resultaten laten zien dat meetinstrumenten die gebruikt worden om mentale traagheid te evalueren onderverdeeld kunnen worden in 4 categorieën: 1) gestandaardiseerde neuropsychologische tests gericht op specifieke stoornissen gerelateerd aan mentale traagheid; 2) tests of vragenlijsten gericht op algemeen cognitief functioneren; 3) meetinstrumenten die sensitief zijn voor gevolgen van mentale traagheid op het dagelijks functioneren; en 4) meetinstrumenten gericht op algemeen dagelijks functioneren. Van de 253 studies geïncludeerd in de review, gebruiken er maar vijf meetinstrumenten uit categorie drie, d.w.z. meetinstrumenten specifiek gericht op beperkingen in activiteiten of op het ervaren van traagheid en gerelateerde gevolgen. Het is niet ondenkbaar dat met name het gebrek aan een duidelijke conceptuele basis betreffende het construct mentale traagheid, de oorzaak is van het feit dat er zo weinig bruikbare instrumenten gevonden zijn. Dit gebrek aan duidelijkheid maakte het zoeken naar relevante instrumenten lastig. Tevens kan dit gebrek aan een duidelijk concept tot een ontmoediging van het ontwikkelen van instrumenten voor mentale traagheid hebben geleid. Concluderend kan gesteld worden dat een kritische herziening van het concept nodig is, en het laatste deel van dit hoofdstuk beschrijft een eerste poging hiertoe.

Het ontbreken van instrumenten die direct bruikbaar zijn in een evaluatiestudie naar het effect van een strategie training voor mentale traagheid, heeft geleid tot de ontwikkeling van twee nieuwe instrumenten voor mentale traagheid. Hoofdstuk 4 beschrijft deze instrumenten. De Mental Slowness Observation Test bestaat uit een set observaties gericht op het uitvoeren van alledaagse taken; de Mental Slowness Questionnaire is een vragenlijst die ingaat op mogelijke gevolgen die de patiënt ervaart door de traagheid. $37 \mathrm{CVA}$ patiënten en 33 controles namen deel aan een studie naar de interne consistentie en construct validiteit van beide instrumenten. Verder werden van een subgroep van tien patiënten en 22 controles de gegevens gebruikt om de inter-beoordelaars betrouwbaarheid van de set observaties te bepalen. Een andere subgroep van 18 patiënten vulde de vragenlijst twee keer in om de test- hertest betrouwbaarheid van de vragenlijst te kunnen vast stellen. De resultaten laten zien dat de interne consistentie acceptabel is voor de set observaties, en goed voor de vragenlijst. De inter-beoordelaars betrouwbaarheid van de observatietest is goed, en de hertest betrouwbaarheid van de vragenlijst is zeer goed. Tot slot laten de resultaten zien dat er positieve correlaties bestaan tussen de prestaties van patiënten en controles op de observatietest en de prestaties op neuropsychologische tests voor snelheid van informatieverwerking. De scores op de vragenlijst correleren vooral met scores op tests voor ADL functioneren, vermoeidheid en sombere stemming. Geconcludeerd wordt dat deze nieuwe instrumenten het doel om alledaagse gevolgen van mentale traagheid (verminderde prestaties en een brede range aan klachten, zoals het ervaren van tijdsdruk en vermoeidheid) te meten, dicht naderen. Deze nieuwe instrumenten zijn praktische, voor de revalidatie-setting bruikbare instrumenten, die direct ingezet kunnen worden in een evaluatiestudie naar het effect van een strategietraining voor mentale traagheid.

Hoofdstuk 5 is een leidraad voor professionals die Time Pressure Management training geven aan patiënten. Time Pressure Management is een cognitieve strategietraining, ge- 
richt op het verminderen van beperkingen die ontstaan door mentale traagheid na verworven hersenletsel. Aan de hand van twee cases uit de randomized controlled trial naar het effect van de training voor CVA patiënten beschrijft hoofdstuk 5 hoe de training in de klinische praktijk gegeven kan worden. Eerst wordt kort ingegaan op de rationale achter de strategie, en de inhoud van de training. Vervolgens wordt in detail uitgelegd hoe de training gegeven moet worden. Er zijn verschillende voorwaarden waaraan voldaan moet worden willen patiënten Time Pressure Management kunnen leren. Er zijn factoren zijn die het trainen van patiënten kunnen compliceren, en voor sommige patiënten is de training mogelijk niet realiseerbaar. Ten eerste is er bij zowel trainer als patiënt voldoende inzicht nodig in de problemen die de patiënt ervaart. Ten tweede moeten patiënten zich realiseren dat gebruik van de strategie zinvol is. Ten derde moet de patiënt voldoende gemotiveerd zijn om te leren. En tot slot is het aan de professional om de training aan te passen aan de leermogelijkheden en cognitieve vaardigheden van de individuele patiënt.

In hoofdstuk 6 worden de resultaten van de multi-center randomized controlled trial naar het effect van Time Pressure Management training voor CVA patiënten gepresenteerd. In totaal werden $37 \mathrm{CVA}$ patiënten at random toegewezen aan de experimentele training of "care as usual". Er waren drie meetmomenten: een voormeting, een nameting direct na het einde van de in totaal tien uur durende trainingsperiode, en een follow-up meting drie maanden na het einde van de training. De belangrijkste uitkomstmaten waren de Mental Slowness Observation Test en de Mental Slowness Questionnaire. In deze studie werd bewijs gevonden voor een positief lange termijn effect van de Time Pressure Management training: hoewel zowel de experimentele als de care as usual groep drie maanden na het einde van de training significant minder klachten rapporteerde op de vragenlijst, liet alleen de experimentele groep een significante verbetering zien in de snelheid waarmee alledaagse taken werden uitgevoerd. Geconcludeerd wordt dat de studie veelbelovende resultaten laat zien. Echter, aanbevolen wordt om nieuwe studies met grotere aantallen en minder geselecteerde patiënten uit te voeren, en daarbij langere trainingsperiodes en langere follow-up periodes in acht te nemen.

Een belangrijke veronderstelling van cognitieve strategietrainingen zoals de Time Pressure Management training is dat verwacht wordt dat de effecten van zulke trainingen generaliseren naar andere, niet-getrainde taken en situaties. Hoofdstuk 7 beschrijft de resultaten van een literatuur studie (citical review) naar het optreden en het meten van transfer van behandelingseffecten in de cognitieve revalidatie. Negenendertig artikelen die in totaal 41 studies beschrijven werden in de literatuurstudie geïncludeerd. Het optreden van transfer is slechts in een relatief klein aantal studies onderzocht. Dit gebeurde op drie verschillende manieren: 1) door het evalueren van prestaties op niet-getrainde items vergelijkbaar met items die in de training gebruikt werden; 2) door gestandaardiseerde observaties van presteren in gesimuleerde alledaagse taken; 3) door middel van zelfrapportages van functioneren in het dagelijks leven, vragenlijsten, of niet-gestandaardiseerde opmerkingen gebaseerd op toevallige observaties door verzorgers of professionals. De meeste studies rapporteerden positieve resultaten wat betreft het optreden van transfer. Echter er dient een kritische kanttekening geplaatst te worden bij de methodologische kwaliteit van de studies. Ten eerste blijkt dat bijna de helft van alle studies die het optreden van transfer rapporteerden, deze resultaten niet statistisch hadden getoetst. Dit geldt 
met name voor de studies waarin transfer naar het dagelijks leven werd gerapporteerd; in driekwart van deze studies werden geen statistische toetsen beschreven. Ten tweede is het lastig om transfer naar het dagelijks leven te meten omdat geschikte meetinstrumenten ontbreken. En ten derde werd het meten van transfer vaak niet vooraf opgenomen als een doel van de studie. Deze studies waren gebaseerd op toevallige observaties, waren ongecontroleerd, en onderzochten transfer niet op een systematische manier. Geconcludeerd wordt dat meer onderzoek nodig is dat specifiek ontworpen is voor het meten van transfer, zodat de effectiviteit van cognitieve strategietraining verder geëvalueerd kan worden.

In hoofdstuk 8 wordt een overzicht gegeven van de belangrijkste bevindingen van dit proefschrift en worden theoretische en methodologische overwegingen besproken. Op basis van de in dit proefschrift beschreven onderzoeksresultaten wordt ten eerste geconcludeerd dat mentale traagheid een multi- dimensioneel concept is. Elke discussie over traagheid moet niet alleen gaan over vertraagd presteren op cognitieve taken in een standaard testomgeving, maar ook over verminderd presteren op alledaagse taken, de perceptie van patiënten dat ze trager zijn, en hun ervaring van secundaire gevolgen zoals vermoeidheid, agitatie en sombere stemming. Bij de behandeling van patiënten wordt aangeraden twee nieuwe instrumenten te gebruiken die zijn ontwikkeld in de loop van dit onderzoeksproject. Deze instrumenten meten ten minste twee belangrijke aspecten van mentale traagheid, namelijk de perceptie van patiënten dat ze trager zijn, en de uitvoering van specifieke activiteiten. Verder wordt geconcludeerd dat in deze studie positieve lange termijn effecten van Time Pressure Management training zijn aangetoond. Daarom wordt voor de behandeling van patiënten met mentale traagheid het gebruik van deze training aangeraden. Nader onderzoek is echter noodzakelijk waarin transfer van de trainingseffecten naar dagelijks functioneren wordt geëvalueerd. Bovendien is verder onderzoek nodig om inzicht te verkrijgen in karakteristieken waarmee patiënten die baat hebben bij Time Pressure Management training onderscheiden kunnen worden van andere patiënten. Verschillende factoren, zoals het vermogen om nieuwe dingen te leren, cognitieve vaardigheden, en inzicht in eigen functioneren, kunnen de effecten van een behandeling beïnvloeden. Inzicht hierin kan de praktische en klinische waarde van revalidatiebehandelingen vergroten, en kan clinici helpen de behandeling beter af te stemmen op de individuele patiënt. 
Dankwoord 

Het werken aan dit proefschrift heb ik vooral als leuk en uitdagend ervaren. Maar natuurlijk zijn er ook momenten geweest waarop het even niet zo gemakkelijk ging als ik graag gewild had. Op die momenten was het fijn om te weten dat ik kon rekenen op de hulp en steun van vele anderen. Deze laatste bladzijden van dit proefschrift wil ik gebruiken om mijn welgemeende dank uit te spreken aan iedereen die op één of andere wijze heeft bijgedragen aan de totstandkoming van dit boekje. Een aantal personen en instanties wil $\mathrm{ik}$ in het bijzonder vernoemen.

First of all I would like to thank my promotion team; both my promoters Derick Wade and Luciano Fasotti and my co-promoter Caroline van Heugten. From day one you really gave me the feeling that we were a team. You listened to my ideas and opinions and treated me as an equal. I really have appreciated that. I do not think that I could have learned more from any other promotion team. Thank you!

Dear Derick. I really do not think that I would have been so proud of and satisfied with this thesis if you had not been part of my promotion team. You have taught me so much during our meetings and during our discussions on the subject. Your capability to write down your thoughts (and mine too!) on paper in such a sharp and clear way, is priceless. As is your hospitality. I will never forget my stays in Oxford!

Beste Luciano. Jouw enthousiasme voor dit vakgebied is aanstekelijk. Daarnaast heb je op de momenten dat het er om ging altijd de juiste input geleverd, waardoor het artikel waar we aan werkten altijd weer een stuk beter werd. Tijdens onze samenwerking heb jij mij altijd als een gelijke behandeld en stond je altijd open voor mijn mening. Daardoor heb ik het gevoel dat dit ook echt "mijn" boekje is geworden. Bedankt!

Beste Caroline. Mijn co-promotor, maar die titel doet je eigenlijk te weinig eer aan. Jij was er altijd. Als ik vragen had of nieuwe stukken stuurde kwam er altijd vrijwel direct reactie. En dat gebeurde altijd op een fijne en prettige manier. Ik kan me herinneren dat ik een keer op mijn kamer zat te snotteren. Jij kwam toen bezorgd vragen of alles wel goed ging. Daar moest ik toen erg om lachen omdat ik zat te snotteren vanwege een verkoudheid. Jij hebt ervoor gezorgd dat ik me nooit ook maar een minuut echt zorgen heb gemaakt over dit proefschrift. Ik mocht je nooit mijn "baas" noemen en zo heeft het ook nooit gevoeld. Ik hoop in de toekomst nog eens met je samen te mogen werken.

Veel dank ben ik vervolgens verschuldigd aan alle patiënten en hun families die hebben meegewerkt aan dit onderzoek. Geheel belangeloos waren zij bereid om, soms wel tot drie keer toe, twee uur lang vragen te beantwoorden en tests uit te voeren. Zonder hun medewerking was dit boekje er nooit gekomen.

Datzelfde geldt voor al mijn familieleden, vrienden en kennissen die in het kader van dit onderzoek door mij en mijn collega's zijn getest en ondervraagd. Bedankt! 
Verder dank ik de psychologen, ergotherapeuten, (cognitief) trainers, onderzoekscoördinatoren, artsen en alle andere medewerkers van de centra die hebben meegewerkt aan het in dit proefschrift beschreven onderzoek. Jullie hebben veel tijd gestoken in het aanmelden en trainen van patiënten. Bedankt voor jullie enthousiasme!

Graag wil ik twee mensen bedanken die een grote steun zijn geweest in de dataverzameling van het project. Allereerst Esther Habets. Esther, jij hebt heel wat kilometers afgelegd om de deelnemers aan dit onderzoek thuis te bezoeken. Ik had al snel door dat ik dat helemaal aan jou kon overlaten en dat "mijn patiënten" bij jou in goede handen waren. En dat heeft mij heel veel tijd bespaard! Ik wens je veel succes in je carrière toe en hoop dat we elkaar nog eens tegenkomen. Ook Gisela Claessens heeft haar steentje bijgedragen aan het onderzoek. Gisela, onze gezamenlijke huisbezoeken waren erg gezellig en een welkome afwisseling. Nu ben je zelf AiO. Ik wens je heel veel succes, maar als je daar net zo enthousiast en leergierig bent als je bij mij was komt dat helemaal goed.

Ook Annelien Duits wil ik op deze plek bedanken voor het meedenken en meeschrijven aan het eerste artikel van mijn proefschrift!

Verder wil ik al mijn collega's (oud-iRv-ers en Vilansers) bedanken voor de prettige samenwerking en gezelligheid de afgelopen jaren. Ieder van jullie heeft bijgedragen aan de totstandkoming van dit proefschrift, ook al ben je je daar zelf misschien niet van bewust. Jullie maken het mogelijk dat ik mijn werk kan doen en jullie maken dat ik altijd met veel plezier naar mijn werk kom (al blijft het opstaan 's ochtends altijd nog moeilijk). Ik hoop dat we nog vele jaren samen koffie drinken, lunchen, lachen, roddelen, Sint en Kerst vieren. Richard, nog bedankt voor het maken van de reactietijdtaak! Josien, bedankt voor het zo snel produceren van de boekjes voor de leescommissie. Béatrice, bedankt dat je deur altijd voor me open staat als ik weer met een vraag over statistiek, methodologie of wat dan ook langs kom. Wilma, ik verheug me erop om samen nog heel veel leuke dingen te gaan doen op het gebied van Niet Aangeboren Hersenletsel.

Ook Elsa Misdom wil ik op deze plek hartelijk danken voor haar hulp bij de laatste loodjes. Wat is het fijn als er iemand is die precies weet wat je moet doen en dat dan ook nog snel en juist voor je afhandelt. Bedankt!

Veel dank gaat uit naar mijn vrienden. Jullie zijn dan misschien niet zozeer betrokken geweest bij het schrijven van dit proefschrift, maar jullie zorgen voor de afleiding, ontspanning en gezelligheid die ik af en toe hard nodig had. Wanneer gaan we weer?!

Chantal en Sharon. Ook jullie wil ik hier even in het bijzonder noemen. Chantal, jij bent me in dit promotietraject steeds voor gegaan, en daar heb ik heel veel aan gehad. Jij hebt op vele fronten de weg voor me geplaveid. Jij had altijd antwoord op mijn vragen, en je hebt me ook bij de laatste loodjes geholpen. Daarnaast ben je veel meer geworden dan een collega. Ik hoop dat er nog vele gezellige etentjes, feestjes en discussies over wie nou die mol is volgen. Sharon, dat geldt natuurlijk ook voor jou. Nog bedankt voor het inspreken van het radionieuws! Ik vind het leuk dat we nu samen de laatste hordes nemen. Ik wens je heel veel succes bij de afronding, en dan gaan we dat eens goed vieren! 
Op deze plek wil ik ook graag mijn neef Bjorn bedanken voor zijn "statistieklessen". Hoewel ik vast niet alles begrepen heb en er soms een beetje nerveus van werd, heb ik er heel veel aan gehad! Ik hoop dat het klopt wat ik in dit boekje heb opgeschreven, en als dat niet zo is, dan ligt dat helemaal aan mij.

Lieve Sascha. Wie anders dan jou had ik kunnen vragen om één van mijn twee paranimfen te zijn. Een aantal jaar geleden ben ik bij jou begonnen als onderzoeksassistent en jij hebt me aangestoken met je enthousiasme voor het onderzoek. Ik wilde altijd al graag $\mathrm{AiO}$ worden maar toen wist ik het zeker. Toen ik naar het iRv ging om daar zelf promotieonderzoek te gaan doen kwam je gelukkig al snel achter me aan. Daar werden we kamergenoten en zijn we zelfs samen naar Amerika geweest. Ik heb in die periode veel van je geleerd en de gezelligheid zal ik nooit vergeten. Ik hoop dat we elkaar in de toekomst nog vaak tegenkomen, in ons werk, en daarbuiten.

Lieve Pien. Natuurlijk stond van het begin af aan al vast dat jij mijn andere paranimf moest worden, ook al ben jij straks in april waarschijnlijk nog nerveuzer dan ik! Dat jij tijdens de verdediging van dit proefschrift letterlijk achter me staat, staat symbool voor het feit dat ik weet dat jij, als "grote zus" overal en altijd achter me staat, en me altijd zult helpen en ondersteunen. Ik ben er trots op dat jij mijn zus bent.

Lieve papa en mama. De laatste regels in dit proefschrift zijn voor jullie. Jullie maken het op zoveel manieren mogelijk dat ik kan doen wat ik graag wil doen en jullie stimuleren mij altijd om het beste uit me zelf te halen. Het allermeeste wil ik jullie bedanken. Voor alles. 

Curriculum Vitae 

Ieke Winkens werd geboren op 7 augustus 1978 te Sittard. In 1996 behaalde zij haar VWO diploma aan de Rooms Katholieke Scholen Gemeenschap Serviam te Sittard.

Hierna begon ze aan haar studie psychologie, afstudeerrichting neuropsychologie, aan de Universiteit Maastricht. In 2000 behaalde Ieke haar doctoraal diploma. Tijdens haar afstuderen werd ze als onderzoeksassistent aangesteld bij het promotieonderzoek MAASBED (MAAstricht Study of BEhaviour in Dementia) van Marjolein De Vugt en Pauline Aalten en het promotieonderzoek CODAS (COgnitive Disorders After Stroke) van Sascha Rasquin. Vervolgens werd ze als promovendus aangesteld bij het iRv, Kenniscentrum voor Revalidatie en Handicap (thans Vilans geheten) te Hoensbroek, waar zij tot heden aan dit proefschrift werkte. In de tussentijd is haar aanstelling verlengd binnen Vilans waar ze zich thans met name richt op verschillende projecten rond het thema Niet Aangeboren Hersenletsel. 